UNIVERSIDADE DE SÃO PAULO

INSTITUTO DE PSICOLOGIA

Renata Genaro Aguiar

\title{
ESTUDO ELETROFISIOLÓGICO DOS EFEITOS DA INJEÇÃO INTRAVÍTREA DE ÁCIDO MICOFENÓLICO (MPA) NA RETINA DE COELHOS
}

(Versão corrigida)

São Paulo 
INSTITUTO DE PSICOLOGIA

CURSO DE PÓS-GRADUAÇÃO

\title{
ESTUDO ELETROFISIOLÓGICO DOS EFEITOS DA INJEÇÃO INTRAVÍTREA DE ÁCIDO MICOFENÓLICO (MPA) NA RETINA DE COELHOS
}

\author{
Renata Genaro Aguiar \\ Orientadora: Prof ${ }^{\mathrm{a}}$ Dr$^{\mathrm{a}}$ Dora Selma Fix Ventura \\ Dissertação apresentada ao Programa de Neurociência e \\ Comportamento do Instituto de Psicologia da \\ Universidade de São Paulo, para obtenção do grau de \\ Mestre em Psicologia.
}

São Paulo 
Aguiar, Renata Genaro.

Estudo eletrofisológico dos efeitos da injeção intravítrea de ácido micofenólico (MPA) na retina de coelhos / Renata Genaro Aguiar; orientadora Dora Selma Fix Ventura. -- São Paulo, 2011.

$100 \mathrm{f}$.

Dissertação (Mestrado - Programa de Pós-Graduação em Psicologia. Área de Concentração: Neurociências e Comportamento) Instituto de Psicologia da Universidade de São Paulo.

1. Eletrorretinografia 2. Retina 3. Coelhos 4. Ácido micofenólico 5. Uveíte 6. Toxicidade I. Título.

RE79.E4 


\section{FOLHA DE APROVAÇÃO}

\section{Renata Genaro Aguiar}

"Estudo eletrofisiológico da injeção intravítrea de ácido micofenólico (MPA) na retina de coelhos."

Dissertação apresentada ao Instituto de Psicologia da Universidade de São Paulo, para obtenção do título de Mestrado.

Área de Concentração: Neurociência e Comportamento.

Dissertação defendida e aprovada em: / /

\section{BANCA EXAMINADORA}

Examinador (a) Assinatura.

Nome.

Instituição.

Examinador (a) Assinatura.

Nome

Instituição.

Examinador (a) Assinatura.

Nome

Instituição. 
Dedico este trabalho a minha mãe, cuja presença é eterna e, se não mais está aqui na forma em que entendemos, permanece todos os momentos em minha essência. 


\section{Agradecimentos}

Em primeiro lugar agradeço a minha orientadora $\operatorname{Prof}^{\mathrm{a}} \operatorname{Dr}^{\mathrm{a}}$ Dora Fix Ventura por ter concedido a mim a oportunidade de aprender um pouco sobre psicofisiologia sensorial, por sua paciência comigo em todos os momentos, pela sua compreensão e dedicação ao grupo do laboratório da visão.

Ao Dr $^{\circ}$ Francisco Max Damico, que realizou todos os procedimentos de injeção intravítrea nos coelhos e me ensinou muito sobre como fazer pesquisa. Considero-o meu Coorientador, e além de sua contribuir de forma decisiva para a realização do trabalho, me atendeu prontamente sempre que eu precisei.

Aos meus colegas de pesquisa, que sempre foram solidários em todas as horas, que dividiram as angústias da vida acadêmica e os bons momentos, frutos de muito trabalho. Agradeço especialmente a Gabriela Ioshimoto que colaborou com todo o meu trabalho, a Mirella Barboni, que sempre se mostrou disposta a me ajudar em todas as situações e a Daniela Bonci, que me acolheu tão simpaticamente quando cheguei ao laboratório.

Ao Prof $^{\mathrm{o}}$ Dr $^{\mathrm{o}}$ Marcelo Fernandes da Costa, do Instituto de Psicologia, por todo subsídio que forneceu ao meu trabalho e por sua disponibilidade em ajudar quando necessário.

A $\operatorname{Prof}^{a} \operatorname{Dr}^{a}$ Christina Joselevicth, da Universidade de São Paulo, pela sua ajuda essencial nas análises dos meus dados e por suas contribuições intelectuais ao trabalho.

Ao secretário do laboratório, Claudiel dos Santos por estar sempre pronto a ajudar e sempre dar uma solução a situações que pareciam não ter solução.

A minha família maravilhosa, que está sempre pronta a me apoiar em todas as minhas decisões. Ao meu esposo que me incentivou muito a começar esse trabalho e me 
apoiou sempre. A minha irmã que nunca me deixou desistir, e esteve sempre ao meu lado, inclusive nos momentos mais árduos. Ao meu pai que nunca escondeu o orgulho de ter uma filha na área da pesquisa biológica. A querida Rosa Malvone que tanto me ajudou a cuidar de minha filha e possibilitou a realização desse trabalho. A minha sogra Zari que sempre se dispôs a me ajudar e que tantas vezes sacrificou seus afazeres para tomar conta de minha filha, enquanto eu me debruçava sobre minhas pesquisas. A minha pequena Laura que acompanhou os experimentos quando ainda estava em meu ventre e fez com que eu conseguisse forças para finalizar a dissertação.

A FAPESP, Cnpq, PROCAD, pela concessão de bolsas e auxílio financeiro para a realização desse trabalho.

A todos os funcionários do Instituto de Psicologia.

Ao Criador que guiou minha mente na realização deste trabalho. 


\section{Índice Geral}

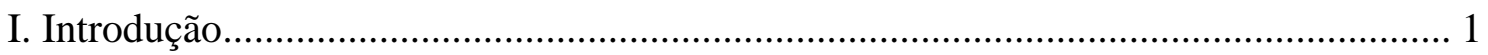

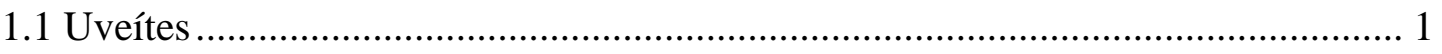

1.2 Medicamentos utilizados para o tratamento de uveíte.......................................... 3

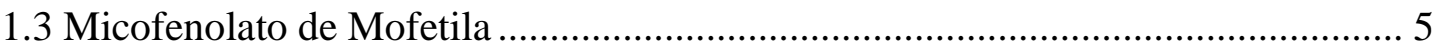

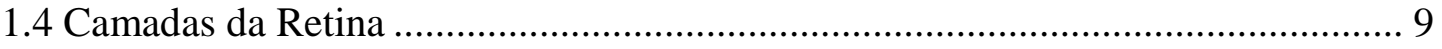

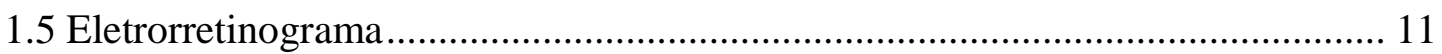

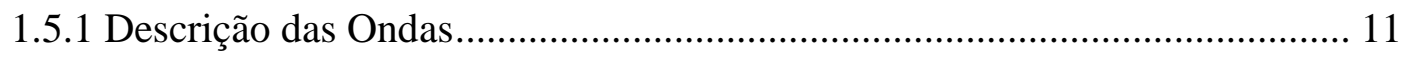

1.5.2 Isolamento dos elementos da retina que contribuem para o ERG ................ 15

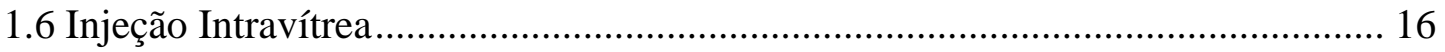

1.7 Uso de Coelhos como Modelo Biológico............................................................... 19

1.8 Estudo de Toxicidade de Drogas em Modelo Animal....................................... 21

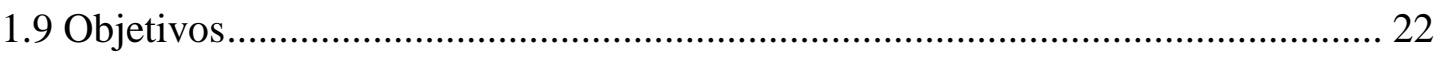

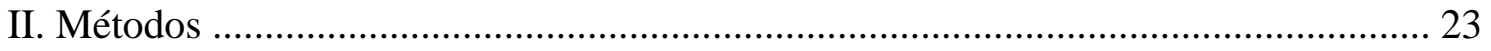

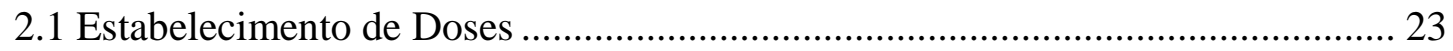

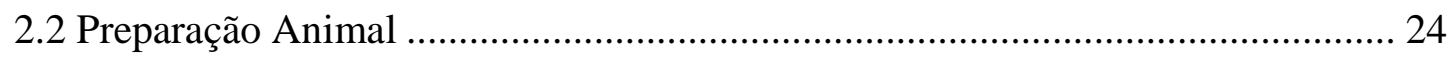

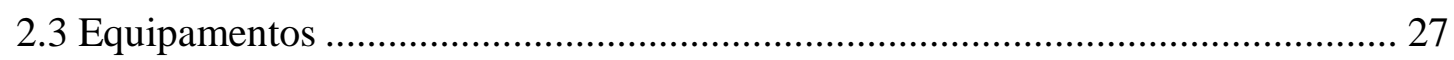

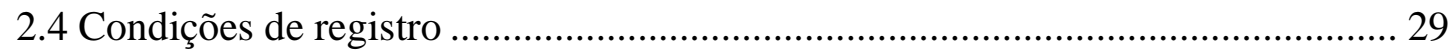

2.5 Protocolo para Realização do Exame Eletrorretinográfico .................................. 30

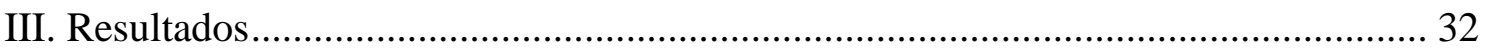

3.1 Estabelecimento dos Parâmetros do Grupo Controle 1 (Situação Pré-Injeção) ... 32

3.2 Estabelecimento dos Parâmetros do Grupo Controle 2 (Administração Intravítrea

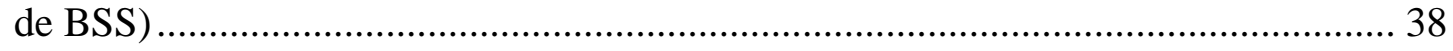

3.3 Estabelecimento dos Parâmetros do Grupo Controle 3 (Administração Intravítrea de Polissorbato) 
3.4 Doses de $5 \mu \mathrm{g}, 50 \mu \mathrm{g}, 200 \mu \mathrm{g}, 1.000 \mu \mathrm{g}$ e $10.000 \mu \mathrm{g}$ de MPA ............................ 48

3.4.1 Doses que não apresentaram alterações eletrorretinográficas ...................... 48

3.4.2 Doses que apresentaram alterações eletrorretinográficas ............................ 58

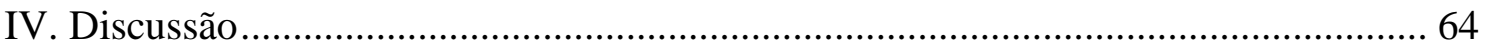

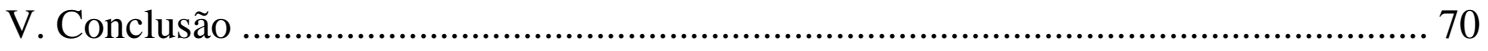

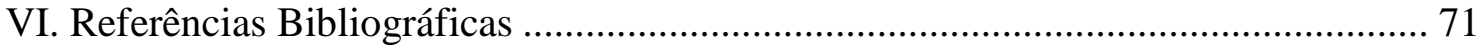




\section{Lista de Figuras}

Figura 1: Cascata metabólica de formação das purinas. $\mathrm{O}$ ácido micofenólico interrompe a transformação de inosina 5-monofosfato em xantosina 5-monofosfato por inativação da IMP desidrogenase. Dessa forma, não é possível completar as reações até guanosina 5-monofosfato (www.dbq.uem.br/met-nucl.ppt).

Figura 2: Divisão das camadas da retina. Camada nucleares interna e externa; camadas plexiformes interna e externa e camada de células ganglionares. (Dowling and, Boycott , 1966) 10

Figura 3: Registro padrão de ERG. a- amplitude da onda a; b- amplitude da onda b; lalatência da onda a e lb- latência da onda b.(Perlman, 2010)

Figura 4: Eliminação da onda b de coelhos por injeção intravítrea de L-glutamato (A) ou ácido aminofosfonobutírico (APB) (B). A droga foi injetada no olho direito (curva abaixo) e a solução salina no olho esquerdo (curva acima), como controle. (http://webvision.med.utah.edu).....

Figura 6: Histórico dos avanços importantes no uso de injeção intravítrea (IVT) para tratamento de doenças oculares (Jager et. al., 2004).

Figura 7: Respostas de ERG escotópico de rato albino, coelho albino e humanos são caracterizados por padrão similar, mas diferem em amplitude e tempo implícito. As respostas de ERG a intenso estímulo de luz das três espécies são compostas por uma onda a negativa seguida de onda $b$ positiva, com potenciais oscilatórios rápidos na fase ascendente da onda b (Perlman, 2009).

Figura 8: Coelho posicionado sobre suporte adaptado ao Ganzfeld, para a realização do eletrorretinograma. No topo do Ganzfeld pode ser vista uma caixa de iluminação que contém a lâmpada para a luz de fundo. Acima desta está posicionado o fotoestimulador sobre a caixa que contém a roda de filtros de densidade neutra. A figura ao lado mostra o fotoestimulador Grass PS33 e respectivo equipamento de controle.

Figura 9: Exemplo de curva de registro eletrorretinográfico do grupo controle. Resposta Escotópica.

Figura 10: Exemplo de curva de registro eletrorretinográfico do grupo controle. Resposta EscotópicaMáxima. 33

Figura 11: Exemplo de curva de registro eletrorretinográfico do grupo controle. Resposta Fotópica.

Figura 12: Relação de amplitude de onda b/onda a na condição escotópica (Resposta Máxima). Cada símbolo representa o registro obtido em um olho. A linha cinza representa a correlação linear entre os dados. 
Figura 13: Relação de amplitude de onda b/onda a na condição fotópica. Cada símbolo representa o registro obtido em um olho. A linha cinza representa a curva de regressão linear entre os dados.

Figura 14: Relação intensidade-resposta da onda b escotópica de animais/olhos da população controle/não injetada (símbolos, $n=40$ ), ajustada pela função de Hill.......... 36

Figura 15: Relação intensidade-resposta da onda b escotópica de animais/olhos da população controle/não injetada, ajustada pela função de Hill (linha preta contínua). As linhas pretas tracejadas mostram a resposta +/- dp para fins de comparação. 37

Figura 16: Traçados eletrorretinográficos médios antes e após a injeção de SSB. A) Resposta Escotópica (3 cd/m² $)$, B) Resposta Escotópica Máxima e C) Resposta fotópica.

Figura 17: Relação intensidade-resposta da onda b escotópica de animais/olhos injetados com $0,1 \mathrm{ml}$ de SSB (símbolos, $n=4$ ), ajustada pela função de Hill (linha cinza escuro, 7 dias após injeção). A função/curva da população controle/não injetada ( $n=9$, linha preta contínua) é mostrada $+/-$ dp (linhas pretas tracejadas) para fins de comparação. 39

Figura 18: Relação de amplitude de onda b/onda a na condição escotópica máxima e fotópica. Cada símbolo representa o registro obtido em um olho. A linha cinza representa a curva de regressão linear e a linha tracejada representa a curva \pm dp......... 41

Figura 19: Relação entre a frequência de estimulação luminosa e amplitude de resposta. Cada símbolo representa o registro obtido em um olho. A linha cinza representa a média e a linha tracejada representa a média \pm dp do controle.

Figura 20: Traçados eletrorretinográficos médios antes e após a injeção de veículo. A) Resposta Escotópica ( $3 \mathrm{~cd} / \mathrm{m}^{2}$ ). B) Resposta Escotópica Máxima e C) Resposta fotópica.

Figura 21: Relação intensidade-resposta da onda b escotópica de animais/olhos injetados com $0,1 \mathrm{ml}$ de polissorbato (símbolos, $\mathrm{n}=4$ ), ajustada pela função de Hill (linha cinza escuro, 7 dias após injeção e cinza claro, 30 dias após injeção). A função/curva da população controle/não injetada ( $n=9$, linha preta contínua) é mostrada +/- dp (linhas pretas tracejadas) para fins de comparação. 45

Figura 22: Relação de amplitude de onda b/onda a na condição fotópica. Cada símbolo representa o registro obtido em um olho. A linha cinza representa a curva de regressão linear e a linha tracejada representa a curva \pm dp do controle. 46

Figura 23: Relação de amplitude de onda b/onda a na condição escotópica máxima. Cada símbolo representa o registro obtido em um olho. A linha cinza representa a curva de regressão linear e a linha tracejada representa a curva \pm dp do controle. 46

Figura 25: Relação intensidade-resposta da onda b escotópica de animais/olhos injetados com $5 \mu \mathrm{g}$ de MPA (símbolos, $\mathrm{n}=4$ ), ajustada pela função de Hill (linha cinza escuro, 7 dias após injeção e cinza claro, 30 dias após injeção). A função/curva da 
população controle/não injetada ( $n=9$, linha preta contínua) é mostrada $+/$ - dp (linhas pretas tracejadas) para fins de comparação.

Figura 26: Relação de amplitude de onda b/onda a na condição escotópica máxima. Cada símbolo representa o registro obtido em um olho. A linha cinza representa a curva de regressão linear e a linha tracejada representa a curva $\pm d p$.

Figura 27: Relação de amplitude de onda b/onda a na condição fotópica. Cada símbolo representa o registro obtido em um olho. A linha cinza representa a curva de regressão linear e a linha tracejada representa a curva \pm dp. 50

Figura 29: Relação intensidade-resposta da onda b escotópica de animais/olhos injetados com $50 \mu \mathrm{g}$ de MPA (símbolos, n=4), ajustada pela função de Hill (linha cinza escuro, 7 dias após injeção e cinza claro, 30 dias após injeção). A função/curva da população controle/não injetada ( $n=9$, linha preta contínua) é mostrada $+/$ - dp (linhas pretas tracejadas) para fins de comparação.

Figura 30: Relação intensidade-resposta da onda b escotópica de animais/olhos injetados com $200 \mu \mathrm{g}$ de MPA (símbolos, $\mathrm{n}=4$ ), ajustada pela função de Hill (linha cinza escuro, 7 dias após injeção e cinza claro, 30 dias após injeção). A função/curva da população controle/não injetada ( $n=9$, linha preta contínua) é mostrada $+/$ - dp (linhas pretas tracejadas) para fins de comparação. 53

Figura 31: Relação de amplitude de onda b/onda a na condição escotópica máxima. Cada símbolo representa o registro obtido em um olho. A linha cinza representa a curva de regressão linear e a linha tracejada representa a curva $\pm d p$. 54

Figura 32: Relação de amplitude de onda b/onda a na condição escotópica máxima. Cada símbolo representa o registro obtido em um olho. A linha cinza representa a curva de regressão linear e a linha tracejada representa a curva \pm dp. 54

Figura 33: Relação de amplitude de onda b/onda a na condição fotópica. Cada símbolo representa o registro obtido em um olho. A linha cinza representa a curva de regressão linear e a linha tracejada representa a curva $\pm d p$. 55

Figura 34: Relação de amplitude de onda b/onda a na condição fotópica. Cada símbolo representa o registro obtido em um olho. A linha cinza representa a curva de regressão linear e a linha tracejada representa a curva $\pm d p$.

Figura 36: Relação frequência de estimulação luminosa e amplitude de resposta. Cada símbolo representa o registro obtido em um olho. A linha cinza representa a média e a linha tracejada representa a média $\pm \mathrm{dp}$ 56

Figura 37: Relação intensidade-resposta da onda b escotópica de animais/olhos injetados com $1.000 \mu \mathrm{g}$ de MPA (símbolos, $\mathrm{n}=4$ ), ajustada pela função de Hill (linha cinza escuro, 7 dias após injeção e cinza claro, 30 dias após injeção). A função/curva da população controle/não injetada ( $n=9$, linha preta contínua) é mostrada $+/$ - dp (linhas pretas tracejadas) para fins de comparação. 58 
Figura 38: Relação intensidade-resposta da onda b escotópica de animais/olhos injetados com $10.000 \mu \mathrm{g}$ de MPA (símbolos, $\mathrm{n}=4$ ), ajustada pela função de Hill (linha cinza escuro, 7 dias após injeção e cinza claro, 30 dias após injeção). A função/curva da população controle/não injetada ( $n=9$, linha preta contínua) é mostrada $+/$ - dp (linhas pretas tracejadas) para fins de comparação.

Figura 39: Relação de amplitude de onda b/onda a na condição escotópica máxima. Cada símbolo representa o registro obtido em um olho. A linha cinza representa a curva de regressão linear e a linha tracejada representa a curva \pm dp. 60

Figura 40: Relação de amplitude de onda b/onda a na condição escotópica máxima. Cada símbolo representa o registro obtido em um olho. A linha cinza representa a curva de regressão linear e a linha tracejada representa a curva $\pm d p$.

Figura 41: Relação de amplitude de onda b/onda a na condição fotópica. Cada símbolo representa o registro obtido em um olho. A linha cinza representa a curva de regressão linear e a linha tracejada representa a curva $\pm d p$.

Figura 42: Relação frequência de estimulação luminosa e amplitude de resposta. Cada símbolo representa o registro obtido em um olho. A linha cinza representa a média e a linha tracejada representa a média \pm dp.

Figura 43: Relação frequência de estimulação luminosa e amplitude de resposta. Cada símbolo representa o registro obtido em um olho. A linha cinza representa a média e a linha tracejada representa a média \pm dp.

Figura 44: Relação amplitude de onda b/onda a dos controles comparados a dois grupos: um tratado com Kenalog e o outro exposto a luz intensa. (Perlman, 2009).

Figura 45: Exemplo de registro de ERG em ratos em três diferentes condições: acordado (A), anestesiado (U) e tratado com escopolamina (S). (GUARINO et. al., 2004). 66

Figura 46: Resultados e desvio padrão de amplitudes e latências sob diferentes estímulos. (MACKIEWICZ et. al., 2007). 


\section{Lista de Tabelas}

Tabela 1: Média e desvio padrão de amplitude encontrados no registros de ERG.

Tabela 2: Média e desvio padrão de latência encontrados nos registros de ERG.

Tabela 3: Comparação das latências das respostas das ondas a e b do grupo controle com o grupo pós-injeção de SSB. Os valores máximos e mínimos do grupo controle são as médias $+\mathrm{dp}$ e $-\mathrm{dp}$, respectivamente.

Tabela 4: Comparação das latências das respostas das ondas a e b do grupo controle com o grupo pós-injeção de SSB. Os valores máximos e mínimos do grupo controle são as médias $+\mathrm{dp}$ e $-\mathrm{dp}$, respectivamente.

Tabela 5: : Comparação das latências das respostas das ondas a e b do grupo controle com o grupo pós-injeção de MPA $(5 \mu \mathrm{g})$. Os valores máximos e mínimos do grupo controle são as médias $+d p$ e $-d p$. Valores em vermelho e verde representam latências abaixo do mínimo respectivamente.

Tabela 6: Comparação das latências das respostas das ondas a e b do grupo controle com o grupo pós-injeção de MPA $(50 \mu \mathrm{g})$. Os valores máximos e mínimos do grupo controle são as médias $+\mathrm{dp}$ e $-\mathrm{dp}$. Valores em vermelho e verde representam latências abaixo do mínimo e do máximo, respectivamente.

Tabela 7: Comparação das latências das respostas das ondas a e b do grupo controle com o grupo pós-injeção de MPA $(200 \mu \mathrm{g})$. Os valores máximos e mínimos do grupo controle são as médias $+\mathrm{dp}$ e $-\mathrm{dp}$. Valores em vermelho e verde representam latências abaixo do mínimo respectivamente.

Tabela 8: Comparação das latências das respostas das ondas a e b do grupo controle com o grupo pós-injeção de MPA $(1.000 \mu \mathrm{g})$. Os valores máximos e mínimos do grupo controle são as médias $+\mathrm{dp}$ e $-\mathrm{dp}$. Valores em vermelho e verde representam latências abaixo do mínimo e do máximo, respectivamente.

Tabela 9: Comparação das latências das respostas das ondas a e b do grupo controle com o grupo pós-injeção de MPA $(10.000 \mu \mathrm{g})$. Os valores máximos e mínimos do grupo controle são as médias $+d p$ e $-d p$. Valores em vermelho e verde representam latências abaixo do mínimo e do máximo, respectivamente. 


\section{RESUMO}

O presente trabalho utilizou o eletrorretinograma (ERG) em coelhos (Oryctolagus cuniculus) para avaliar uma forma alternativa de aplicação do ácido micofenólico no tratamento da uveíte, uma doença ocular inflamatória. Uveíte é o termo utilizado para definir a inflamação da íris, coróide e corpo ciliar. O ERG é um registro de potenciais elétricos originados na retina em resposta à estimulação luminosa. O objetivo desse estudo é analisar alterações em funções da retina em olhos tratados com diferentes doses intravítreas de ácido micofenólico. Foram medidas amplitude e latência das ondas a e b do ERG para a função de intensidade-resposta e de resolução temporal. O micofenolato de mofetila (MMF) é um potente medicamento imunossupressor e vem sendo empregado com sucesso no tratamento de uveítes. O MMF é uma pró-droga, que é transformada no fígado em ácido micofenólico (MPA), o imunossupressor ativo. $\mathrm{O}$ uso de MMF causa efeitos colaterais e, para diminuir esses efeitos, este estudo analisa a injeção intravítea de MPA em coelhos. Foram utilizados um total de quarenta animais, divididos em seis grupos. Primeiramente, foram realizados exames eletrorretinográficos em olhos intactos, sem administração de nenhuma substância, para determinação dos parâmetros dos registros. Foram testados também os olhos injetados apenas com solução salina balanceada (SSB). Após essa etapa, foram feitos testes com olhos injetados apenas com o veículo (Polissorbato 80). Esse procedimento foi necessário para estabelecer se o veículo pode ser utilizado ou se apresenta algum grau de toxicidade para a retina. As doses usadas para avaliação da toxicidade da droga foram cinco: $5 \mu \mathrm{g} / \mathrm{ml}, 50 \mu \mathrm{g} / \mathrm{ml}, 200 \mu \mathrm{g} / \mathrm{ml}, 1.000 \mu \mathrm{g} / \mathrm{ml} \mathrm{e} 10.000$ $\mu \mathrm{g} / \mathrm{ml}$. Os exames eletrorretinográficos foram realizados 7 e 30 dias após injeção intravítrea de MPA. Os resultados indicam que não houve alteração nos parâmetros de ERG nos olhos que receberam apenas o veículo. Também não acusaram indícios de toxicidade os olhos tratados com as doses de 5, 50 e $200 \mu \mathrm{g} / \mathrm{ml}$ da droga. Apenas com as doses mais altas, de 1.000 e $10.000 \mu \mathrm{g} / \mathrm{ml}$, os olhos apresentaram diminuição de sensibilidade ao estímulo luminoso. Não é possível afirmar que as células da retina não foram danificadas pela injeção intravítrea de MPA, pois o ERG de campo total não detecta lesões pontuais. O pequeno número de olhos analisados e a necessidade de utilização de anestésicos podem levar a interpretações equivocadas dos resultados. As substâncias anestésicas podem afetar a neurotransmissão e, consequentemente, os resultados obtidos nos registros do ERG. As análises dos dados de amplitude e tempo implícito das ondas a e b foram muito consistentes e apresentam variações compatíveis com a literatura. 


\section{ABSTRACT}

This work uses the application of the electroretinogram (ERG) in rabbits (Oryctolagus cuniculus) in order to evaluate an alternative way of using the mycophenolic acid for treatment of uveitis, an inflammatory eye disease. Uveitis is an inflammation of the iris, choroid and ciliary body. The ERG is the record of electrical responses originated in the retina to luminous stimulation. The purpose of this study is to analyse changes in the retinal functions of eyes treated with distinct intravitreous doses of mycophnolic acid. A and $\mathrm{b}$ waves amplitude and implicit times for the intensity-response and temporal resolution functions. Mofetil mycophenolate (MMF) is a powerful immunossupressant drug successfully used for treating the uveitis. It is a pro-drug that is transformed in the liver into mycophenolic acid (MPA), the active immunossupressor. MMF causes collateral effects and, in order to reduce these effects, the intravitreous MPA injection in rabbits is analysed in this study. Forty rabbits were used, divided in 6 groups. First of all, electroretinografic exams in control eyes were made, without the application of any substance, for determining the recording parameters. Then were tested the eyes injected with only balanced saline solution (BSS). After that, tests were made in eyes injected only with the vehicle (Polissorbato 80). This procedure was necessary for finding out whether the vehicle may be used or is in some degree toxic for the retina. The doses for evaluation of the drug toxicity were five: $5 \mu \mathrm{g} / \mathrm{ml}, 50 \mu \mathrm{g} / \mathrm{ml}, 200 \mu \mathrm{g} / \mathrm{ml}, 1.000 \mu \mathrm{g} / \mathrm{ml}$ e $10.000 \mu \mathrm{g} / \mathrm{ml}$. By the examination of the distinct parameters of the ERG, several visual functions can be evaluated (inner and outer retina) and possible impairments in the temporal resolution, in the relationship luminous intensity and amplitude of the response, and in other functions. The results show there were no changes in the ERG parameters for the eyes where only the vehicle was applied. Also, no toxicity signs were detected in 5,50 or $200 \mu \mathrm{g} / \mathrm{ml}$ doses. Sensitivity to the luminous stimulus was only shown in eyes treated with higher doses, or, 1.000 and $10.000 \mu \mathrm{g} / \mathrm{ml}$. It is not possible to assert that the retina cells were not injured by the MPA injection, as the total field ERG does not detect spot lesions. The small quantity of tested eyes and the usage of anesthetics may lead to erroneous interpretations of the results. The anesthetic substances can affect the neurotransmission and consequently the results of ERG records. The analysis of the a and b wave amplitude and implicit time were very consistent and show variations consistent with the pertinent literature. 


\section{Introdução}

\subsection{Uveítes}

A enfermidade denominada uveíte é definida como inflamação do trato uveal, a camada intermediária do olho, composta por vasos sanguíneos e tecido conjuntivo, e que é dividida em íris, o corpo ciliar e a coróide, de acordo com a localização e composição histológica. A uveíte pode ser resultado de infecções (bacterianas, fúngicas ou virais), processos autoimunes ou ser decorrente de trauma ocular cirúrgico ou não (Silverstein et al., 1997).

O nervo óptico e a retina podem também estar afetados por contiguidade. Pouco se sabe sobre a patogênese da uveíte, mas em casos de uveítes endógenas em que não há ligação com um agente infeccioso, a causa invocada é a autoimunidade. Os sintomas de uveíte incluem: sensibilidade à luz, borramento da visão, dor e vermelhidão nos olhos. Em relação ao tempo de doença, a uveíte é dividida em aguda (até seis semanas), crônica (superior a seis semanas) e recorrente (com surtos de recorrência [Bloch et. al., 1987].).

A uveíte é uma das doenças oculares mais danosas, que pode levar à formação de edema dos tecidos oculares, aumento da pressão ocular e suas sequelas podem provocar destruição de tecidos intraoculares, causando cegueira. (Nussenblatt, Whitcup e Palestine, 1996). O achado histopatológico da uveíte é caracterizado pela infiltração de leucócitos e proteínas dentro do globo ocular. Essas reações são mediadas por citocinas pró e anti-inflamatórias, como o fator de necrose tumoral $\alpha(\mathrm{TNF} \alpha)$, as 
interleucinas 1, 2, 4 e 10 (IL-1, IL-2, IL-4 e IL-10) e o fator de crescimento do endotélio vascular (VEGF) (Mo et. al., 1998).

Estima-se que cerca de $10 \%$ dos casos de cegueira nos Estados Unidos sejam causados por uveíte, ou seja, que cerca de 30.000 americanos por ano tornem-se legalmente cegos devido à uveíte. Entre as complicações e sequelas da uveíte estão: o glaucoma, a catarata, o descolamento de retina e o edema macular (Darrell et. al., 1962; Gouveia et. al., 2004).

Entre as causas de uveíte, encontram-se agentes infecciosos como Toxoplasma gondii (toxoplasmose), Mycobacterium tuberculosis (tuberculose) e Treponema pallidum (sífilis). As uveítes também ser manifestações de doenças auto-imunes, como artrite reumatóide juvenil e sarcoidose (Helm et. al., 1993). Muitos casos, ainda, são frequentemente rotulados como idiopáticos (Deschenes et. al., 2008).

Apesar dos tecidos intraoculares poderem ser visualizados através da córnea com o oftalmoscópio e a lâmpada de fenda, eles não podem ser acessados diretamente e não é possível realizar biópsia para auxilio no diagnóstico das afecções. Isso acontece com o trato uveal e a retina. Por esse motivo, o diagnóstico etiológico das uveítes baseia-se em exames laboratoriais específicos (sorologias) e inespecíficos, alem do aspecto clínico das lesões, da epidemiologia e de uma anamnese sistêmica completa Obter o diagnóstico de uveíte pode não ser simples, o tratamento pode ser prolongado e repetidas consultas podem ser necessárias (Silverstein et al., 1997). 


\subsection{Medicamentos utilizados para o tratamento de uveíte}

O tratamento das uveítes auto-imunes geralmente é longo, pois a doença costuma ser crônica. A medicação de primeira linha para o tratamento dessas condições é o corticóide. Em casos resistentes, nos quais as doses altas de corticóides provocam efeitos colaterais graves, ou nos quais o tratamento prolonga-se muito, opta-se por outras drogas imunossupressoras, como ciclosporina A, clorambucil, azatioprina e metotrexato. Todos esses medicamentos agem sobre linfócitos modulando sua ação (Vavvas \& Foster, 2004)

No entanto, essas drogas também oferecem riscos devido a seus efeitos tóxicos sobre o fígado e sobre o metabolismo de proteínas e de glicose. A azatioprina, por exemplo, pode causar supressão da medula óssea (particularmente leucopenia), distúrbios hepáticos, perda de apetite, náusea, vômitos e diarréia. A administração de ciclosporina (CsA) pode levar à perda de consciência, dificuldade no controle dos movimentos corporais e mudanças na visão. O clorambucil pode provocar perda de apetite ou peso, diarréia, fraqueza e o metotrexato (MTX), dores no peito, visão borrada, perda repentina da visão, sangue na urina. (Díaz-Llopis et. al., 2009)

Desde 1998 têm sido descritos estudos do uso de MMF como adjuvante no tratamento de uveítes (Kilmartin et. al., 1998). No trabalho de Siepmann et al. (2006), foi feita uma análise retrospectiva que representa o primeiro relato de um grande número de pacientes $(\mathrm{n}=106)$, afetados exclusivamente pela uveíte (em suas várias formas) que foram tratados por um período prolongado. As razões para introdução de MMF foram: intolerância a altas doses de esteróides (>20 mg/dia) administrado há pelo menos 6 meses, hipertensão arterial e danos à função hepática (uso de ciclosporina A), alterações significativas na contagem de células sanguíneas (uso de MTX) e uveítes 
refratárias em que prednisolona tinha sido usada combinada à CsA ou ao MTX ou aos dois.

Ocorreram poucos efeitos colaterais, como dor de estômago, náusea e diarréia (15\%), dores de cabeça $(9,3 \%)$, fadiga $(5,7 \%)$, eczema (5\%) e perda de cabelo $(3.5 \%)$. A maioria dos sintomas foi transitório e desapareceram após algumas semanas de tratamento. MMF controlou a inflamação intraocular com sucesso e houve redução de administração de corticosteróide (Siepmann et al., 2006). 


\subsection{Micofenolato de Mofetila}

O micofenolato de mofetila (MMF) é a droga precursora de ácido micofenólico (MPA), um inibidor de inosina monofosfato desidrogenase (IMPDH). Esta é a enzima limitante na síntese de novo das purinas, e o linfócito B é mais dependente dessa via do que os outros tipos celulares. Além disso, o MPA é um inibidor cinco vezes mais potente da isoforma tipo II de IMPDH, que é expressa em linfócitos ativados, do que da isoforma tipo I, que aparece na maioria das células. O MPA tem, dessa forma, um efeito citotóxico mais potente nos linfócitos do que em outras células. Este é o principal mecanismo pelo qual MPA exerce efeitos imunossupressores (Allison et. al., 2000).

Os nucleotídeos são essenciais para as células, principalmente para a produção de proteínas e proliferação celular. Os nucleotídeos são formados por um grupo fosfato, uma pentose e uma base nitrogenada; estão divididos em nucleotídeos de purina e nucleotídeos de pirimidina. A síntese de novo das purinas permite que precursores nãopurínicos, adquiridos através da dieta, sejam transformados em nucleotídeos de purina. Essa via consiste de vários passos metabólicos, e o ácido micofenólico interrompe a formação de purinas no final do processo (Fig.1, Allison et al., 1996) 


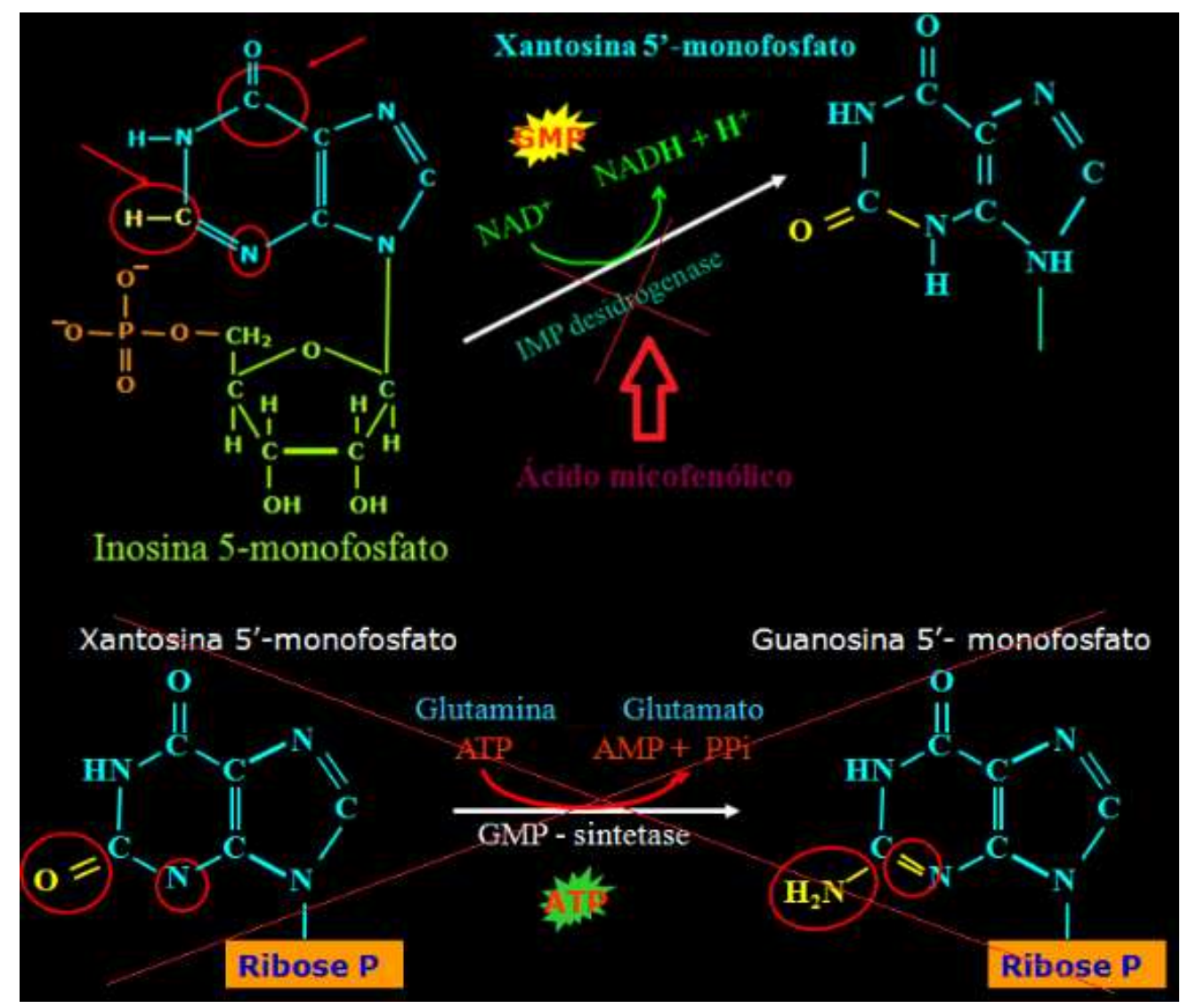

Figura 1: Cascata metabólica de formação das purinas. O ácido micofenólico interrompe a transformação de inosina 5-monofosfato em xantosina 5-monofosfato por inativação da IMP desidrogenase. Dessa forma, não é possível completar as reações até guanosina 5-monofosfato (www.dbq.uem.br/met-nucl.ppt).

O MPA pode ativar outros três mecanismos. Primeiro, pode induzir apoptose em linfócitos T ativados. Segundo, por esgotamento de nucleotídeo de guanina, o MPA suprime a expressão de algumas moléculas de adesão, diminuindo o recrutamento de linfócitos e monócitos no sítio de inflamação e rejeição de enxerto. Terceiro, suprimindo a produção de óxido nítrico sintase, e consequentemente danos teciduais mediados por peroxinitrito (Allison et. al., 1993).

A descoberta do ácido micofenólico (MPA) como um potente imunossupressor, capaz de inibir a proliferação de células B e T permitiu que seu potencial no campo dos transplantes fosse compreendido. Apesar do MMF ser geralmente bem tolerado, a 
terapia pode ser limitada por efeitos colaterais associados, em particular toxicidade gastrointestinal, que pode ocorrer em mais de 40\% dos pacientes. (Morris et. al., 1990)

Testes clínicos em pacientes que receberam transplante de rim, coração e fígado têm demonstrado que, em combinação com ciclosporina, o tratamento com MMF pode reduzir a incidência de episódios de rejeição aguda e aumentar a sobrevivência dos pacientes, assim como melhorar o funcionamento dos órgãos transplantados (Sollinger et al., 2004).

Segundo Thorne et all. (2005), o uso desse medicamento em doenças oculares inflamatórias foi satisfatório: aproximadamente $70 \%$ dos pacientes terminou o tratamento com sucesso mas $17 \%$ necessitaram de uma redução na dose do micofenolato devido aos efeitos colaterais do tratamento. No entanto, $64 \%$ desses pacientes finalizaram com sucesso o tratamento apesar da dose baixa.

Estudos clínicos mostraram que o uso sistêmico do MMF apresenta bons resultados no tratamento de uveítes. A introdução da droga, como primeira opção terapêutica ou como adjuvante de corticosteróides e outros imunossupressores, cursou com melhora da acuidade visual, controle da inflamação ocular e diminuição da dose dessas outras drogas (Baltatzis et. al., 2003).

O ácido micofenólico foi primeiramente usado com sucesso na década de 1970 para o tratamento de psoríase. O micofenolato de mofetila também tem sido usado para tratar artrite reumatóide, com melhora clínica significativa em pacientes cuja doença é refratária a outras drogas anti-reumáticas. O último uso relatado para MMF foi para anemia hemolítica autoimune; ele foi usado com sucesso como agente de segunda linha para hemólise severa após quimioterapia (Larkin and Lightman, 1999).

O micofenolato de mofetila é um imunossupressor relativamente novo, e tem um efeito citostático maior nos linfócitos do que em outros tipos celulares. Devido a essa 
ação seletiva, a droga apresenta poucos efeitos colaterais em relação a outros agentes imunossupressores com potência similar (Doycheva et al., 2007).

Além disso, os corticoesteróides, que são geralmente o usados para tratamento de uveíte não-infecciosa, causam efeitos colaterais consideráveis, especialmente em crianças. Tratamentos que se limitam a uso de esteróides aumentam a susceptibilidade das crianças a infecções. Outros efeitos adversos incluem: toxicidade para alguns órgãos, supressão reversível da medula óssea e formação de tumores malignos (Holland et al., 2003 e Jabs et al., 2000). 


\subsection{Camadas da Retina}

A absorção de um fóton pelo fotorreceptor é traduzida para um primeiro sinal bioquímico e depois é transformada em uma mensagem elétrica, que estimulará as demais células da retina (Kolb, 2011).

A retina de todos os vertebrados é composta de três camadas de corpos celulares e duas camadas de sinapses. A camada nuclear externa contém corpos celulares de cones e bastonetes, a camada nuclear interna contém corpos celulares de células bipolares, horizontais e amácrinas e a camada de células ganglionares, apresenta o corpo celular das células ganglionares e das amácrinas deslocadas (Fig.2).

$\mathrm{Na}$ divisão de cada camada celular estão duas regiões em que o contato sináptico ocorre. A primeira área é chamada de camada plexiforme externa, onde as conexões entre bastonetes e cones ocorrem verticalmente com as células bipolares e horizontalmente com as células horizontais. A segunda área é a camada plexiforme interna e funciona como uma retransmissão vertical da informação, em que as células bipolares se conectam às células ganglionares. Essa camada pode apresentar células amácrinas, que interagem em redes adicionais, influenciando e integrando os sinais das células ganglionares (Kolb, 2011). 


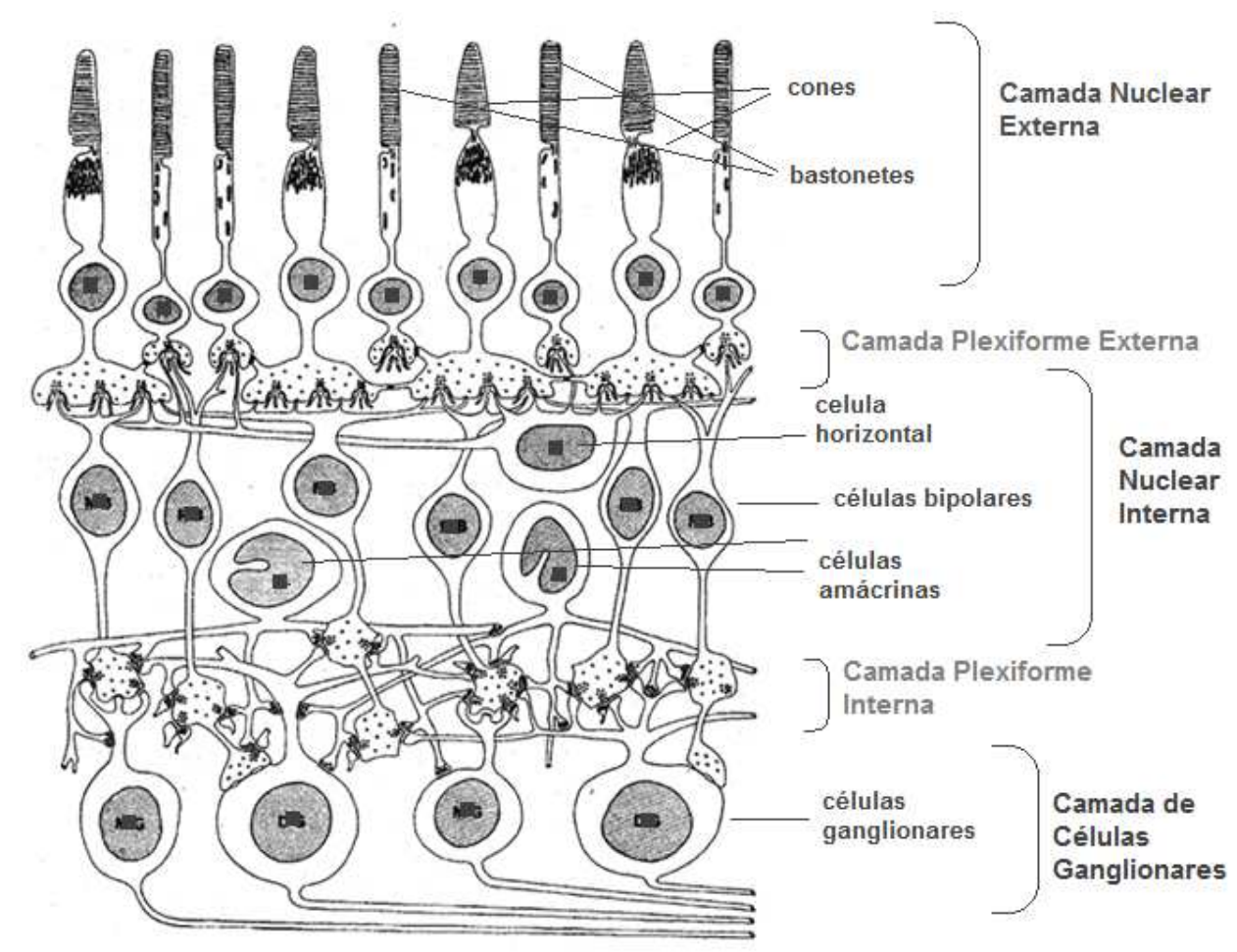

Figura 2: Divisão das camadas da retina. Camada nucleares interna e externa; camadas plexiformes interna e externa e camada de células ganglionares. (Dowling and, Boycott , 1966) 


\subsection{Eletrorretinograma}

\subsubsection{Descrição das Ondas}

Uma resposta elétrica do olho à luz, que pode ser captada na superfície da córnea, tem origem na atividade da retina e foi primeiramente demonstrada por Holmgren em 1865 em olho de rã (Perlman, 2010). Esta resposta resulta da atividade somada das células da retina e é por isso chamada de eletrorretinograma. Quando o olho adaptado ao escuro é estimulado por um flash de luz abrangendo toda a retina, a resposta elétrica resultante, em amplificação por corrente alternada, é constituída por uma onda bifásica com um componente negativo (onda a) e outro positivo (onda b) em cuja fase ascendente aparecem potenciais oscilatórios (Fig.3). Condições de registro com amplificação por corrente contínua e estimulação de longa duração permitem registros de onda c e onda $\mathrm{d}$. Nesse trabalho, no entanto, foram analisados apenas os padrões de ondas a e b.

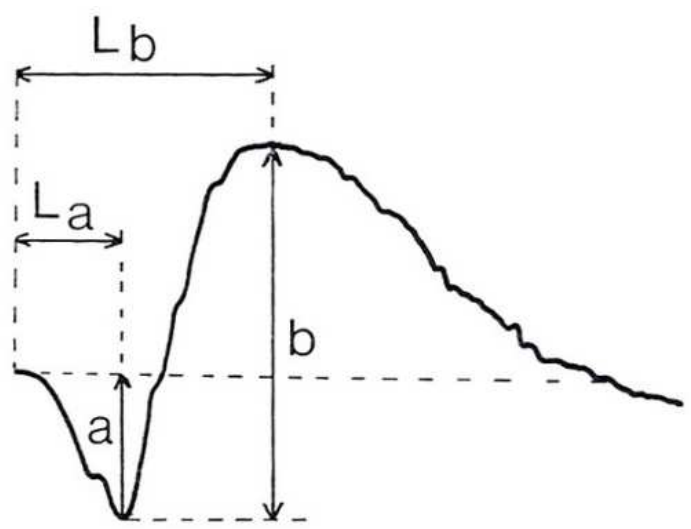

Figura 3: Registro padrão de ERG. a- amplitude da onda a; b- amplitude da onda b; la- latência da onda a e lb- latência da onda b.(Perlman, 2010)

A onda a, originada no início do registro eletrorretinográfico, resulta da ocorrência de hiperpolarização da membrana dos fotorreceptores, originando uma onda 
com amplitude negativa. Essa onda foi identificada como reflexo da atividade de fotorreceptores (Lent, 2008).

A onda a inclui dois componentes: um rápido, o potencial receptor precoce (early receptor potential-ERP) resultante da reação do fotopigmento à luz (Sillman et. al., 1969a) e um lento, que representa a resposta neural dos fotorreceptores. O ERP é uma resposta instantânea à luz, constituído por uma deflexão positiva $R_{1}$, seguida por uma negativa, $\mathrm{R}_{2}$. Após $2 \mathrm{~ms}$, surge o potencial tardio do receptor, que juntamente com o ERP forma a onda a (Fig.5) (Malmivuo et. al., 1995).

A onda $\mathrm{b}$ tem sido tema frequente de pesquisa por ser o maior componente do registro de ERG e tem sido usada em análises clínicas e experimentais da função retiniana. Como o L-glutamato é o neurotransmissor dos fotorreceptores para os neurônios de segunda ordem da retina, expondo-se a retina a agonistas e antagonistas de L- glutamato é possível bloquear por saturação a transmissão sináptica dos fotorreceptores e isolar sua contribuição no ERG (Perlman, 2010).

A figura 4 indica claramente que a onda $\mathrm{b}$ resulta de atividade pós-sináptica aos receptores. Bloquear a transmissão sináptica dos fotorreceptores para os neurônios de segunda ordem por saturação de receptores pos-sinápticos com L-glutamato, elimina a onda b (Perlman, 2011). 


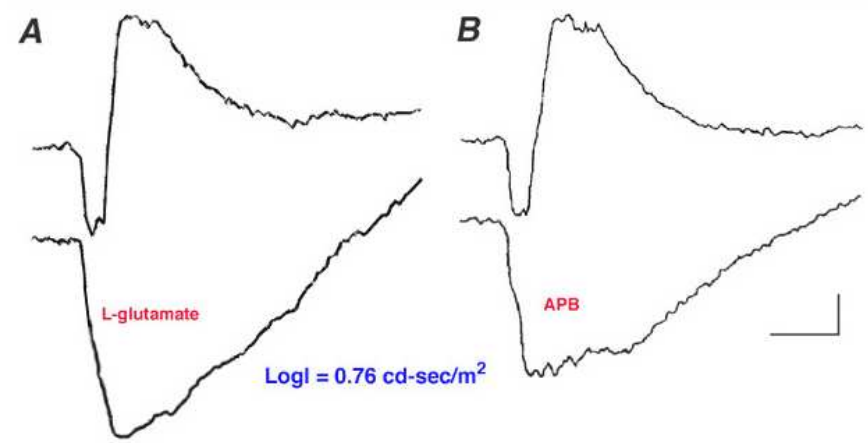

Figura 4: Eliminação da onda b de coelhos por injeção intravítrea de L-glutamato (A) ou ácido aminofosfonobutírico (APB) (B). A droga foi injetada no olho direito (curva abaixo) e a solução salina no olho esquerdo (curva acima), como controle. (http://webvision.med.utah.edu)

Faber e colaboradores (1969) foram os primeiros a calcular a corrente extracelular que forma a base da onda b. A lenta despolarização das células de Muller ao estímulo luminoso segue um padrão temporal similar à onda b registrada na mesma retina. Eles relataram que a onda $b$ era gerada na parte distal da retina, provavelmente na camada plexiforme externa (sugeriram as células de Muller). Outros estudos relatam um aumento no potássio extracelular induzido pela luz na camada plexiforme externa. Supõe-se que a origem desse aumento refere-se às células bipolares, mais especificamente às células bipolares do tipo centro-ON, que são despolarizadas pela luz (Dick et. al., 1985).

A exposição da retina de vertebrados à $\mathrm{APB}$, um agonista específico a receptores metabotrópicos de glutamato, elimina a onda b (Gurevich and Slaughter, 1993). Como receptores metabotrópicos de glutamato sensíveis a APB são encontrados apenas nas células bipolares centro-ON (Slaughter and Miller, 1981), esta descoberta constitui uma clara indicação do envolvimento dessas células bipolares na formação da onda b (Perlman, 2011).

$\mathrm{Na}$ fase de ascendente da onda b, muitas vezes, é possível notar a sobreposição de ondas de pequena amplitude - os potenciais oscilatórios (OPs). Como a relação entre 
amplitude dos OPs e a intensidade do estímulo difere significativamente da relação intensidade-resposta e amplitude da onda b, a origem dessas ondas foi atribuída a outras estruturas, principalmente à camada plexiforme interna (Asi \& Perlman, 1992; Ogden,1973). Estudos farmacológicos e registros internos na retina sugerem que os OPs são reflexos de correntes elétricas extracelulares geradas por interações entre células amácrinas, bipolares e ganglionares (Wachtmeister \& Dowling, 1978; Yonemura \& Kawasaki, 1979; Heynen et. al., 1985, Perlman, 2010) (Fig.5)

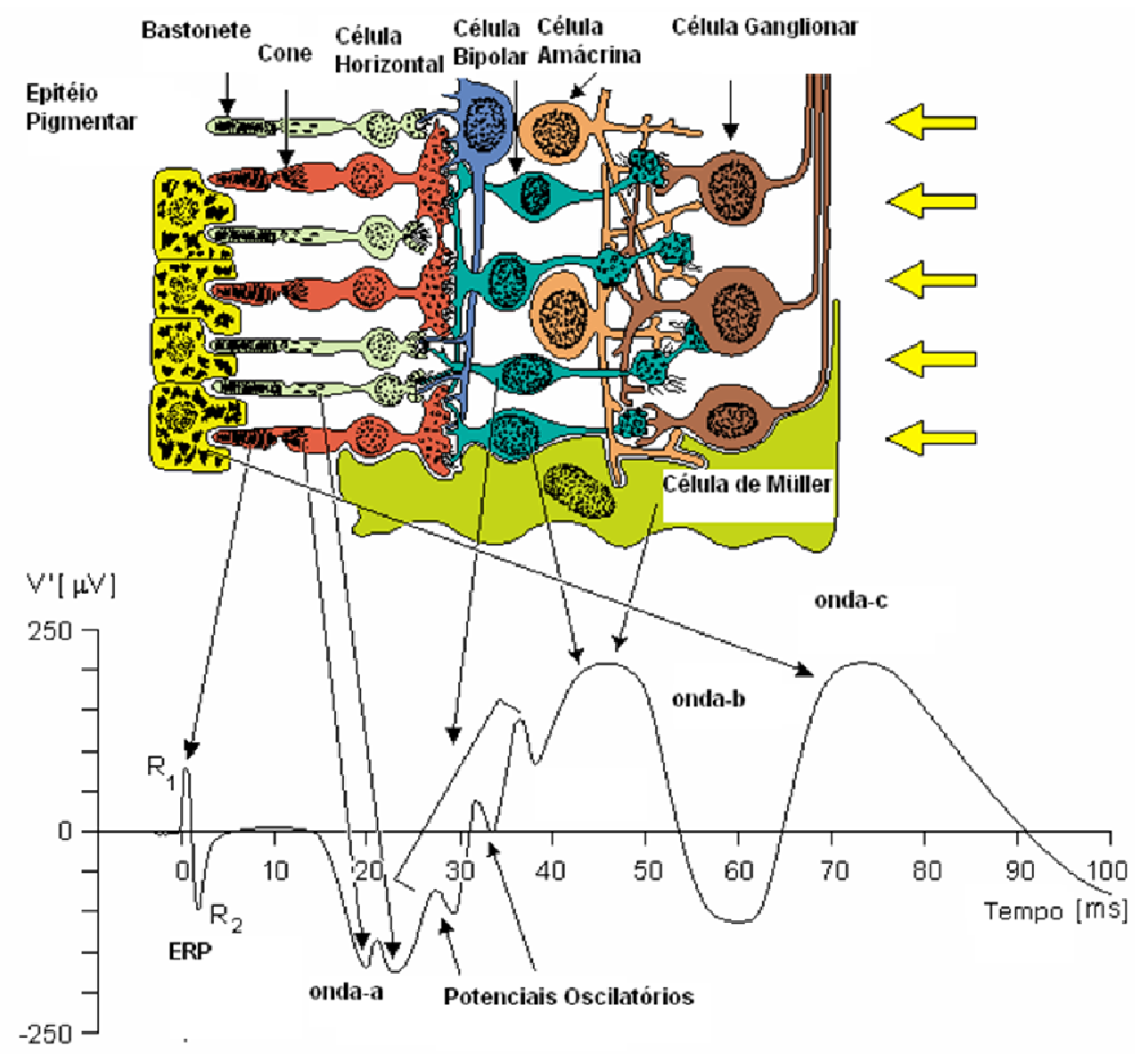

Figura 5: As células da retina e suas respostas ao flash de luz. Os fotorreceptores apresentam potencial negativo. Isto leva a célula bipolar a se tornar despolarizada ou hiperpolarizada. As células amácrinas possuem um efeito de feedback negativo. As células ganglionares disparam um pulso de ação, o que leva resultados proporcionais ao nível de estímulo luminoso (Malmivuo \& Plonse, 1995). 


\subsubsection{Isolamento dos elementos da retina que contribuem para o ERG}

O registro de ERG pode ser feito sob diferentes condições de adaptação. Designa-se ERG escotópico o registro feito em adaptação ao escuro e ERG fotópico o registro feito em adaptação à luz de fundo. É possível isolar o sistema de cones do de bastonetes, manipulando o nível de adaptação (ERG fotópico ou escotópico), além de mudanças na iluminação de fundo, intensidade e cor do flash (Gjörloff, 2004).

O ERG de campo total é um método objetivo para medir separadamente distúrbios nas funções de cones e bastonetes em estudos farmacológicos ou em doenças degenerativas em humanos. Nos estudos do ERG escotópico, os bastonetes contribuem primariamente para o resultado, mas dependendo da intensidade da luz ou da cor do filtro, diferentes níveis de funções dos cones serão incluídos (Gouras, 1970). Uma limitação do ERG de campo total é o fato de ser o resultado de um potencial de massa da retina, não permitindo distinguir contribuições de diferentes regiões (Creel, 2010)

Algumas drogas podem produzir efeitos degenerativos na retina, dependendo da dose e do tempo de uso (Inada et. al., 2005). Doenças metabólicas sistêmicas, como diabetes, podem apresentar seus reflexos na fisiologia da retina (Gualtieri, 2009), reduzindo a amplitude da onda $b$. 


\subsection{Injeção Intravítrea}

A administração intravítrea foi inicialmente realizada para tratamento de descolamento de retina e hemorragia do vítreo. A injeção intravítrea de ar foi usada pela primeira vez em 1911, com o propósito de reparar o descolamento de retina. Durante as décadas seguintes, a injeção intravítrea ficou limitada à administração de solução salina e ar. Na década de 40 eram realizadas administrações intravítreas de penicilina para o tratamento de endoftalmites (Jager et. al., 2004). Um histórico dos avanços importantes é mostrado na figura 6 .

Nos anos 70 os antiinflamatórios começaram a ser administrados de forma intravítrea e, entre 1970-80, os antivirais. No decorrer da década até 1990, foi comum o uso de triamcinolona acetonida (TA) e no início desse século, inibidores de fatores de crescimento do endotélio vascular. Atualmente, as injeções intravítreas têm sido usadas para a administração de muitos medicamentos, como antibióticos, antifúngicos, antivirais e antiinflamatórios não-esteróides, esteróides e imunomoduladores (Peyman et. al., 2009).

Algumas das desvantagens da injeção intravítrea são os riscos inerentes ao procedimento em si e os resultados dependem não apenas da segurança e eficácia dos fármacos, mas também da ausência de eventos adversos associados a essa forma de administração (Scott et. al., 2003), incluindo a endoftalmite, a toxicidade ocular e retiniana do fármaco (Aiello et. al., 2004; Jaissle et. al., 2005), descolamento de retina, hemorragia vítrea, catarata, hipertensão ocular (Rodrigues et. al., 2008).

Esse procedimento tem se tornado uma técnica cada vez mais difundida na administração de drogas para tratamento de inúmeras doenças do segmento posterior do olho, como degeneração macular relacionada a idade, retinopatia diabética e oclusões venosas da retina. 
A grande eficácia de administração de agentes antivirais no tratamento de retinite por citomegalovírus usada frequentemente, e a injeção direta de antivirais no vítreo de pessoas com a síndrome da imunodeficiência adquirida são exemplos que mostram ser possível aumentar dosagem de drogas intraoculares e minimizar os riscos de toxicidade associada à administração sistêmica desses agentes (Jager et. al., 2004).

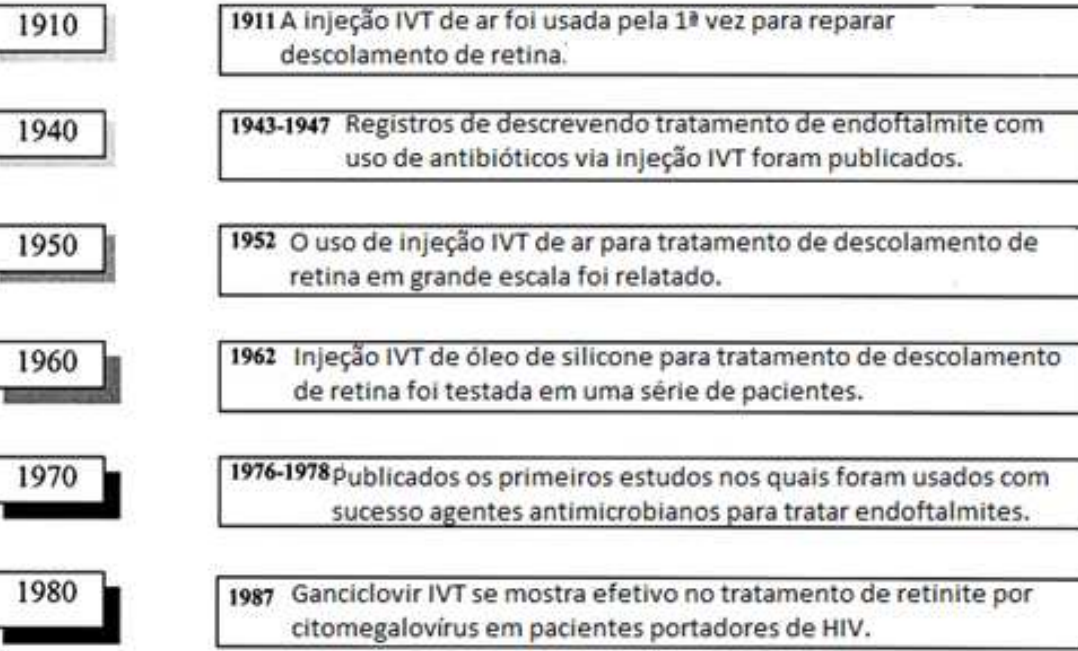

1950 1952 O uso de injeçăo IVT de ar para tratamento de descolamento de retina em grande escala foi relatado.

1960 injeçăo IVT de óleo de silicone para tratamento de descolamento de retina foi testada em uma série de pacientes.

1970 1976-1978 publicados os primeiros estudos nos quais foram usados com sucesso agentes antimicrobianos para tratar endoftalmites.

19801987 Ganciclovir IVT se mostra efetivo no tratamento de retinite por citomegalovirus em pacientes portadores de HIV. dexametasona IVT para tratar retinopatia diabética.

1995 Resultados de um estudo piloto com acetonil triamcinolona IVT para tratamento de degeneração macular foram publicados.

1997 Injeção IVT de metotrexato mostrou eficiência no tratamento de linfoma ocular em um pequeno número de pacientes.

1998 A FDA (U.S. Food and Drug Administration) aprovou o uso de Fomivirsen IVT para tratar retinite por citomegalovirus.

1999 Publicado o 12 estudo relatando sucesso no tratamento de hemorragia submacular por ativador de tecido plasminogênico

2000 2002-2003 Publicados os resultados de testes que avaliam a injeçro IVT de pegaptanib sódico para degeneração macular relacionada à idade.

2003 Resultados iniciais de testes para validação de administração IVT de ranibizumab para tratamento de degeneração macular ręlacionada à idade

Figura 6: Histórico dos avanços importantes no uso de injeção intravítrea (IVT) para tratamento de doenças oculares (Jager et. al., 2004). 
A injeção intravítrea é uma técnica amplamente usada em pesquisas científicas do sistema visual. Pode ser utilizada em modelos animais de moléstias oculares ou como aplicação para tratamento local. É possível realizar o procedimento com instrumentos simples e de baixo custo. Para conduzir o procedimento com sucesso, três aspectos devem ser observados: 1) o local da injeção não pode romper a estrutura da retina.; 2) sangramentos devem ser evitados para reduzir riscos de infecção; 3) o cristalino não deve ser tocado para evitar a catarata traumática (Chiu et. al., 2007). 


\subsection{Uso de Coelhos como Modelo Biológico}

A escolha do modelo deve ser criteriosa e é ponto fundamental do planejamento da pesquisa. Um modelo animal deve atender aos pressupostos de que: a-permita o estudo dos fenômenos biológicos ou de comportamento do animal; b- um processo patológico espontâneo ou induzido possa ser investigado; c- o fenômeno, em um ou mais aspectos, seja semelhante ao fenômeno em seres humanos (Fagundes et. al., 2004).

A escolha de um modelo inadequado implicará em restrições comprometedoras na análise e interpretação dos resultados e no processo de indução destes resultados para os seres humanos. O metabolismo de pequenos roedores é muitas vezes mais rápido do que o de humanos. Os órgãos viscerais que controlam e exercem o metabolismo crescem mais devagar do que o tamanho corporal como um todo (Fagundes et. al., 2004).

As doses intravítreas utilizadas atualmente, assim como de antibióticos para o tratamento de endoftalmite, foram estabelecidas com base nos resultados de estudos experimentais em coelhos. Segundo Gjörloff et. al. (2004), o coelho é amplamente usado em estudos oftalmológicos experimentais com diferentes drogas e métodos cirúrgicos.

A Figura 7 mostra que o padrão de ondas eletrorretinograficas das diferentes espécies de animais é similar, apresentando diferenças apenas em valores de amplitude e latência das ondas a e b (Perlman, 2009).

Os coelhos albinos foram escolhidos para o estudo por não apresentarem pigmento no epitélio da retina, e há relatos na literatura descrevendo que a pigmentação ocular pode ser um fator de proteção contra os efeitos tóxicos das drogas (Perlman, 2009). 

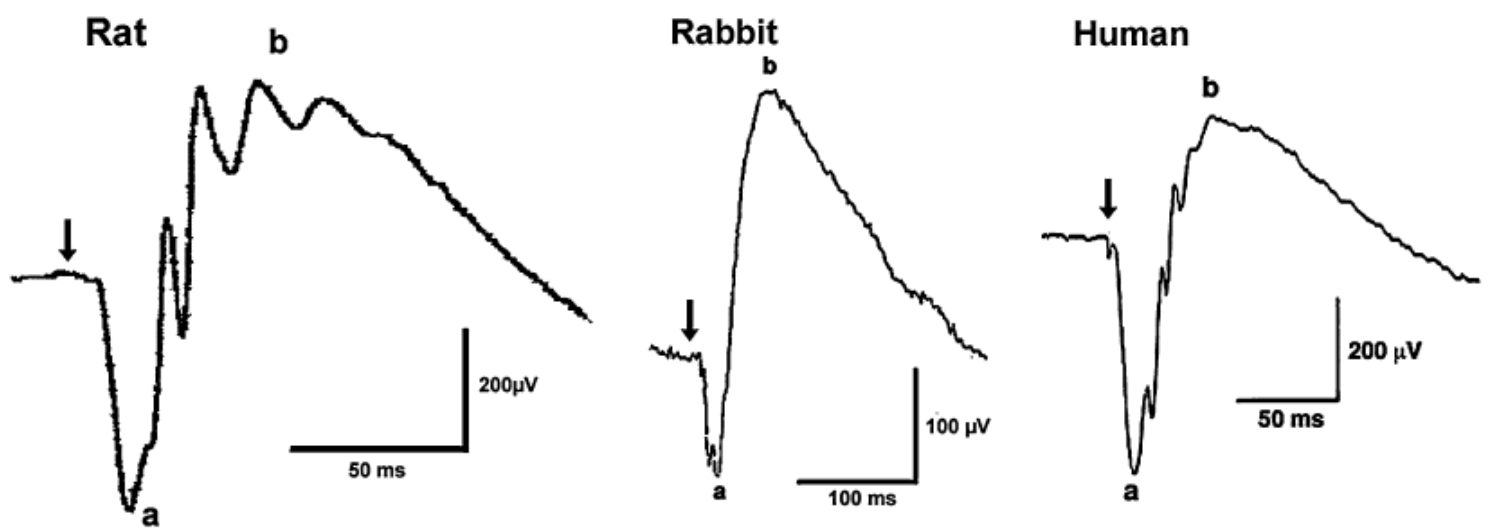

Figura 7: Respostas de ERG escotópico de rato albino, coelho albino e humanos são caracterizados por padrão similar, mas diferem em amplitude e tempo implícito. As respostas de ERG a intenso estímulo de luz das três espécies são compostas por uma onda a negativa seguida de onda b positiva, com potenciais oscilatórios rápidos na fase ascendente da onda b (Perlman, 2009). 


\subsection{Estudo de Toxicidade de Drogas em Modelo Animal}

Entre os fatores que devem ser considerados em um estudo de toxicidade estão: a espécie animal que será usada, o tipo de técnicas de experimentação (funcional e/ou morfológica), procedimentos de testes, período de acompanhamento e formas de análises de dados.

Existem várias vantagens no estudo de toxicidade de drogas em modelos animais. (1) Várias doses podem ser usadas para determinação de toxicidade e margem de segurança. (2) Diferentes componentes da formulação da droga podem ser utilizadas separadamente para identificação de componente tóxico, com a possibilidade de substituí-lo. (3) Uma gama de técnicas experimentais, como exames eletrofisiológicos invasivos e não-invasivos, técnicas de morfologia, celular e molecular, podem ser aplicadas em experimentos agudos ou crônicos.

O procedimento mais comum de ERG, usado em experimentação animal, inclui as respostas evocadas por flash em estados de adaptação ao claro e ao escuro, com o propósito de avaliar a integridade funcional dos sistemas de cones e bastonetes da retina, respectivamente (Perlman et al., 2009).

No presente estudo, a técnica experimental escolhida foi o eletrorretinograma de campo total, por constituir um teste sensível para acompanhamento de funções da retina de animais de laboratório (Perlman, 2009).

A forma de administração utilizada foi a intravítrea, pois a dificuldade no controle da inflamação ocular com medicações sistêmicas e os efeitos colaterais do uso prolongado de imunossupressores são fatores que justificam a hipótese de que essa forma de administração de MPA (a forma ativa do MMF) pode minimizar algumas dessas limitações. 


\subsection{Objetivos}

1. Estabelecer a metodologia e validar os padrões de resposta em olhos controle (sem administração de nenhuma substância) para comparação com os demais grupos.

2. Determinar a segurança da injeção intravítrea de polisorbato 80 em olhos de coelhos através da analise eletrorretinografica da função retiniana.

3. Determinar a segurança da injeção intravítrea de diferentes doses de ácido micofenólico (MPA) em olhos de coelhos através da analise do eletrorretinograma de campo total. 


\section{Métodos}

\subsection{Estabelecimento de Doses}

Os dados de biodisponibilidade do MMF após administração oral indicam uma absorção e biodisponibilidade de cerca de $90 \%$ da droga e conversão em MPA (Armstrong et al., 2005). Considerando-se os fenômenos de absorção/eliminação e de difusão da droga através da barreira hematorretiniana, estima-se que apenas 1/10 da droga presente na circulação penetre no olho.

Considerando-se alguns fatores, como a dose comumente utilizada de MMF por via oral (2 mg/dia), a taxa de penetração intra-ocular, a diferença entre o peso médio de humanos e coelhos, e a diferença entre o volume do olho humano e dos coelhos, estimase que cerca de $200 \mu \mathrm{g}$ de MMA atinjam o vítreo. Foi utilizada a razão de 1:1 para o cálculo das doses a serem testadas. Dessa forma foram estabelecidas as seguintes doses intravítreas: $10.000 \mu \mathrm{g}, 1000 \mu \mathrm{g}, 200 \mu \mathrm{g}, 50 \mu \mathrm{g}$ e $5 \mu \mathrm{g}$ de MPA para o estudo dos efeitos retinianos da droga. 


\subsection{Preparação Animal}

Foram utilizados coelhos da espécie New Zealand, mantidos em gaiolas individuais no biotério do Departamento de Psicologia Experimental do Instituto de Psicologia da USP. O projeto foi aprovado pela Comissão de Ética para Pesquisa em Animais do Instituto de Psicologia da USP e os animais foram tratados de acordo com as Normas para o Uso de Animais em Pesquisa Oftalmológica e da Visão, da Associação para Pesquisa em Visão e Oftalmologia (Association for Research in Vision and Ophthalmology, ARVO).

Foram utilizados quarenta coelhos, com peso entre 2,2 e $2,5 \mathrm{~kg}$, divididos em seis grupos: grupo veículo ( $\mathrm{n}=11$ ), que recebeu $0,1 \mathrm{ml}$ de Polissorbato 80 (OD) e $0,1 \mathrm{ml}$ de solução salina balanceada (BSS) (OE) e cinco grupos experimentais compostos por animais injetados com diferentes doses de MPA. As doses intravítreas de MPA administradas foram $5 \mu \mathrm{g}(\mathrm{n}=4), 50 \mu \mathrm{g}(\mathrm{n}=4), 200 \mu \mathrm{g}(\mathrm{n}=4), 1.000 \mu \mathrm{g}(\mathrm{n}=4)$ e 10.000 $\mu \mathrm{g}(\mathrm{n}=4)$. No grupo experimental, OE constituiu sempre o controle e recebeu injeções intravítreas de $1 \mathrm{ml}$ de veículo.

As análises e os registros de eletrorretinograma foram realizados nas situações: pré-injeção, 7 e 30 dias após a administração do medicamento, para todos os grupos. Os animais foram mantidos em gaiolas individuais, sem privação de água ou alimento. O biotério possui um sistema de ar condicionado, a temperatura ambiente é mantida por volta de $25^{\circ} \mathrm{C}$ e a iluminação obedece ao ciclo $12 \mathrm{~h}$ claro/ $12 \mathrm{~h}$ escuro.

Para estabelecimento dos padrões de ERG em coelhos albinos, foram feitos registros eletrorretinográficos em olhos de nove animais, que não foram submetidos a nenhum tipo de tratamento. Olhos na situação pré-injeção também foram utilizados e, a partir desses dados, foi possível fazer comparações com os olhos que receberam injeção 
intravítrea da droga e, consequentemente, análise da toxicidade da substância para o tecido retiniano.

Para administração intravítrea foi necessário realizar paracentese: punção de 0,1 ml de humor aquoso da câmara anterior com agulha 30G acoplada à seringa de insulina. Logo após esse procedimento, o globo ocular recebeu injeção intravítrea. Os 11 animais incluídos no estudo da toxicidade do veículo do MPA (polisorbato 80) receberam injeção de $0,1 \mathrm{ml}$ do veiculo no olho direito e $0,1 \mathrm{ml}$ de soro fisiológico no olho esquerdo. Os 20 animais incluídos no estudo das 5 doses de MPA receberam injeção de 0,1 $\mathrm{ml}$ de MPA no olho direito e $0,1 \mathrm{ml}$ de polisorbato 80 no olho esquerdo. As soluções foram injetados $3 \mathrm{~mm}$ posteriormente ao limbo corneano de cada olho e as injeções intravítreas foram realizadas com os animais sob sedação profunda.

As drogas usadas na preparação para registro de ERG foram: sedação com injeção intramuscular de $6,7 \mathrm{mg} / \mathrm{kg}$ de cloridrato de xilasina $2 \%$ (Calmiun ${ }^{\circledR}$, laboratório, cidade) e $50 \mathrm{mg} / \mathrm{kg}$ de cloridrato de cetamina $10 \%$ ( Ketamina Agener ${ }^{\circledR,}$ laboratório, cidade). Para a anestesia tópica foram administrados: anestésico local cloridrato de proximetacaína $0,5 \%$ (Visonest ${ }^{\circledR}$, laboratório, cidade), dilatador pupilar tropicamida

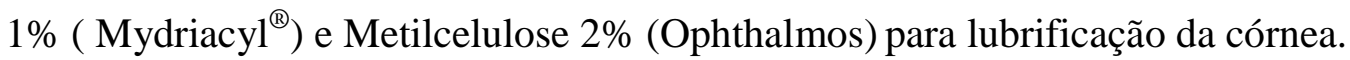

Antes de qualquer medição, os animais foram adaptados ao escuro por 1 hora. Para o registro eletrofisiológico, os animais eram acomodados dentro de uma gaiola de Faraday, vedada à luz para manter o estado de adaptação ao escuro. Os animais foram posicionados lateralmente sobre um anteparo, imobilizados por duas cintas e mantidos aquecidos por uma coberta (Fig.8). 

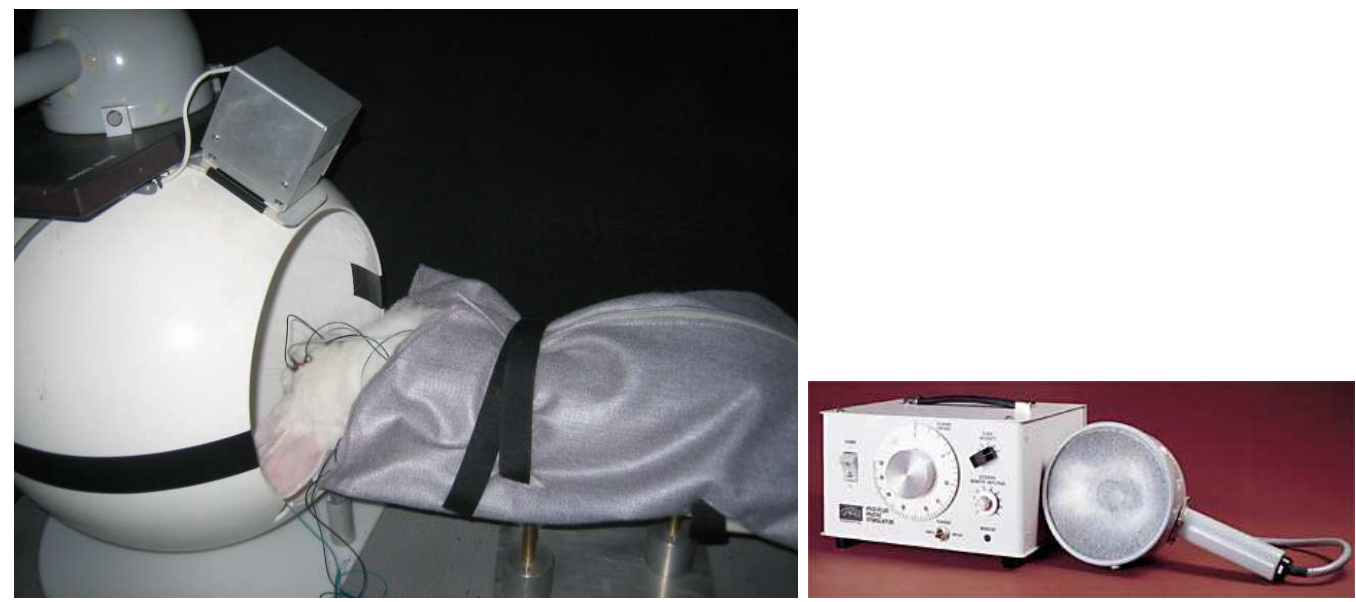

Figura 8: Coelho posicionado sobre suporte adaptado ao Ganzfeld, para a realização do eletrorretinograma. No topo do Ganzfeld pode ser vista uma caixa de iluminação que contém a lâmpada para a luz de fundo. Acima desta está posicionado o fotoestimulador sobre a caixa que contém a roda de filtros de densidade neutra. A figura ao lado mostra o fotoestimulador Grass PS33 e respectivo equipamento de controle.

Toda a preparação e manuseio do animal foram feitos sob fraca iluminação vermelha. No total, desde a aplicação da anestesia até a conclusão das medições, os experimentos duravam por volta de 1 hora e trinta minutos. Geralmente os animais acordavam após 20 minutos do término dos registros. Em certas ocasiões, foi necessário administrar uma dose adicional de sedativos para finalização das gravações. 


\subsection{Equipamentos}

Os registros de ERG foram obtidos com um eletrodo bipolar GoldLens de lente de contato sobre a córnea, e um eletrodo terra de disco (Grass E5; Grass-Telefactor, West Warwick, RI) fixado na orelha com pasta para EEG. Os sinais foram amplificados por um amplificador AC (Grass - Telefactor, West Warwick, RI) com filtragem de 0,3 a $1000 \mathrm{~Hz}$, monitorados em um osciloscópio (TDS 210, Tektronix, Richardson, TX). O olho testado era constantemente lubrificado com metilcelulose e o outro olho era coberto com um tampão para conservar a adaptação ao escuro.

Para realizar o exame eletrorretinográfico de campo total em humanos, é utilizado, na maioria das vezes, o ganzfeld. O equipamento consiste em um globo com uma grande abertura, suporte para o queixo, lâmpada estroboscópica no topo, lâmpada comum para luz de fundo e filtros de densidade neutra para atenuação dos flashes.

Para o registro do ERG os animais eram posicionados sobre um suporte adaptado a Ganzfeld (LKC 2503B), dentro de uma gaiola de Faraday (Fig. 8). O Ganzfeld é uma esfera de estimulação que pode ser iluminada utilizando-se uma lâmpada incandescente para a luz de fundo e um fotoestimulador (Grass Mod. PS33) para a apresentação de pulsos de luz, cuja frequência pode ser controlada, e cuja intensidade é atenuada usando-se um disco com diferentes filtros de densidade neutra.

Foi utilizado um sistema de aquisição e análise de dados, desenvolvido e gentilmente cedido por Steven Nusinowitz $(\mathrm{PhD}$, Professor Assistente de Oftalmologia/Laboratório de Fisiologia Visual) e John Ramirez do Jules Stein Eye Institute (UCLA, Los Angeles, USA).

O sistema utiliza digitalização do sinal na taxa de $1 \mathrm{~Hz}$ por um computador equipado com uma placa de aquisição A/D (National Instruments, Austin, TX) e o programa Monodaq permite controle digital da frequência e duração do estímulo, 
sincronização do estímulo com a resposta adquirida, monitoramento em tempo real de cada ERG, bem como programação do número e intervalo de estimulações e resposta média. Após os experimentos, o Programa Index permite análise offline dos registros integrada ao Microsoft Excel 2007, indexação dos parâmetros analisados (amplitude e latência da onda a e onda b) e filtragem offline do sinal. 


\subsection{Condições de registro}

As medições foram feitas nas condições: escotópica, escotópica máxima e fotópica. $\mathrm{Na}$ condição escotópica foram usadas cinco intensidades de flashes: 0,003 $\mathrm{cd} / \mathrm{m}^{2}, 0,03 \mathrm{~cd} / \mathrm{m}^{2}, 0,3 \mathrm{~cd} / \mathrm{m}^{2}, 3 \mathrm{~cd} / \mathrm{m}^{2}$ e $30 \mathrm{~cd} / \mathrm{m}^{2}$. A intensidade gerada pela lâmpada estroboscópica acoplada ao Ganzfeld era de $30 \mathrm{~cd} / \mathrm{m}^{2}$. Para diminuição da intensidade foram usados filtros de densidade neutra, que permitiram realizar as medições com diferentes intensidade de luz utilizando a mesma lâmpada. Na condição fotópica, a intensidade do flash foi de $78 \mathrm{~cd} / \mathrm{m}^{2}$ e a luz de fundo era mantida em $15 \mathrm{~cd} / \mathrm{m}^{2}$ durante todas as medições.

Foram também utilizadas diferentes frequências de estímulo luminoso, denominadas resposta ao flicker $(12 \mathrm{~Hz}, 18 \mathrm{~Hz}, 24 \mathrm{~Hz}$ e $30 \mathrm{~Hz})$. Foi mantida a mesma intensidade de flash e a mesma intensidade de luz de fundo da condição fotópica. 


\subsection{Protocolo para Realização do Exame Eletrorretinográfico}

O protocolo utilizado, baseado no procedimento de Harazny e colaboradores (2009) foi uma ampliação do protocolo padrão proposto pela ISCEV (International Society for Clinical Electrophysiology of Vision). Incluiu diferentes intensidades para medição de ERG escotópico e variação da frequência temporal e intensidade do estímulo na resposta ao flicker em condições fotópicas. Foram realizados os seguintes passos, iniciados com o animal previamente adaptado por $1 \mathrm{~h}$ ao escuro:

1. ERGs de flashes sob adaptação ao escuro. A sequência de apresentação de estímulos foram:

1.1- Três flashes de $0.003 \mathrm{~cd} . \mathrm{s} / \mathrm{m}^{2}$ com 5 segundos de intervalo entre cada flash;

1.2- Após 20 segundos de adaptação ao escuro, três flashes de 0.03 cd.s $/ \mathrm{m}^{2}$ com 10 segundos de intervalo entre cada flash;

1.3- 60 segundos de adaptação ao escuro seguido de três flashes de 0.3 cd.s $/ \mathrm{m}^{2}$ com 10 segundos de intervalo entre cada flash;

1.4- Após 120 segundos de adaptação ao escuro apresentação de três flashes de $3 \mathrm{~cd} . \mathrm{s} / \mathrm{m}^{2}$ com 14 segundos de intervalo entre cada flash.

1.5- Finalmente, após mais 120 segundos de adaptação ao escuro apresentação de três flashes de $30 \mathrm{~cd} . \mathrm{s} / \mathrm{m}^{2}$ com 14 segundos de intervalo entre cada flash.

2. ERGs de flashes sob adaptação ao claro. Os animais foram adaptados à luz de fundo de $15 \mathrm{~cd} / \mathrm{m}^{2}$ por 2 minutos e as respostas de seis flashes de $3 \mathrm{~cd} . \mathrm{s} / \mathrm{m}^{2}$, com 5 segundos de intervalo entre os flashes, são gravadas. 
3. ERGs de flashes sob adaptação ao claro em diferentes frequências. Em seguida, são registrados as respostas a estímulos de luz de 12, 18, 24 e $30 \mathrm{~Hz}$ na presença de luz de fundo de $15 \mathrm{~cd} / \mathrm{m}^{2}$. Cada medição dura 6 segundos.

Os registros escotópicos foram utilizados na relação intensidade-resposta e a curva foi feita de acordo com a equação de Hill: $y=V_{\text {máx }} x^{n} / k^{n}+x^{n}$. 


\section{Resultados}

\subsection{Estabelecimento dos Parâmetros do Grupo Controle 1 (Situação Pré-Injeção)}

A finalidade da primeira etapa desse estudo foi estabelecer os parâmetros de eletrorretinografia para coelhos New Zealand para o presente estudo e padronizar os resultados, utilizando o protocolo proposto por Harazny et. al., (2009). Para que fosse possível comparar os resultados obtidos com as diferentes doses de MPA, houve necessidade de realização do experimento na situação pré-injeção, em todos os olhos.

Os valores de amplitudes e latência de resposta das ondas a e b, para este trabalho, são baseados nos dados obtidos em um número suficiente de olhos, e devem ser representativos para a amostra de coelhos albinos da raça New Zealand escolhida. Exemplos de traçados de curvas de registros eletrorretinográficos estão representados nas figuras 9, 10 e 11.

\section{Padrão de Registro Eletrorretinográfico Resposta Escotópica}

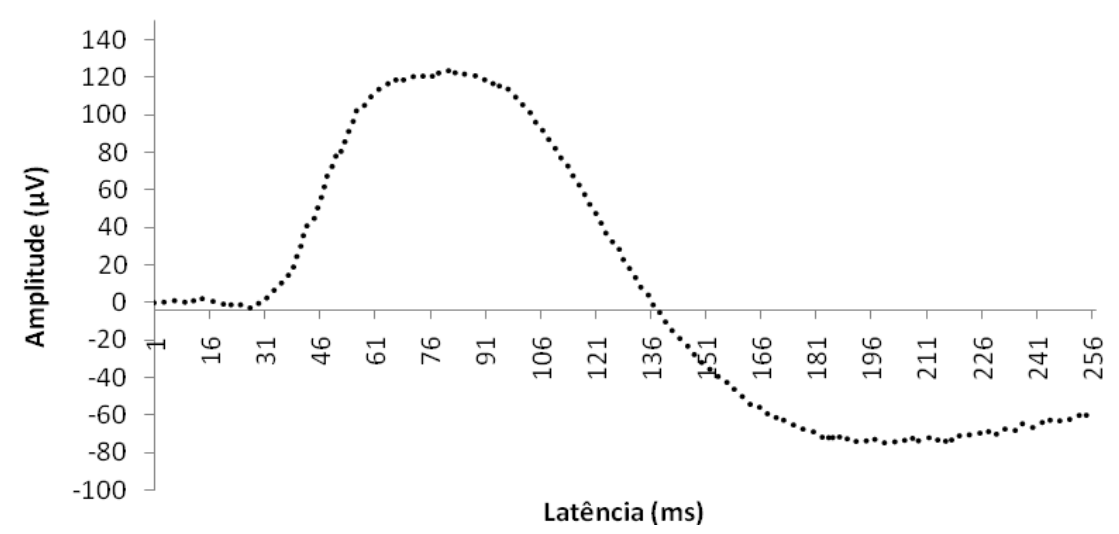

Figura 9: Exemplo de curva de registro eletrorretinográfico do grupo controle. Resposta Escotópica. 


\section{Padrão de Registro Eletrorretinográfico \\ Resposta Escotópica Máxima}

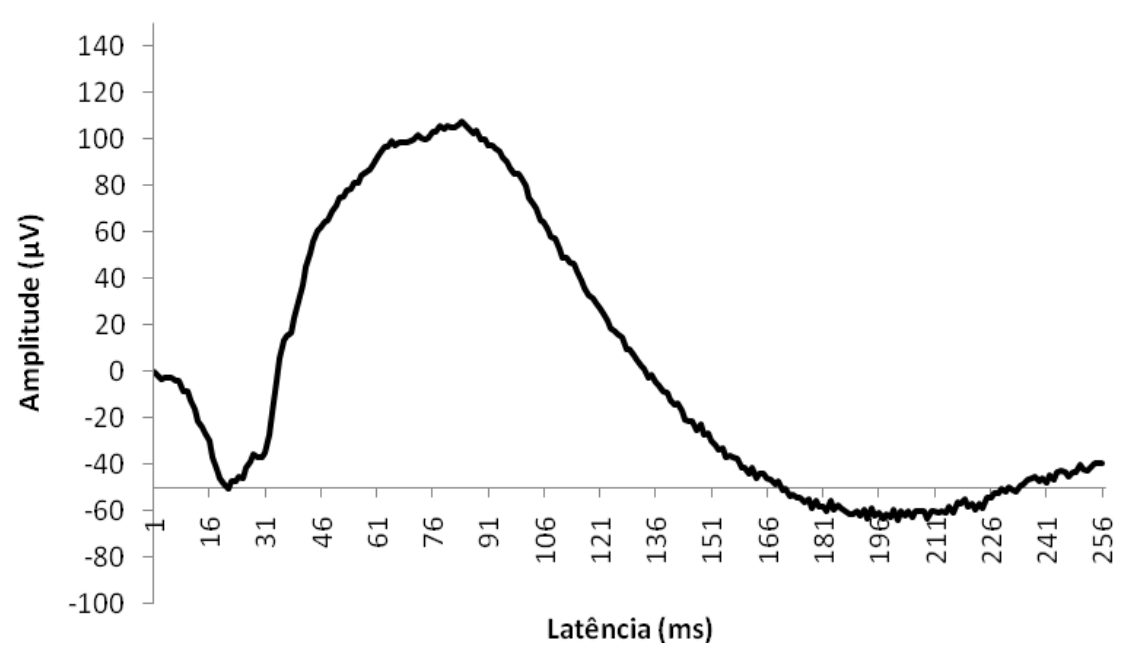

Figura 10: Exemplo de curva de registro eletrorretinográfico do grupo controle. Resposta EscotópicaMáxima.

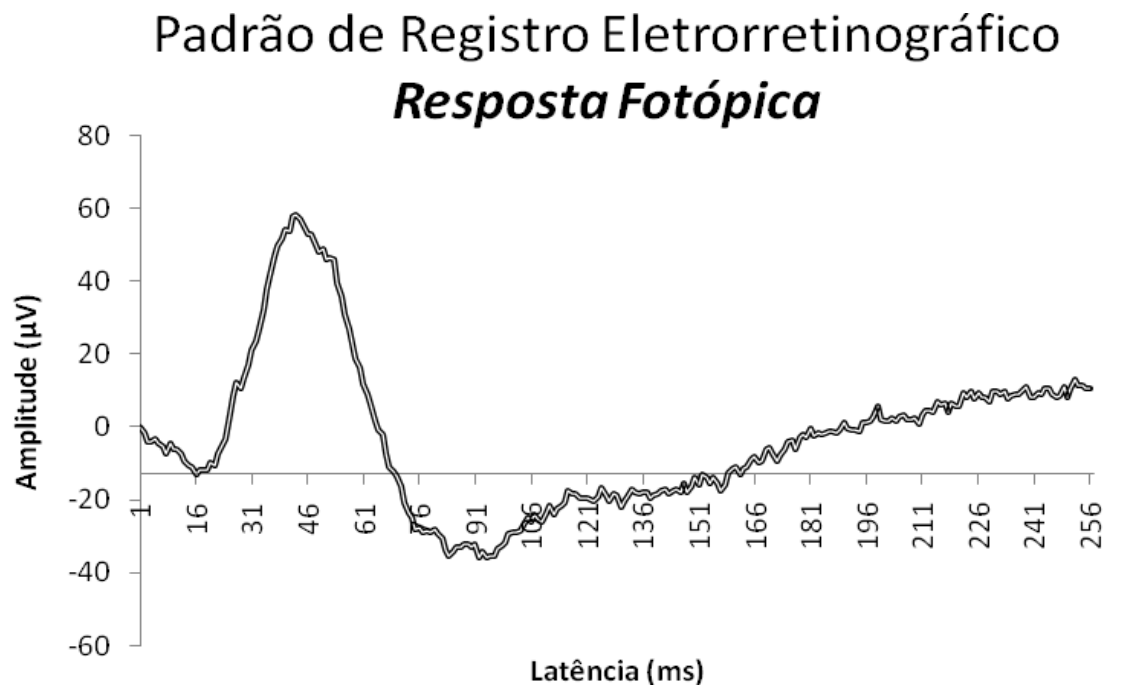

Figura 11: Exemplo de curva de registro eletrorretinográfico do grupo controle. Resposta Fotópica.

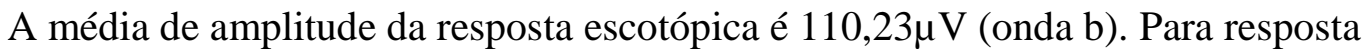
escotópica máxima foram encontrados os seguintes valores: onda $a,-44,5 \mu \mathrm{V}$; onda $b$, $145,9 \mu \mathrm{V}$. Na condição fotópica, os valores obtidos foram $-12,84 \mu \mathrm{V}$ (onda a), $62,31 \mu \mathrm{V}$ (onda b) e $42,65 \mu \mathrm{V}$ para a amplitude de resposta ao flicker de $12 \mathrm{~Hz}$ (Tabela 1). 
As médias das latência foram: 50,32 ms (onda b escotópica); 16,58 ms e 53,63 ms (ondas a e b escotópica máxima, respectivamente); 12,46ms (onda a fotópica) e 32,8 ms (onda $b$ fotópica) (Tabela 2). Essas médias de latência foram utilizadas para comparação com todos os outros grupos controles (controle 2- injeção intravítrea de SSB e controle 3- injeção intravítrea do veículo) e experimentais (dose de $5 \mu \mathrm{g}, 50 \mu \mathrm{g}$, $200 \mu \mathrm{g}, 1.000 \mu \mathrm{g}$ e $10.000 \mu \mathrm{g})$.

Tabela 1: Média e desvio padrão de amplitude encontrados no registros de ERG.

\begin{tabular}{|c|c|c|c|c|}
\hline & & Amplitude & & \\
\hline \multirow[t]{2}{*}{ CONTROLE } & Resposta Escotópica & Resposta Esc. Máxima & Resposta Fotópica & Resposta ao Flicker \\
\hline & $1=3 c d / m^{2}$ & $1=30 \mathrm{~cd} / \mathrm{m}^{2}$ & $1=78 \mathrm{~cd} / \mathrm{m}^{2} \quad\left(B G=15 \mathrm{~cd} / \mathrm{m}^{2}\right)$ & $=30 \mathrm{~cd} / \mathrm{m}^{2} \quad(12 \mathrm{~Hz})$ \\
\hline onda-a $(-\mu \mathrm{V})$ & & $44,5( \pm 29)$ & $12,84( \pm 4,25)$ & \\
\hline onda-b $(\mu \mathrm{V})$ & $110,23( \pm 40,8)$ & $145,9 \pm(69,9)$ & $62,31( \pm 15,8)$ & $42,65( \pm 10,74)$ \\
\hline
\end{tabular}

Tabela 2: Média e desvio padrão de latência encontrados nos registros de ERG.

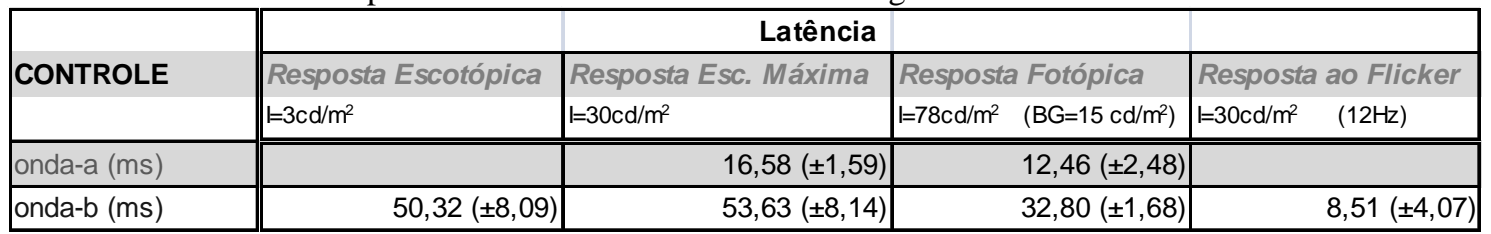

Foi realizada a análise usada no trabalho de Perlman, (2008), que ressalta a relevância da relação onda b/onda a para estudos de toxicidade em modelos animais. Para a relação onda b/onda a da condição escotópica máxima é mostra na Figura 12, com coeficiente de correlação linear de 0,83 e valor de $p<0,0001$.

A amplitude do registro fotópico também foi usada para a relação onda b/onda a (Fig. 13), com coeficiente de correlação linear de 0,64 e valor de $p<0,0001$. As amplitudes de resposta fotópica a diferentes frequências de intensidade luminosa foram analisadas e diagramadas, e estabelecida a faixa de média \pm dp. 
No trabalho Hoeve et. al. (2011), os autores utilizaram o logaritmo da amplitude de onda-b nos gráficos. Com os dados obtidos nos registros escotópicos foi possível fazer a relação logaritmo da amplitude da onda b x logaritmo da intensidade do flash, denominada relação intensidade-resposta (Figs. 14 e 15). Esse tipo de gráfico é realizado plotando-se as respostas escotópicas de acordo com a intensidade dos flashes emitidos.

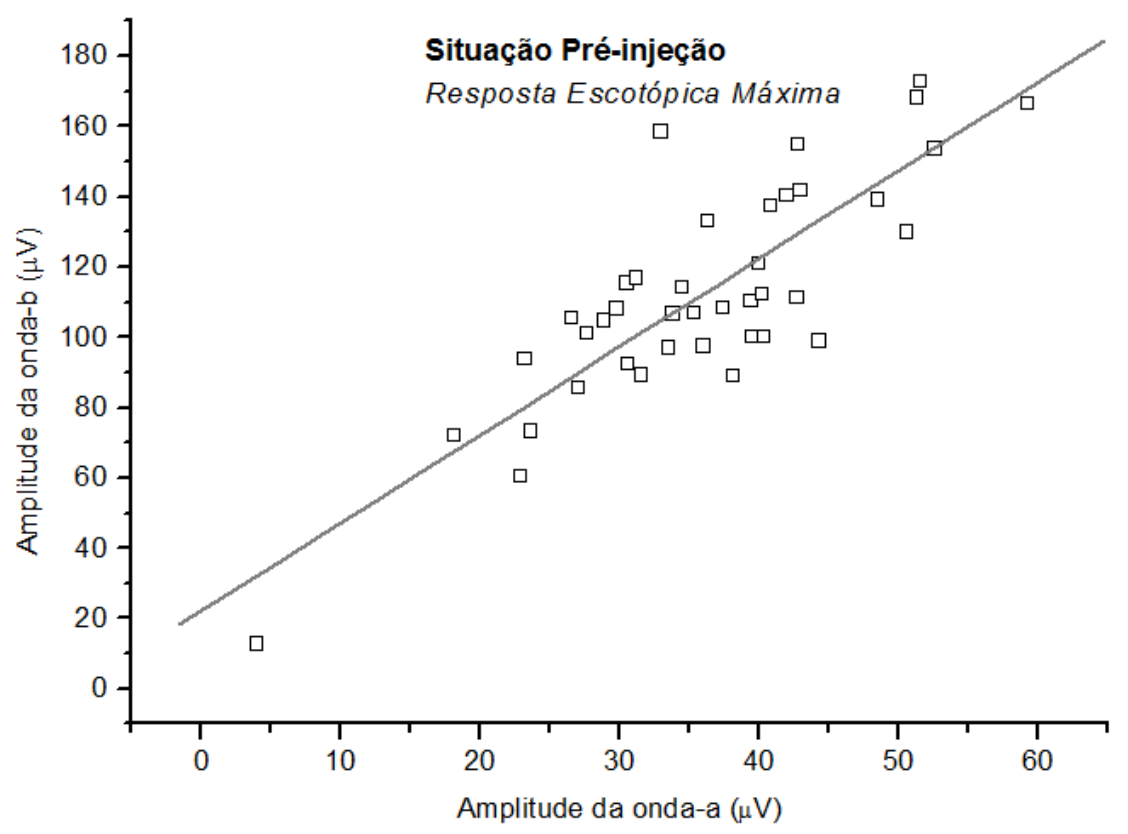

Figura 12: Relação de amplitude de onda b/onda a na condição escotópica (Resposta Máxima). Cada símbolo representa o registro obtido em um olho. A linha cinza representa a correlação linear entre os dados. 


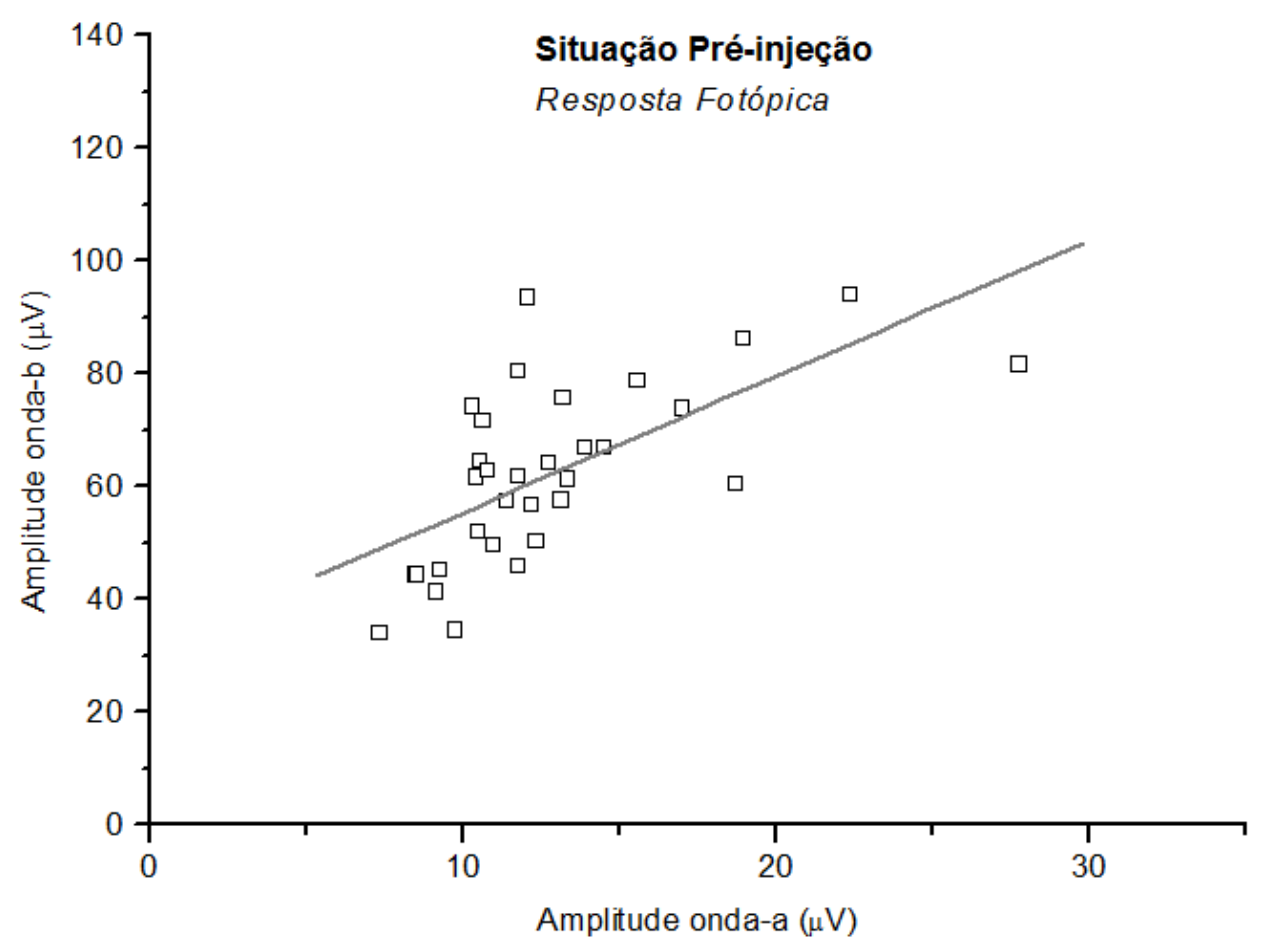

Figura 13: Relação de amplitude de onda b/onda a na condição fotópica. Cada símbolo representa o registro obtido em um olho. A linha cinza representa a curva de regressão linear entre os dados.

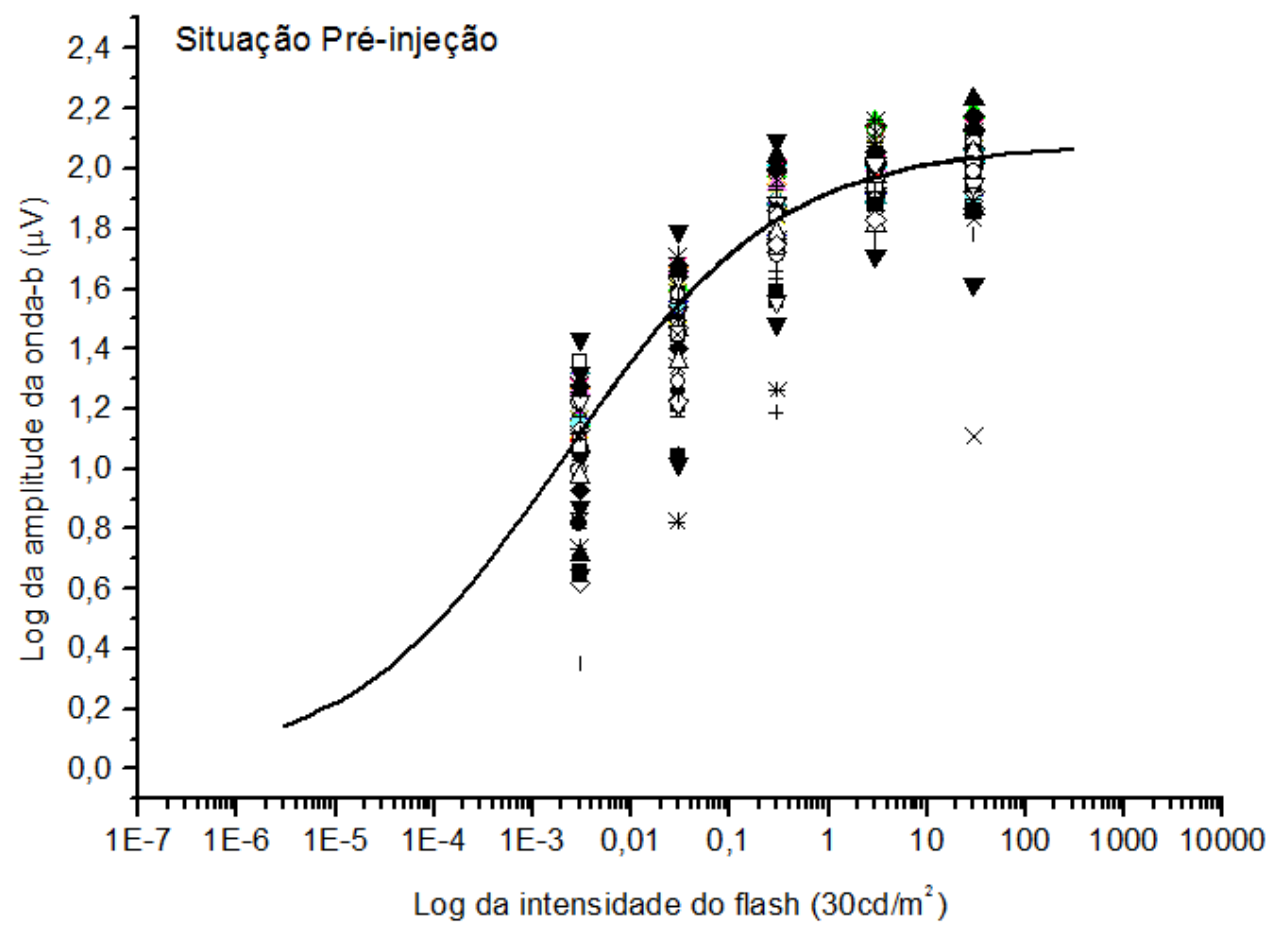

Figura 14: Relação intensidade-resposta da onda b escotópica de animais/olhos da população controle/não injetada (símbolos, n=40), ajustada pela função de Hill. 


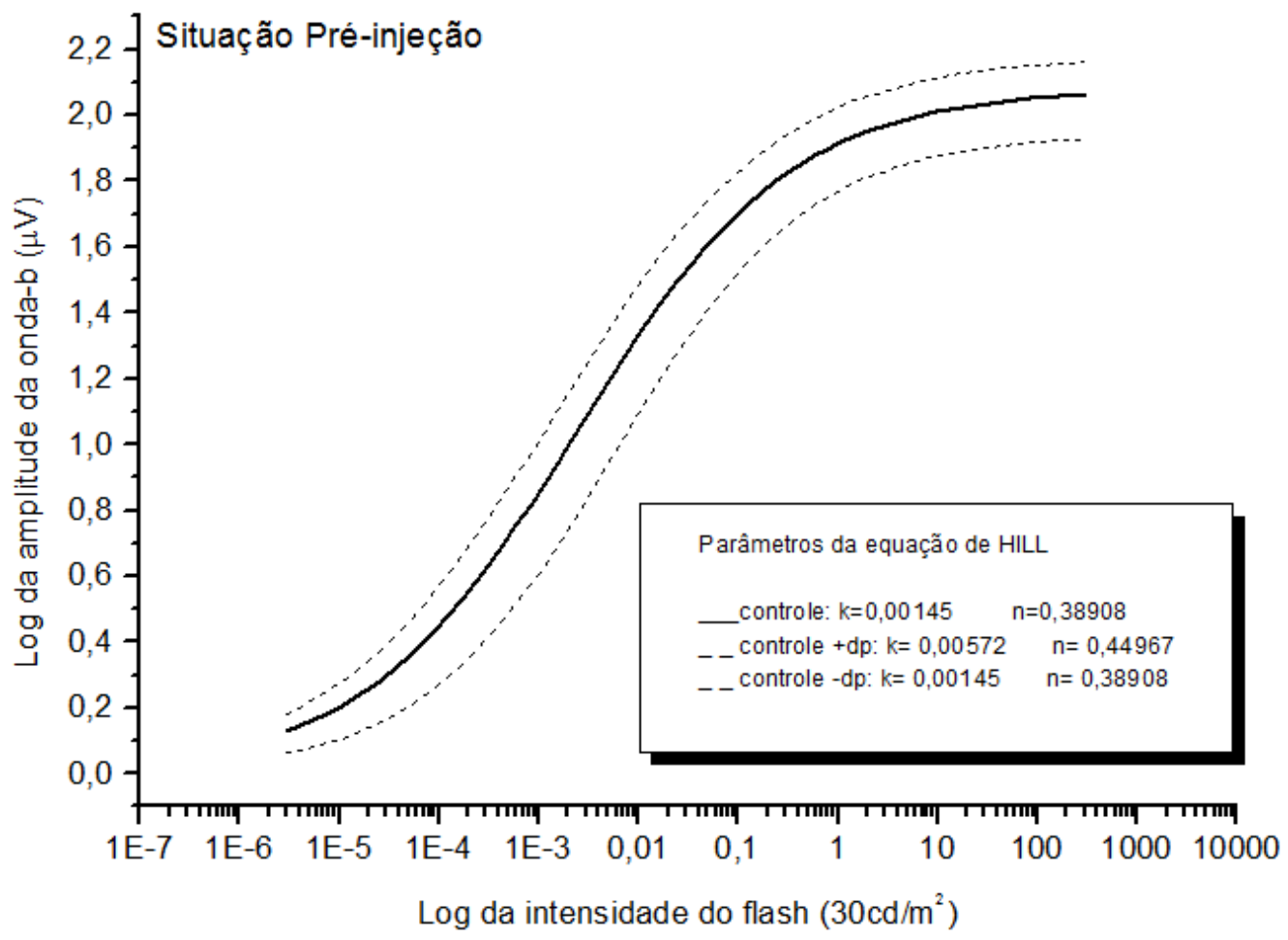

Figura 15: Relação intensidade-resposta da onda b escotópica de animais/olhos da população controle/não injetada, ajustada pela função de Hill (linha preta contínua). As linhas pretas tracejadas mostram a resposta $+/$ - dp para fins de comparação. 


\subsection{Estabelecimento dos Parâmetros do Grupo Controle 2 (Administração Intravítrea de BSS)}

Os animais que receberam injeção intravítrea de Polissorbato (OD) tiveram seus olhos esquerdos tratados com $0,1 \mathrm{ml}$ de solução salina balanceada. Esse grupo é formado por onze olhos e constitui mais um grupo controle, que apenas sofreu o procedimento da injeção intravítrea e não teve influência de nenhuma substância nas células da retina. Não foram realizadas as medições 30 dias após a administração intravítrea e, por isso, apenas serão analisadas as situações pré-ínjeção e 7 dias após a injeção.
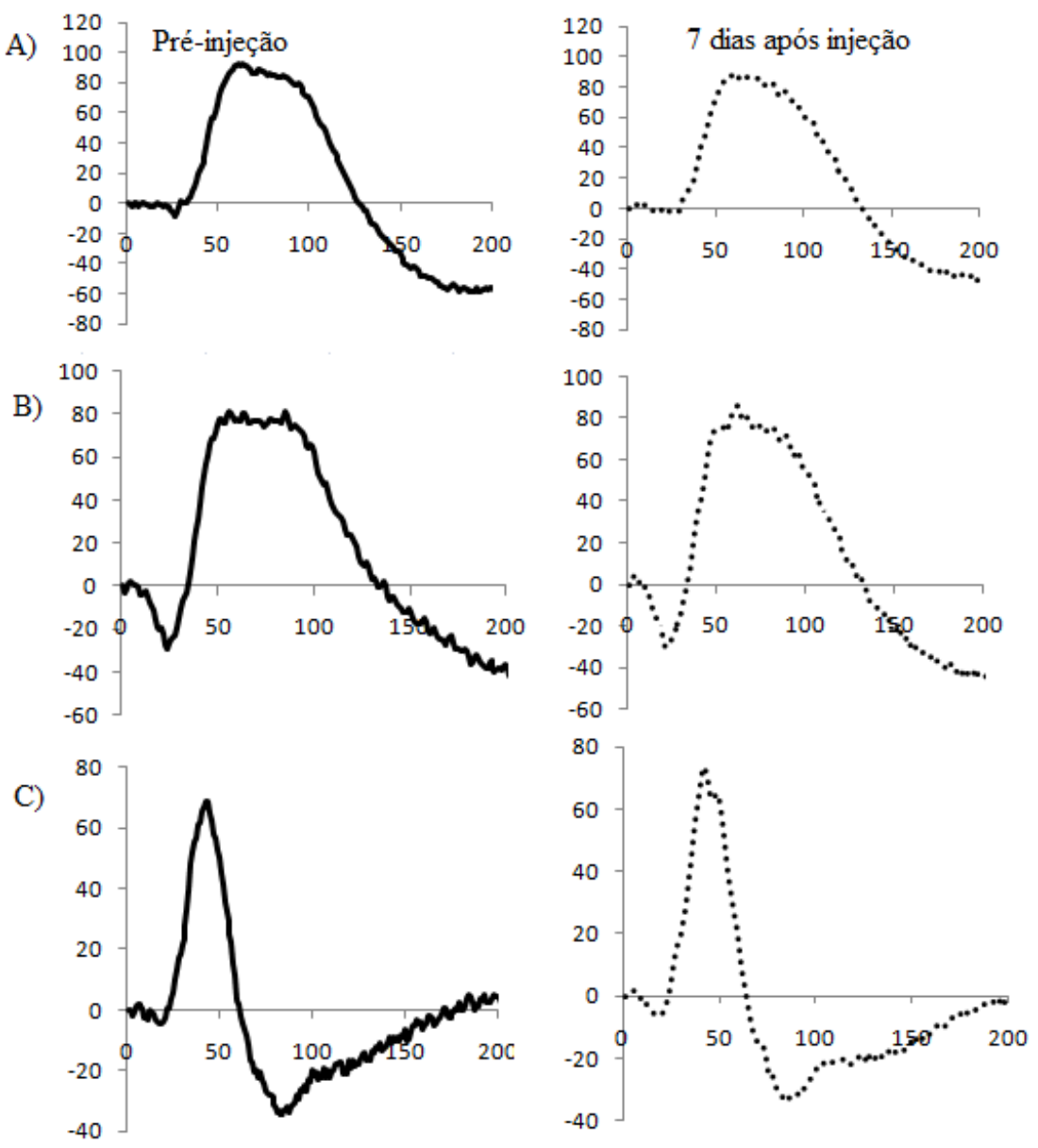

Figura 16: Traçados eletrorretinográficos médios antes e após a injeção de SSB. A) Resposta Escotópica $\left(3 \mathrm{~cd} / \mathrm{m}^{2}\right)$, B) Resposta Escotópica Máxima e C) Resposta fotópica. 
A figura 16 mostra o aspecto geral das curvas de eletrorretinograma antes e após as injeções, nas condições escotópica, escotópica máxima e fotópica. Pelo traçado é possível notar que as amplitudes, tanto de onda a quanto de onda b se conservam bastante semelhantes em todas as situações, obedecendo o mesmo padrão dos controles (Figs. 9, 10 e 11).

Os parâmetros da equação de Hill para a dose de 0,1ml de SSB, 7 dias após injeção foram: $\mathrm{k}=0,00439$ e $\mathrm{n}=0,40736$ (Fig.17). Comparado aos parâmetros de sensibilidade de resposta (k) e inclinação (n) da média dos controles, a curva gerada está dentro dos padrões normais, demonstrando que o procedimento da injeção intravítrea não traz nenhum prejuízo à função de sensibilidade das células da retina.

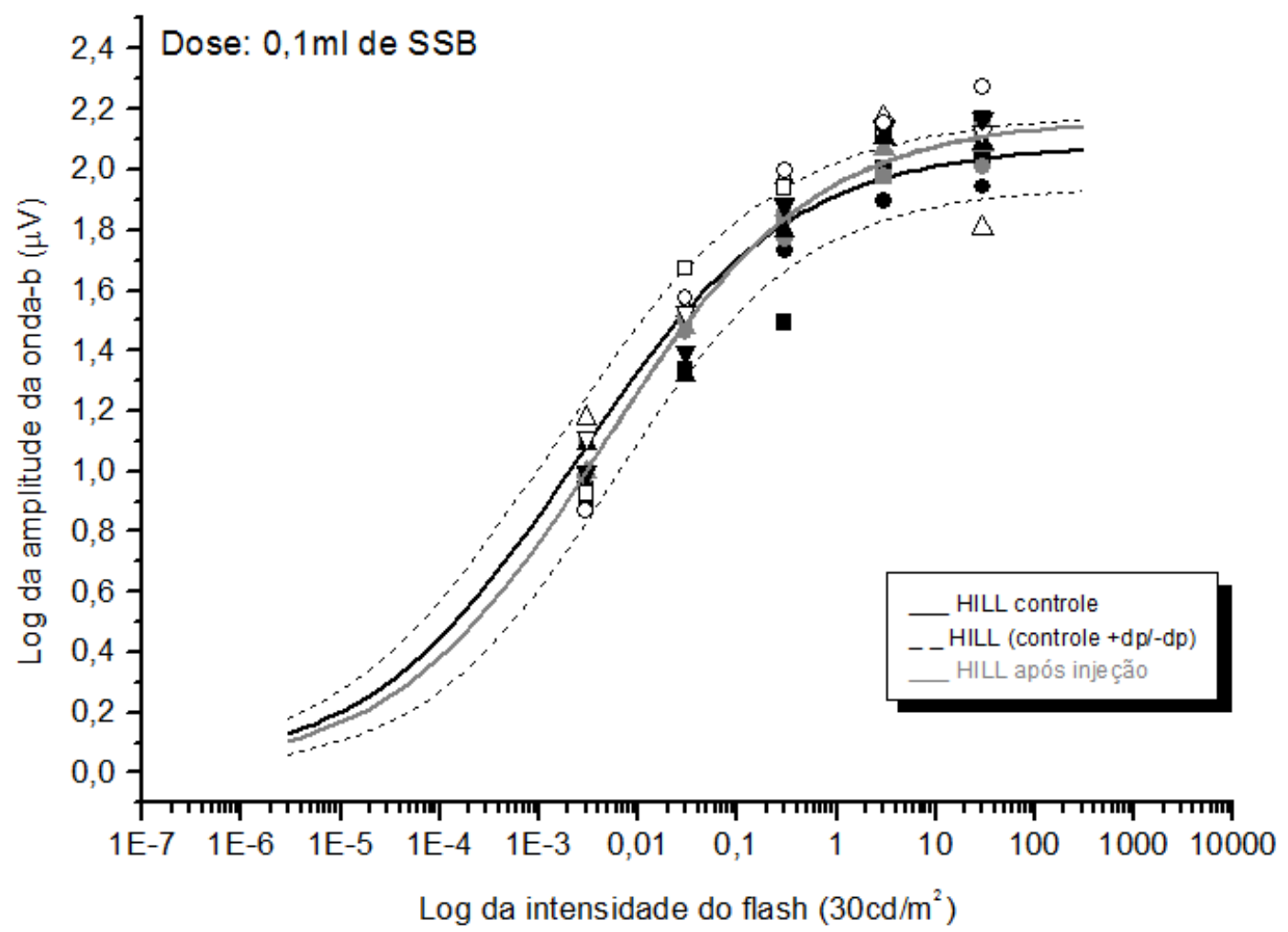

Figura 17: Relação intensidade-resposta da onda b escotópica de animais/olhos injetados com $0,1 \mathrm{ml}$ de SSB (símbolos, $n=4$ ), ajustada pela função de Hill (linha cinza escuro, 7 dias após injeção). A função/curva da população controle/não injetada ( $n=9$, linha preta contínua) é mostrada +/- dp (linhas pretas tracejadas) para fins de comparação. 
A figura 18 mostra a relação onda b/onda a das respostas escotópicas máximas e fotópicas, respectivamente, dos olhos que receberam $0,1 \mathrm{ml}$ de solução salina. Apesar da aparente inadequação dos dados da resposta fotópica, é interessante notar que apresenta a mesma tendência que a figura14. As respostas de onda a abaixo de $15 \mu \mathrm{V}$ parecem não obedecer à reta de correlação obtida, ou seja, mesmo que a amplitude de onda a seja pequena, a onda b não diminui na mesma proporção.

Na figura 17 é perceptível a adequação dos resultados desse grupo aos do controle, com exceção de um dado.

Na tabela 3 estão os resultados das médias de latência das ondas a e b do grupo que recebeu SSB intravítreo. Não houve nenhum valor que ficasse fora dos parâmetros estabelecidos, baseados nos registros do grupo controle. 

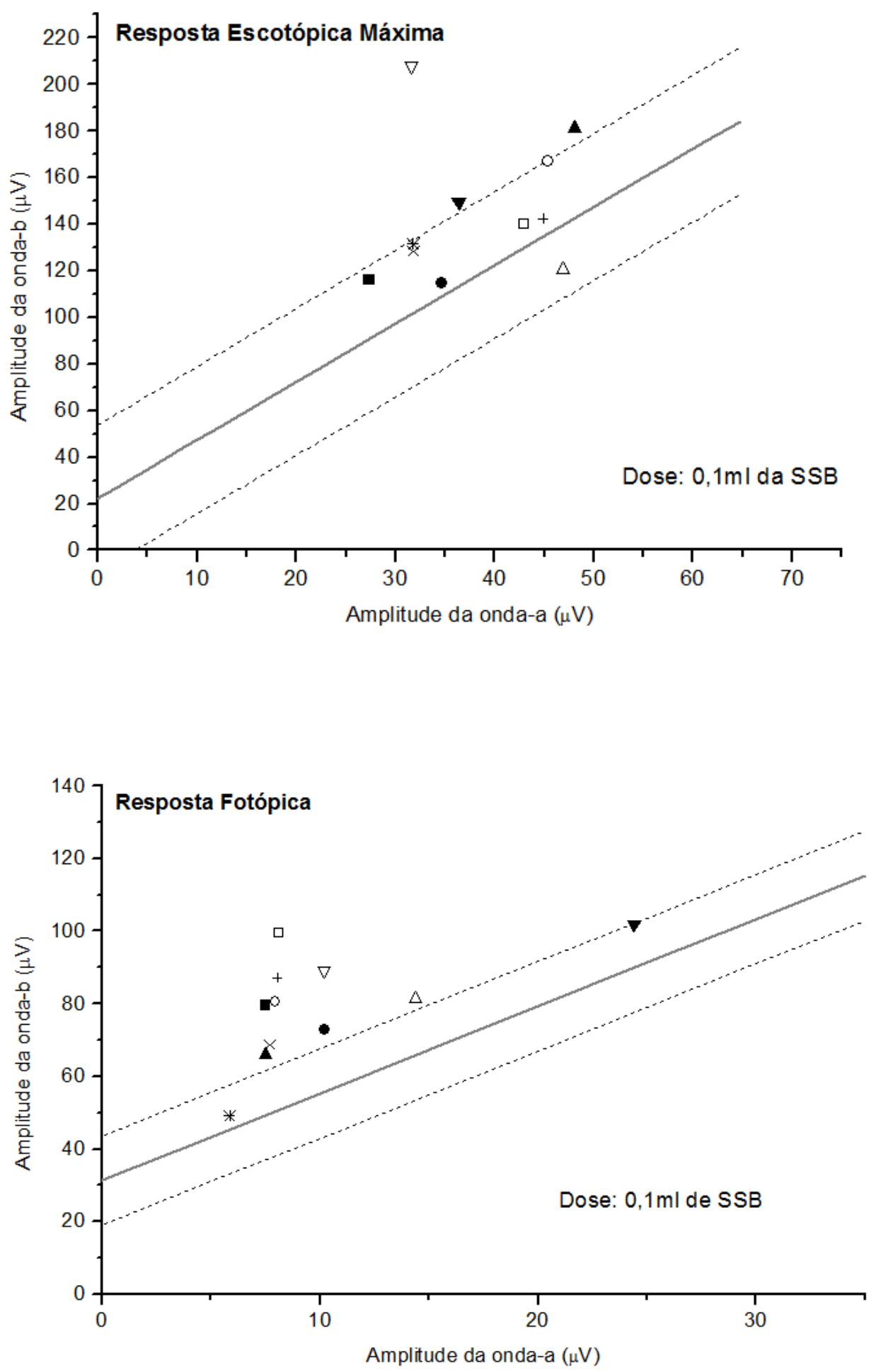

Figura 18: Relação de amplitude de onda b/onda a na condição escotópica máxima e fotópica. Cada símbolo representa o registro obtido em um olho. A linha cinza representa a curva de regressão linear e a linha tracejada representa a curva \pm dp. 


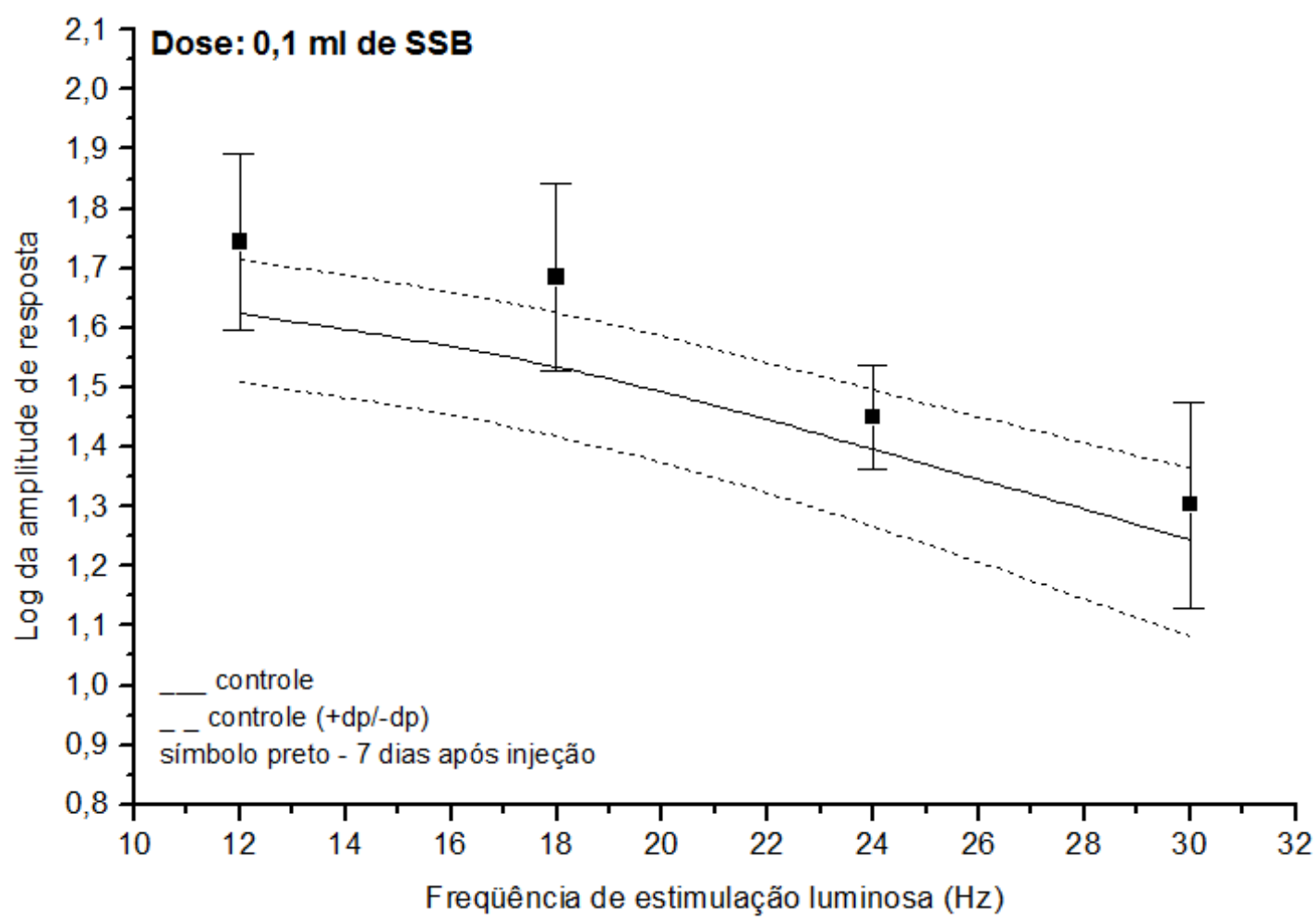

Figura 19: Relação entre a frequência de estimulação luminosa e amplitude de resposta. Cada símbolo representa o registro obtido em um olho. A linha cinza representa a média e a linha tracejada representa a média \pm dp do controle.

Tabela 3: Comparação das latências das respostas das ondas a e b do grupo controle com o grupo pósinjeção de SSB. Os valores máximos e mínimos do grupo controle são as médias $+d p$ e $-d p$, respectivamente.

\begin{tabular}{|c|c|c|c|c|c|c|c|}
\hline \multirow{2}{*}{\multicolumn{2}{|c|}{ LATÊNCIA (ms) }} & \multicolumn{3}{|c|}{ onda-a } & \multicolumn{3}{|c|}{ onda-b } \\
\hline & & mínINO & MÁXIMO & MÉDIA & MÍNINO & MÁXIMO & MÉDIA \\
\hline \multirow{4}{*}{ CONTROLE } & \begin{tabular}{|l} 
Resposta Escotópica \\
$=3 \mathrm{~cd} / \mathrm{m}^{2}$
\end{tabular} & & & & 42,23 & 58,41 & $50,32( \pm 8,09)$ \\
\hline & $\begin{array}{l}\text { Resposta Esc. Máxima } \\
1=30 \mathrm{~cd} / \mathrm{m}^{2}\end{array}$ & 14,99 & 18,17 & $16,58( \pm 1,59)$ & 45,49 & 61,77 & $53,63( \pm 8,14)$ \\
\hline & $\begin{array}{l}\text { Resposta Fotópica } \\
1=78 \mathrm{~cd} / \mathrm{m} 2(\mathrm{BG}=15 \mathrm{~cd} / \mathrm{m} 2)\end{array}$ & 9,98 & 14,94 & $12,46( \pm 2,48) \mid$ & 31,12 & 34,48 & $32,80( \pm 1,68)$ \\
\hline & & \multicolumn{3}{|c|}{ MÉDIA } & \multicolumn{3}{|c|}{ MÉDIA } \\
\hline \multirow{3}{*}{ PÓS-INJEÇÃO (BSS) } & \begin{tabular}{|l} 
Resposta Es cotópica \\
$1=3 \mathrm{~cd} / \mathrm{m}^{2}$
\end{tabular} & & & & \multicolumn{3}{|c|}{$49,84( \pm 5,93)$} \\
\hline & $\| \begin{array}{l}\text { Resposta Esc. Máxima } \\
=30 \mathrm{~cd} / \mathrm{m}^{2}\end{array}$ & \multicolumn{3}{|c|}{$16,89( \pm 1,24)$} & \multicolumn{3}{|c|}{$54,24( \pm 8,29)$} \\
\hline & $\begin{array}{l}\text { Res posta Fotópica } \\
1=78 \mathrm{~cd} / \mathrm{m} 2(\mathrm{BG}=15 \mathrm{~cd} / \mathrm{m} 2)\end{array}$ & \multicolumn{3}{|c|}{$13,67( \pm 1,51)$} & \multicolumn{3}{|c|}{$33,95( \pm 1,78)$} \\
\hline
\end{tabular}




\subsection{Estabelecimento dos Parâmetros do Grupo Controle 3 (Administração Intravítrea de Polissorbato)}

Antes de qualquer análise de toxicidade da droga, foram feitos testes com o veículo (Polissorbato 80) para garantir que sua administração é segura e inócua para o tecido retiniano. Foram realizados experimentos com os olhos direitos de 11 animais, nos dias 7 e 30 pós-injeção. Os olhos esquerdos foram injetados com solução salina balanceada (BSS).

Os resultados foram comparados aos valores obtidos nos registros da situação pré-injeção, usados na padronização dos parâmetros de ERG. Os traçados eletrorretinográficos após injeção de veículo não apresentaram reduções em amplitude de ondas a e b, apenas aumento significativo de onda-b, que chegou a 50\% na resposta escotópica máxima e a 90\% na resposta fotópica, em relação aos olhos pré-injeção (Fig. 20).

Os valores considerados úteis para validar a questão de não-toxicidade do veículo foram as repostas obtidas nas curvas logaritmo da amplitude da onda $\mathrm{b} x$ logaritmo da intensidade do flash, 7 e 30 dias pós-injeção (Fig.21). Os parâmetros da equação de Hill da dose de $0,1 \mathrm{ml}$ de Polissorbato, 7 e 30 dias após injeção foram: $\mathrm{k}=0,00778$ e $\mathrm{n}=0,36819$ e $\mathrm{k}=0,00417$ e $\mathrm{n}=0,44615$, respectivamente. Os valores ficaram muito próximos ao da média dos controles, não sendo notada, portanto, nenhuma alteração na sensibilidade à luz nos olhos administrados com o veículo.

Os gráficos onda b/onda a apresentam as respostas individuais comparadas à curva de regressão linear obtida com os controles, e cada padrão de marcador corresponde a um indivíduo (Figs. 22 e 23). Os símbolos sólidos são referentes às 
medições feitas 7 dias após injeção e os símbolos abertos representam os registros realizados 30 dias após a administração intravítrea do veículo.

VEÍCULO

A)

Pré-injeção

7 dias

30 dias
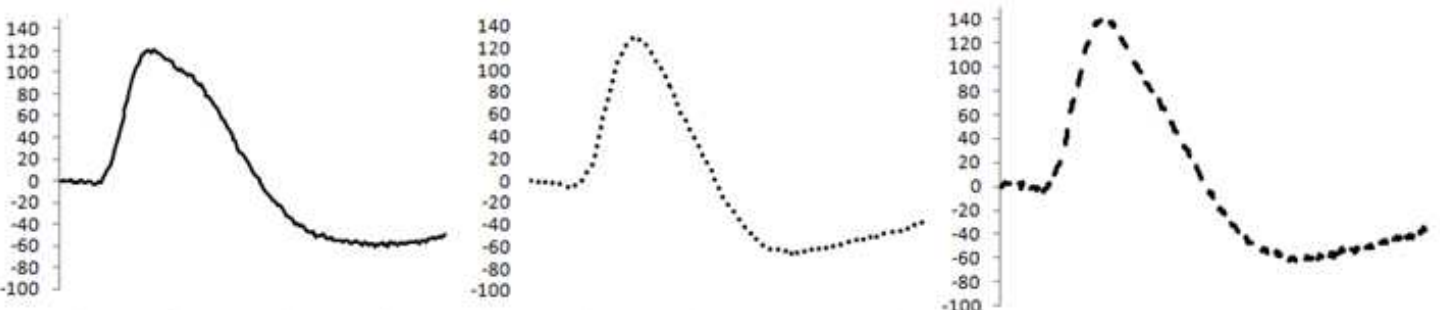

B)
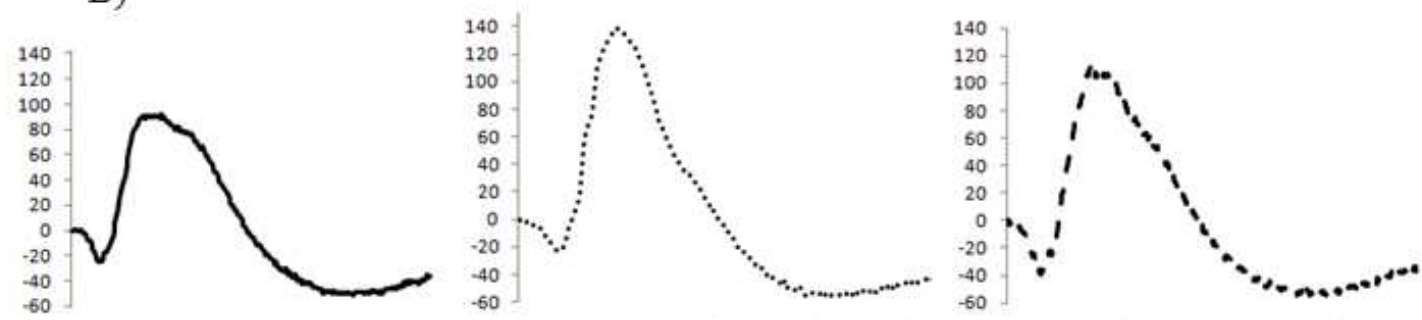

C)
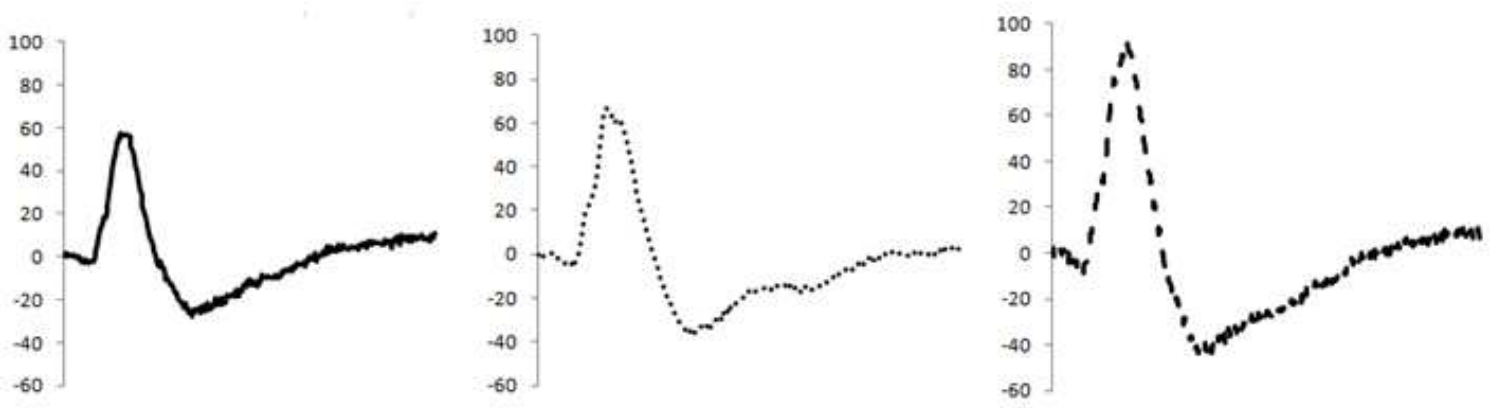

Figura 20: Traçados eletrorretinográficos médios antes e após a injeção de veículo. A) Resposta Escotópica $\left(3 \mathrm{~cd} / \mathrm{m}^{2}\right)$. B) Resposta Escotópica Máxima e C) Resposta fotópica. 


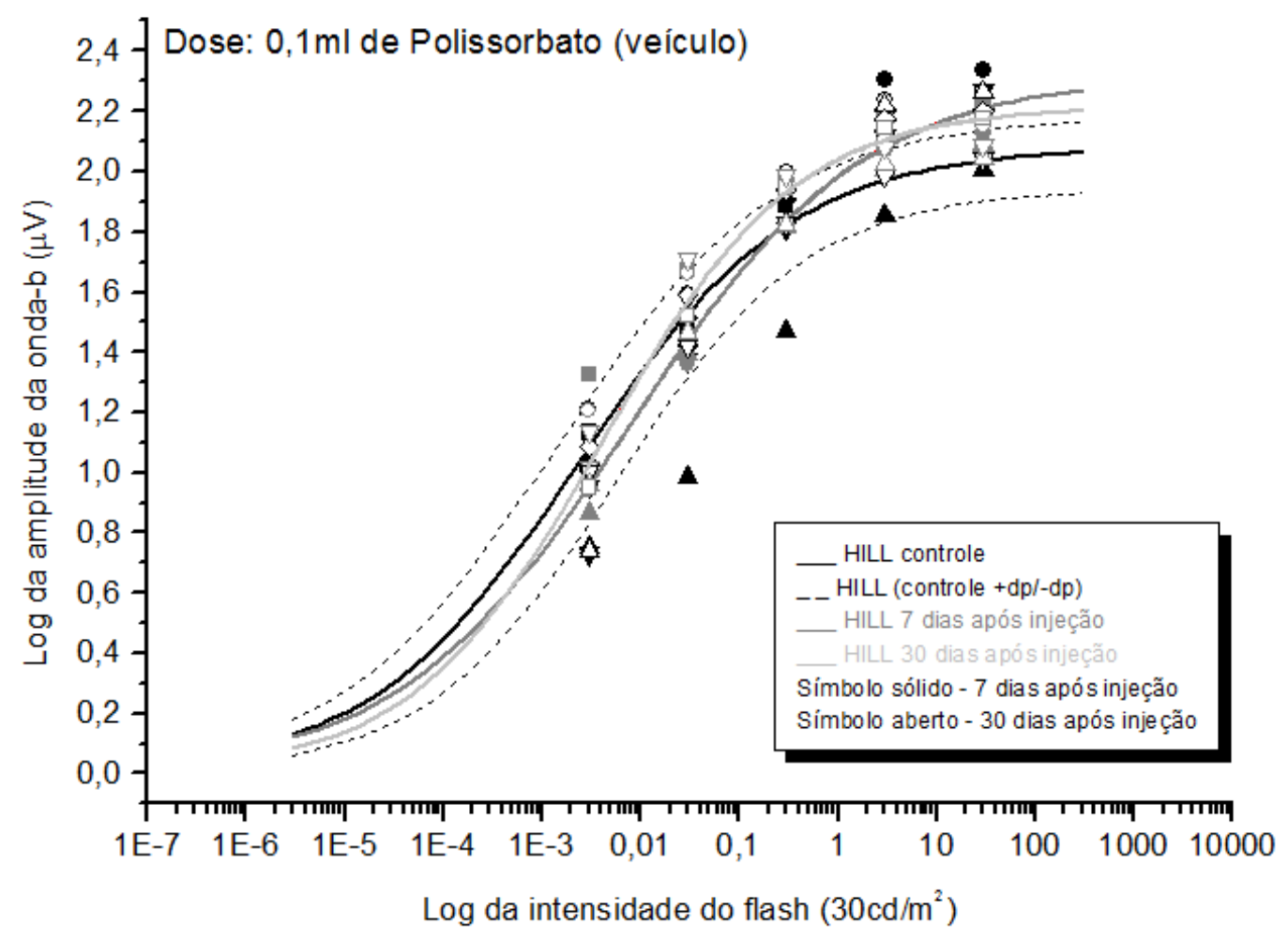

Figura 21: Relação intensidade-resposta da onda b escotópica de animais/olhos injetados com $0,1 \mathrm{ml}$ de polissorbato (símbolos, $n=4$ ), ajustada pela função de Hill (linha cinza escuro, 7 dias após injeção e cinza claro, 30 dias após injeção). A função/curva da população controle/não injetada ( $\mathrm{n}=9$, linha preta contínua) é mostrada +/- dp (linhas pretas tracejadas) para fins de comparação.

Nos gráficos referentes à relação onda b/onda a é possível notar os indivíduos próximos à curva de regressão linear (Figs. 22 e 23). Apesar de alguns indivíduos apresentarem discrepâncias nessa relação, a média das latências mostra que as medições são adequadas aos parâmetros dos controles (Tabela 4), com exceção da onda b escotópica máxima, que apresentou discreta redução (5\%). Em nenhuma frequência de estimulação luminosa houve tendência à diminuição da amplitude da resposta (Fig.24). 


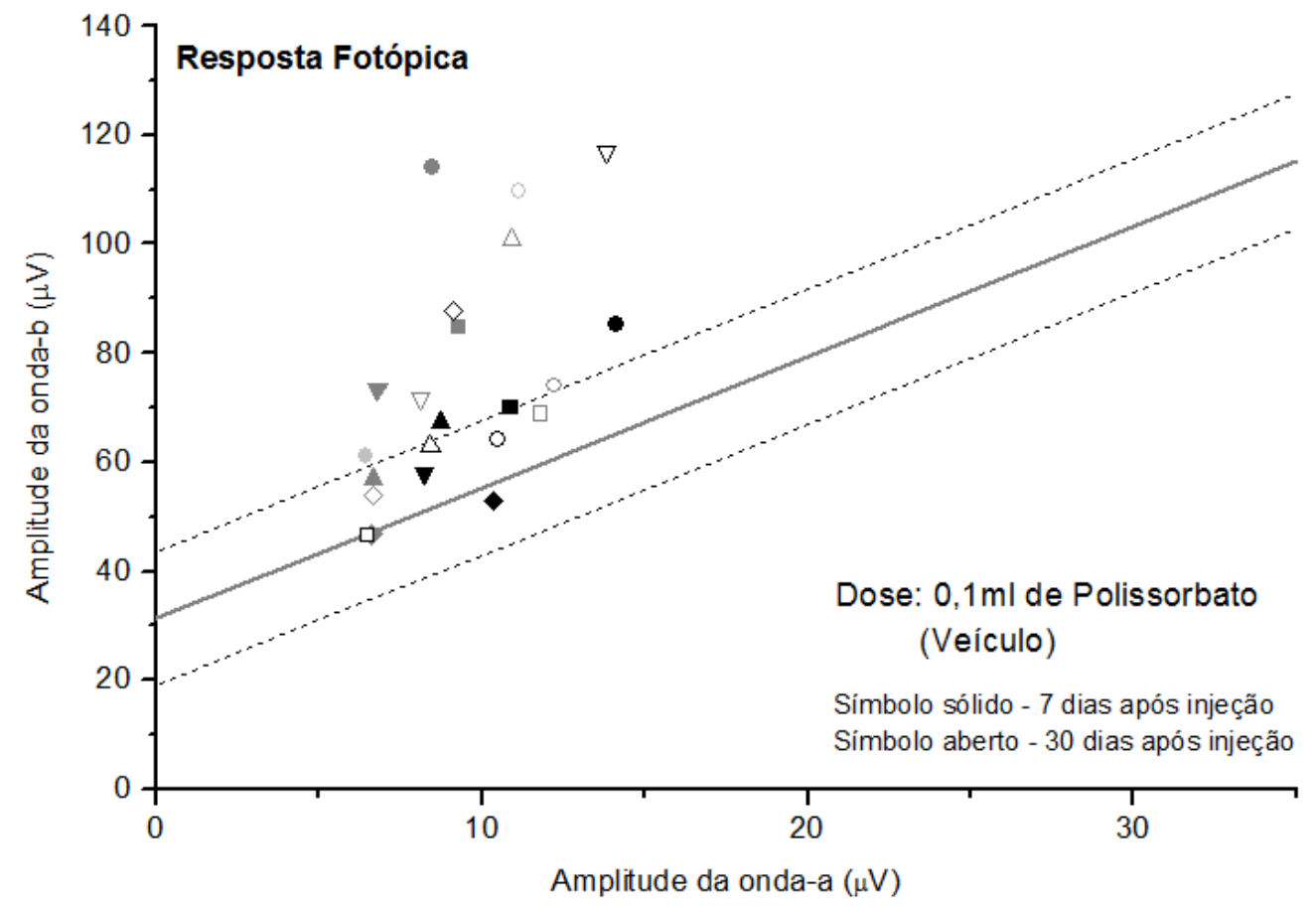

Figura 22: Relação de amplitude de onda b/onda a na condição fotópica. Cada símbolo representa o registro obtido em um olho. A linha cinza representa a curva de regressão linear e a linha tracejada representa a curva \pm dp do controle.

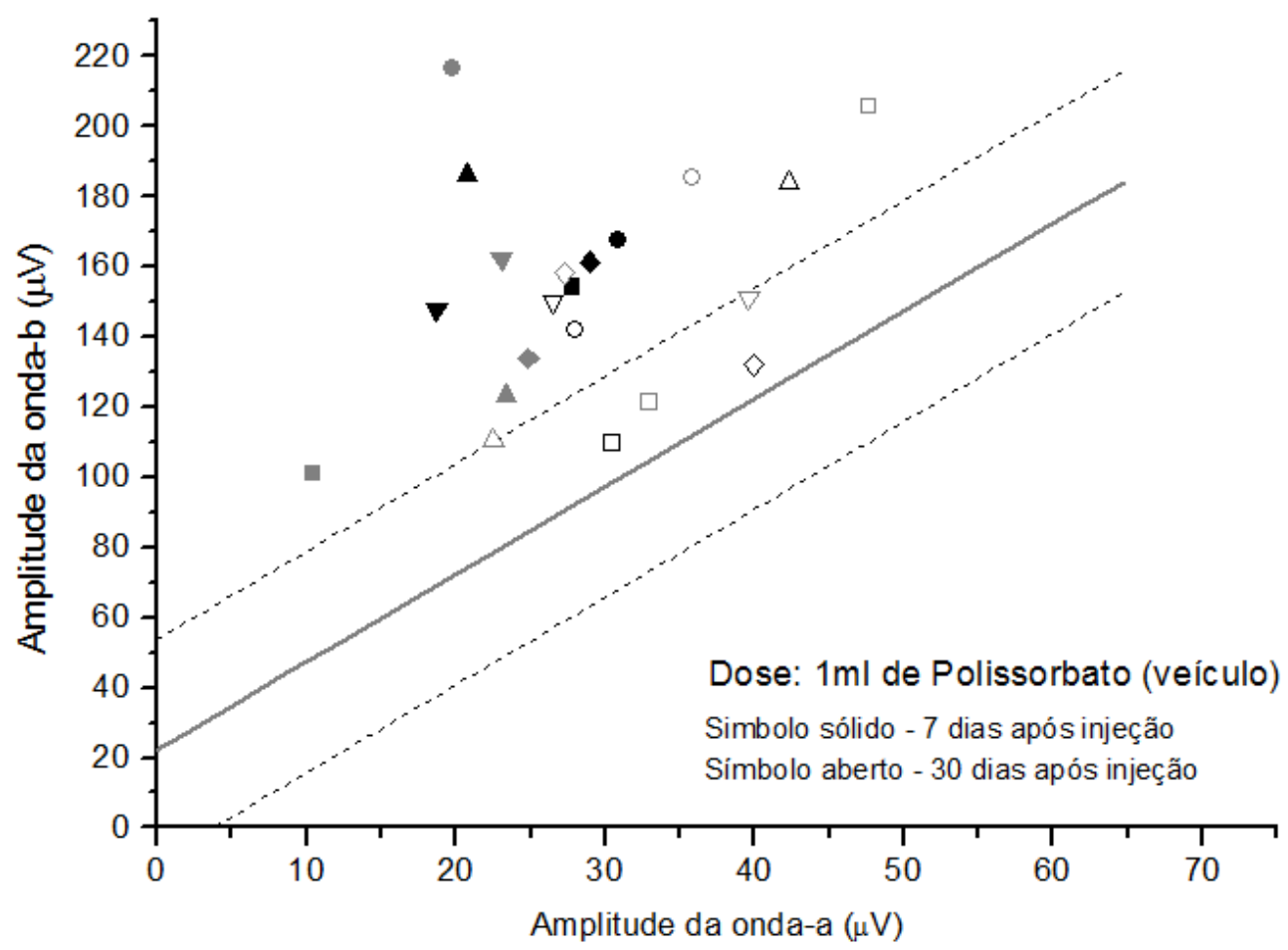

Figura 23: Relação de amplitude de onda b/onda a na condição escotópica máxima. Cada símbolo representa o registro obtido em um olho. A linha cinza representa a curva de regressão linear e a linha tracejada representa a curva \pm dp do controle. 


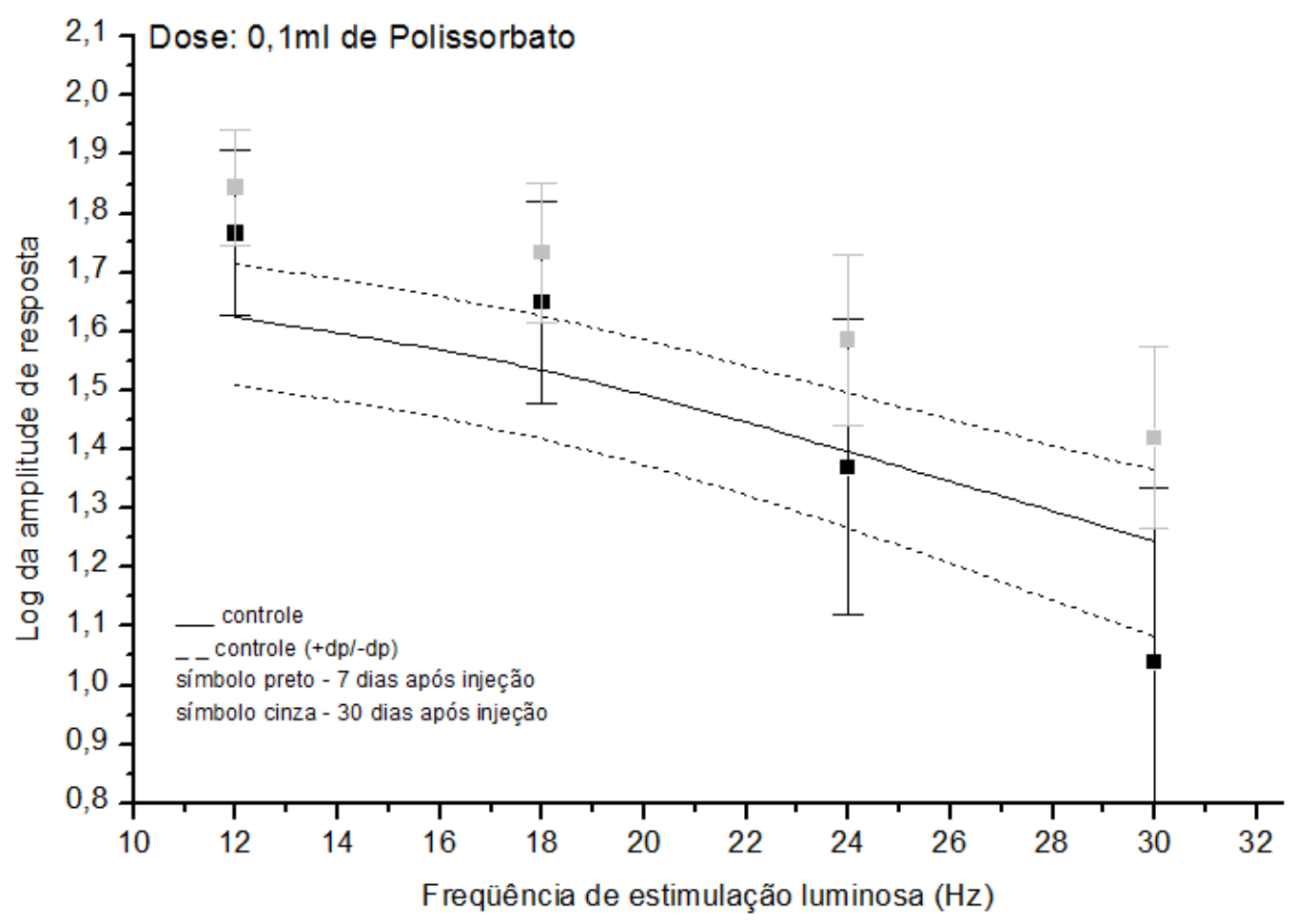

Figura 24: Relação entre a frequência de estimulação luminosa e amplitude de resposta. Cada símbolo representa o registro obtido em um olho. A linha cinza representa a média e a linha tracejada representa a média \pm dp do controle.

Tabela 4: Comparação das latências das respostas das ondas a e b do grupo controle com o grupo pósinjeção de SSB. Os valores máximos e mínimos do grupo controle são as médias $+d p$ e $-d p$, respectivamente.

\begin{tabular}{|c|c|c|c|c|c|c|c|}
\hline \multirow{2}{*}{\multicolumn{2}{|c|}{ LATÊNCIA (ms) }} & \multicolumn{3}{|c|}{ onda-a } & \multicolumn{3}{|c|}{ onda- $b$} \\
\hline & & MÍNINO & MÁXIMO & MÉDIA & MÍNINO & MÁXIMO & MÉDIA \\
\hline \multirow{4}{*}{$\begin{array}{l}\text { PRÉ-INJEÇÃO } \\
\text { (40 OLHOS) }\end{array}$} & \begin{tabular}{|l} 
Resposta Escotópica \\
$l=3 \mathrm{~cd} / \mathrm{m}^{2}$
\end{tabular} & & & & 42,23 & 58,41 & $50,32( \pm 8,09)$ \\
\hline & $\begin{array}{l}\text { Resposta Esc. Máxima } \\
l=30 \mathrm{~cd} / \mathrm{m}^{2}\end{array}$ & 14,99 & 18,17 & $16,58( \pm 1,59)$ & 45,49 & 61,77 & $53,63( \pm 8,14)$ \\
\hline & $\begin{array}{l}\text { Resposta Fotópica } \\
=78 \mathrm{~cd} / \mathrm{m} 2(\mathrm{BG}=15 \mathrm{~cd} / \mathrm{m} 2)\end{array}$ & 9,98 & 14,94 & $12,46( \pm 2,48)$ & 31,12 & 34,48 & $32,80( \pm 1,68)$ \\
\hline & & \multicolumn{3}{|c|}{ MÉDIA } & \multicolumn{3}{|c|}{ MÉDIA } \\
\hline \multirow{3}{*}{$\begin{array}{l}\text { PÓS-INJEÇÃo } \\
\text { (VÉCULO) }\end{array}$} & $\begin{array}{l}\text { Resposta Es cotópica } \\
l=3 \mathrm{~cd} / \mathrm{m}^{2}\end{array}$ & & & & \multicolumn{3}{|c|}{$49,49( \pm 3,57)$} \\
\hline & $\begin{array}{l}\text { Resposta Esc. Máxima } \\
=30 \mathrm{~cd} / \mathrm{m}^{2}\end{array}$ & \multicolumn{3}{|c|}{$16,74( \pm 1,39)$} & \multicolumn{3}{|c|}{$43,16( \pm 3,62)$} \\
\hline & \begin{tabular}{|l} 
Resposta Fotópica \\
$=78 \mathrm{~cd} / \mathrm{m} 2(\mathrm{BG}=15 \mathrm{~cd} / \mathrm{m} 2)$
\end{tabular} & \multicolumn{3}{|c|}{$14,14( \pm 1,59)$} & \multicolumn{3}{|c|}{$34,02( \pm 2,16)$} \\
\hline
\end{tabular}


3.4 Doses de $5 \mu \mathrm{g}, 50 \mu \mathrm{g}, 200 \mu \mathrm{g}, 1.000 \mu \mathrm{g}$ e $10.000 \mu \mathrm{g}$ de MPA

\subsubsection{Doses que não apresentaram alterações eletrorretinográficas}

A análise dos parâmetros da equação de Hill da dose de 5 g. Tanto 7 quanto 30 dias após injeção se mostraram perfeitamente dentro do limite estabelecido de não toxicidade (Fig.25). Os valores foram: k=0,001490 e n=0,38908 (7 dias após injeção) e $\mathrm{k}=0,00188$ e $\mathrm{n}=0,38101$ (30 dias após injeção).

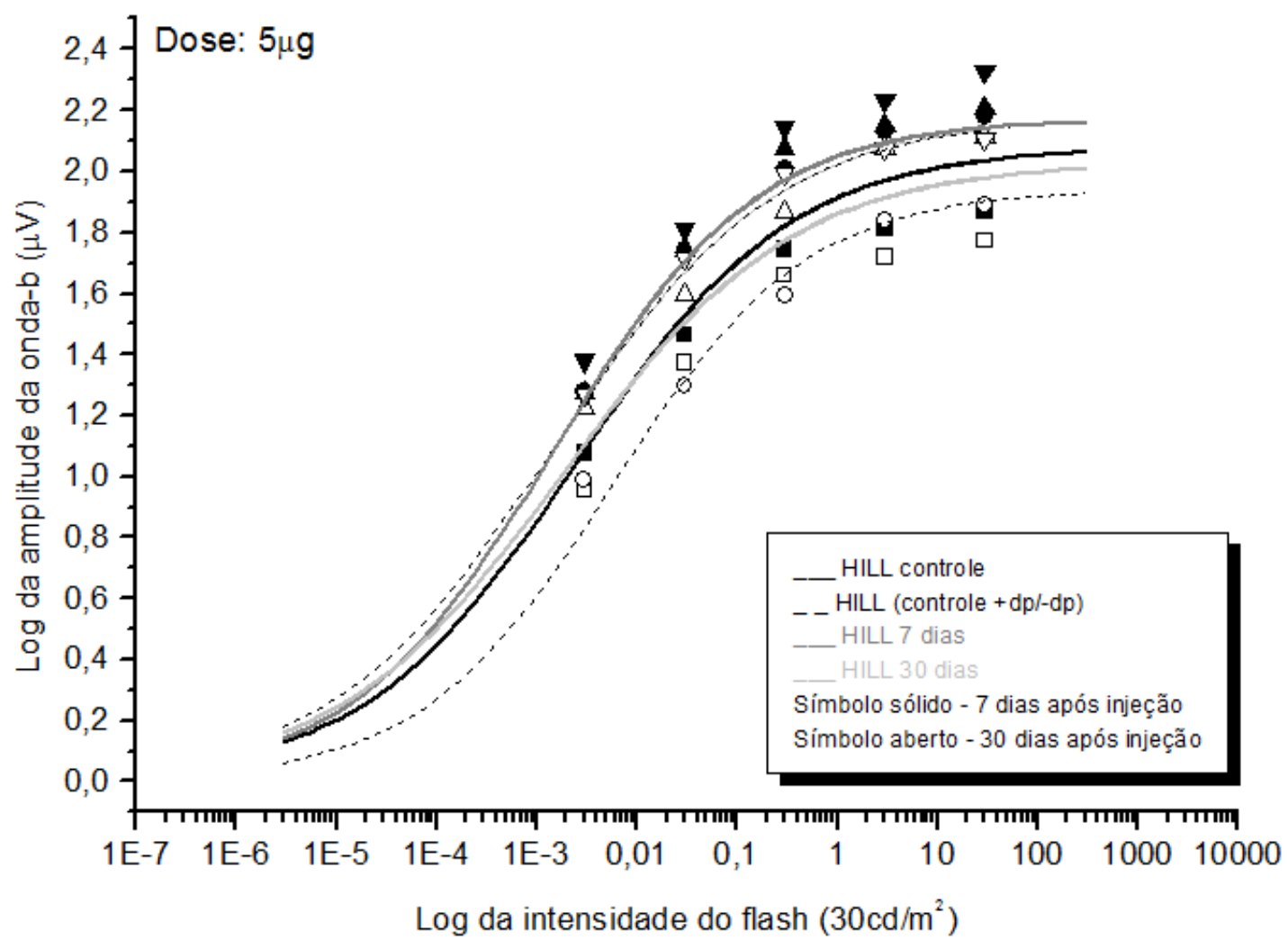

Figura 25: Relação intensidade-resposta da onda b escotópica de animais/olhos injetados com $5 \mu \mathrm{g}$ de MPA (símbolos, $n=4$ ), ajustada pela função de Hill (linha cinza escuro, 7 dias após injeção e cinza claro, 30 dias após injeção). A função/curva da população controle/não injetada ( $\mathrm{n}=9$, linha preta contínua) é mostrada +/- dp (linhas pretas tracejadas) para fins de comparação. 
A relação onda b/onda a da maioria dos olhos, tanto para a condição escotópica quanto para a fotópica, se mostraram dentro ou bastante próximas aos limites dos controles (Figs. 26 e 27).

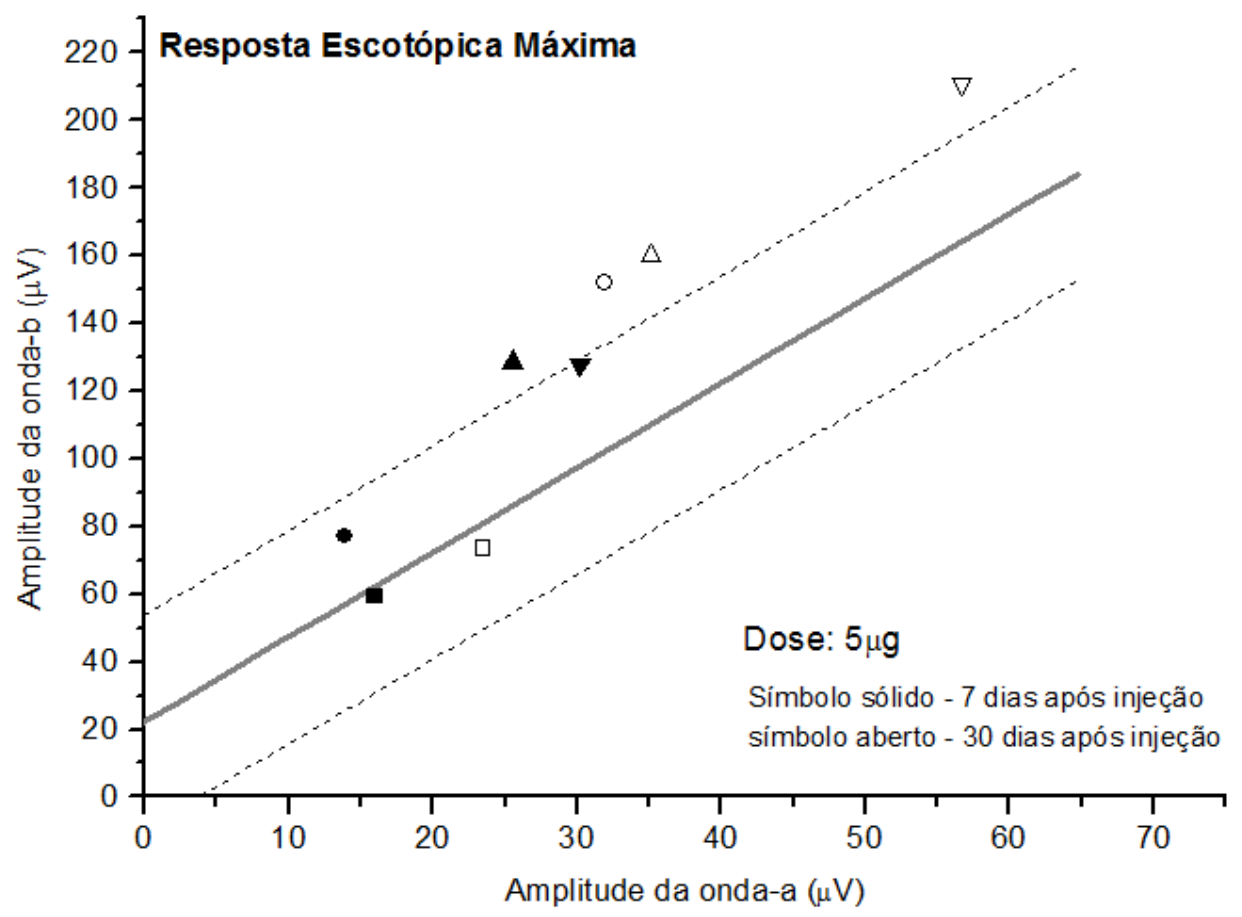

Figura 26: Relação de amplitude de onda b/onda a na condição escotópica máxima. Cada símbolo representa o registro obtido em um olho. A linha cinza representa a curva de regressão linear e a linha tracejada representa a curva \pm dp. 


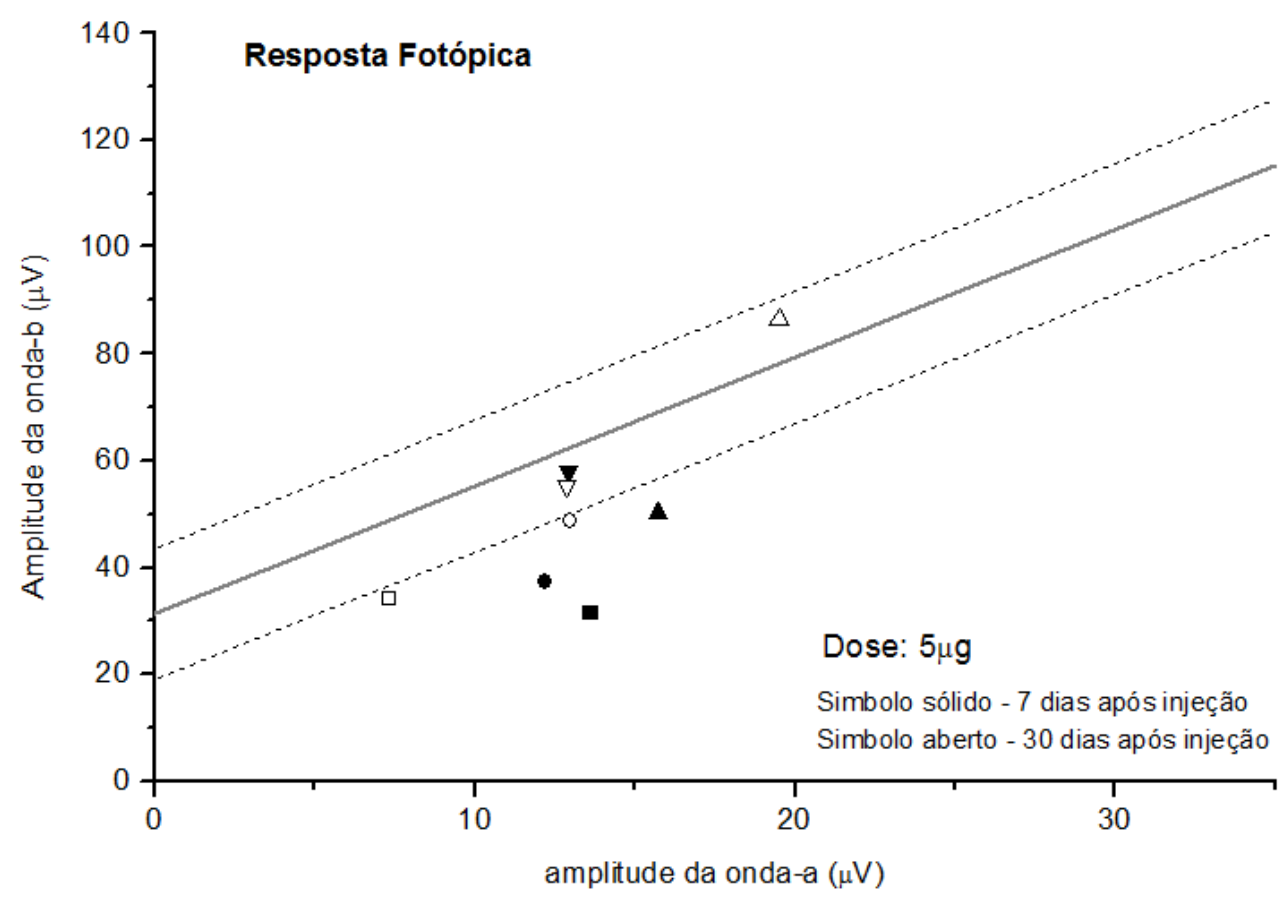

Figura 27: Relação de amplitude de onda b/onda a na condição fotópica. Cada símbolo representa o registro obtido em um olho. A linha cinza representa a curva de regressão linear e a linha tracejada representa a curva \pm dp.

Apesar de algumas respostas ao flicker aparecerem um pouco abaixo dos limites aceitáveis (Fig. 28), na Tabela 5 é possível observar que apenas na resposta fotópica o tempo implícito foi maior que os do grupo controle. 


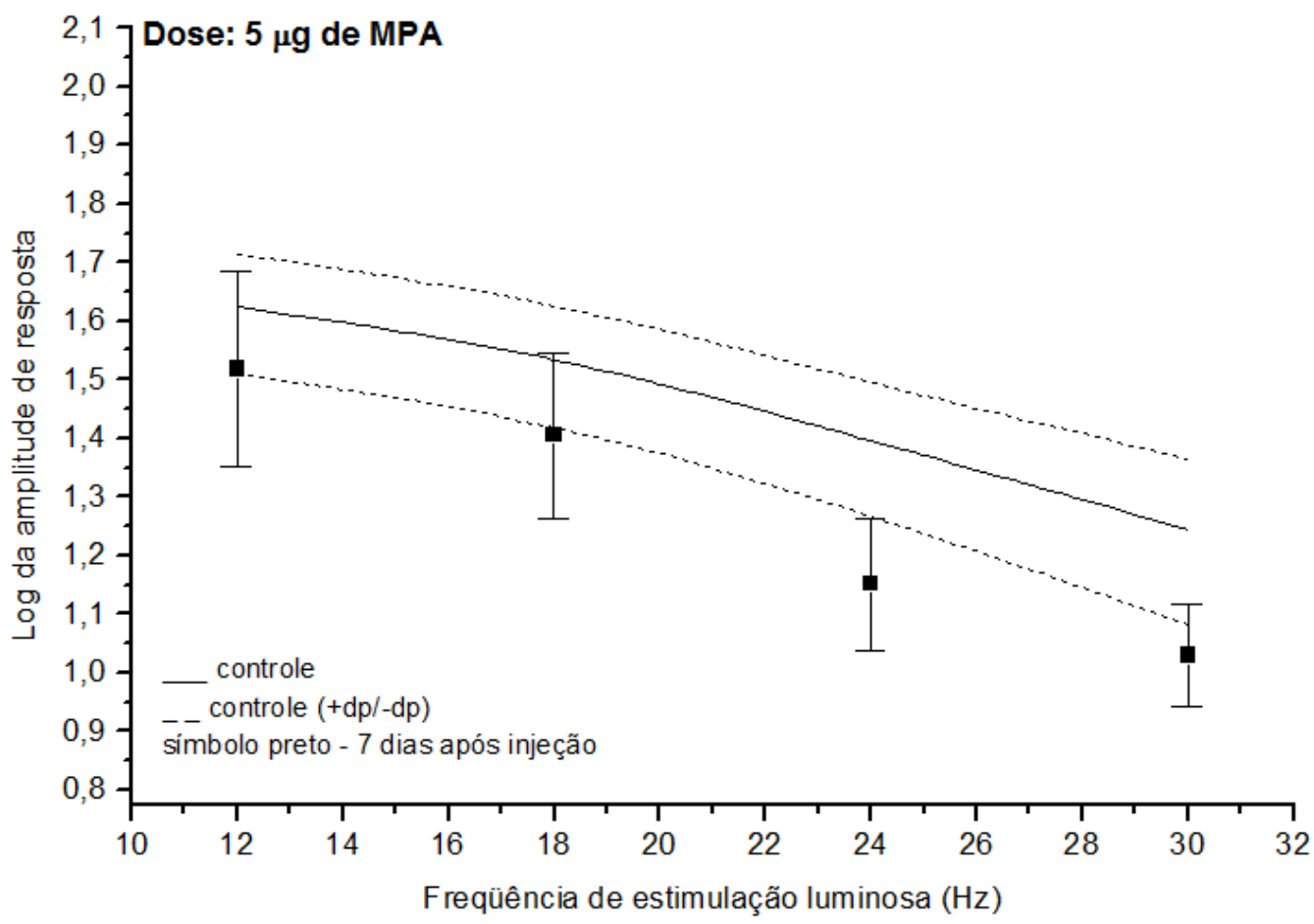

Figura 28: Relação frequência de estimulação luminosa e amplitude de resposta. Cada símbolo representa o registro obtido em um olho. A linha cinza representa a média e a linha tracejada representa a média \pm dp.

Tabela 5: : Comparação das latências das respostas das ondas a e b do grupo controle com o grupo pósinjeção de MPA ( $5 \mu \mathrm{g})$. Os valores máximos e mínimos do grupo controle são as médias +dp e -dp. Valores em vermelho e verde representam latências abaixo do mínimo respectivamente.

\begin{tabular}{|c|c|c|c|c|c|c|c|}
\hline \multirow{2}{*}{\multicolumn{2}{|c|}{ LATÊNCIA (ms) }} & \multicolumn{3}{|c|}{ onda-a } & \multicolumn{3}{|c|}{ onda-b } \\
\hline & & MIÍNINO & MÁXIMO & MÉDIA & MÍNINO & MÁXIMO & MÉDIA \\
\hline \multirow{4}{*}{$\begin{array}{l}\text { PRÉ-INJEÇÃO } \\
\text { (CONTROLE) }\end{array}$} & $\begin{array}{l}\text { Res posta Es cotópica } \\
=3 \mathrm{~cd} / \mathrm{m}^{2}\end{array}$ & & & & 42,23 & 58,41 & $50,32( \pm 8,09)$ \\
\hline & \begin{tabular}{||l} 
Resposta Esc. Máxima \\
$=30 \mathrm{~cd} / \mathrm{m}^{2}$
\end{tabular} & 14,99 & 18,17 & $16,58( \pm 1,59)$ & 45,49 & 61,77 & $53,63( \pm 8,14)$ \\
\hline & \begin{tabular}{l||l} 
Res posta Fotópica \\
$=78 \mathrm{~cd} / \mathrm{m} 2(\mathrm{BG}=15 \mathrm{~cd} / \mathrm{m} 2)$
\end{tabular} & 9,98 & 14,94 & $12,46( \pm 2,48)$ & 31,12 & 34,48 & $32,80( \pm 1,68)$ \\
\hline & & \multicolumn{3}{|c|}{ MÉDIA } & \multicolumn{3}{|c|}{ MÉDIA } \\
\hline \multirow{3}{*}{$\begin{array}{l}\text { OD (MPA) } \\
(\text { Dose }=5 \mu \mathrm{g})\end{array}$} & $\begin{array}{l}\text { Res posta Es cotópica } \\
=3 \mathrm{~cd} / \mathrm{m}^{2}\end{array}$ & & & & \multicolumn{3}{|c|}{$47,21( \pm 3,38)$} \\
\hline & $\begin{array}{l}\text { Resposta Esc. Máxima } \\
=30 \mathrm{~cd} / \mathrm{m}^{2}\end{array}$ & \multicolumn{3}{|c|}{$15,31( \pm 0,98)$} & \multicolumn{3}{|c|}{$41,83( \pm 4,08)$} \\
\hline & \begin{tabular}{l||l} 
Res posta Fotópica \\
$=78 \mathrm{~cd} / \mathrm{m} 2(\mathrm{BG}=15 \mathrm{~cd} / \mathrm{m} 2)$
\end{tabular} & \multicolumn{3}{|c|}{$12,79( \pm 2,44)$} & \multicolumn{3}{|c|}{$36,65( \pm 2,83)$} \\
\hline
\end{tabular}

Para as doses de 50 e $200 \mu \mathrm{g}$, os parâmetros da equação de Hill também permaneceram dentro do limite adequado (Figs. 29 e 30). Os valores da dose de $50 \mu \mathrm{g}$ foram: $\mathrm{k}=0,00305$ e $\mathrm{n}=0,4244,7$ dias após injeção e $\mathrm{k}=0,00115$ e $\mathrm{n}=0,42362,30$ dias 
após a administração intravítrea da droga. Para a dose de $200 \mu \mathrm{g}$ foram obtidos: $\mathrm{k}=0,00448 / \mathrm{n}=0,43118$ e $\mathrm{k}=0,00087 / \mathrm{n}=0,40527,7$ e 30 dias após injeção, respectivamente.

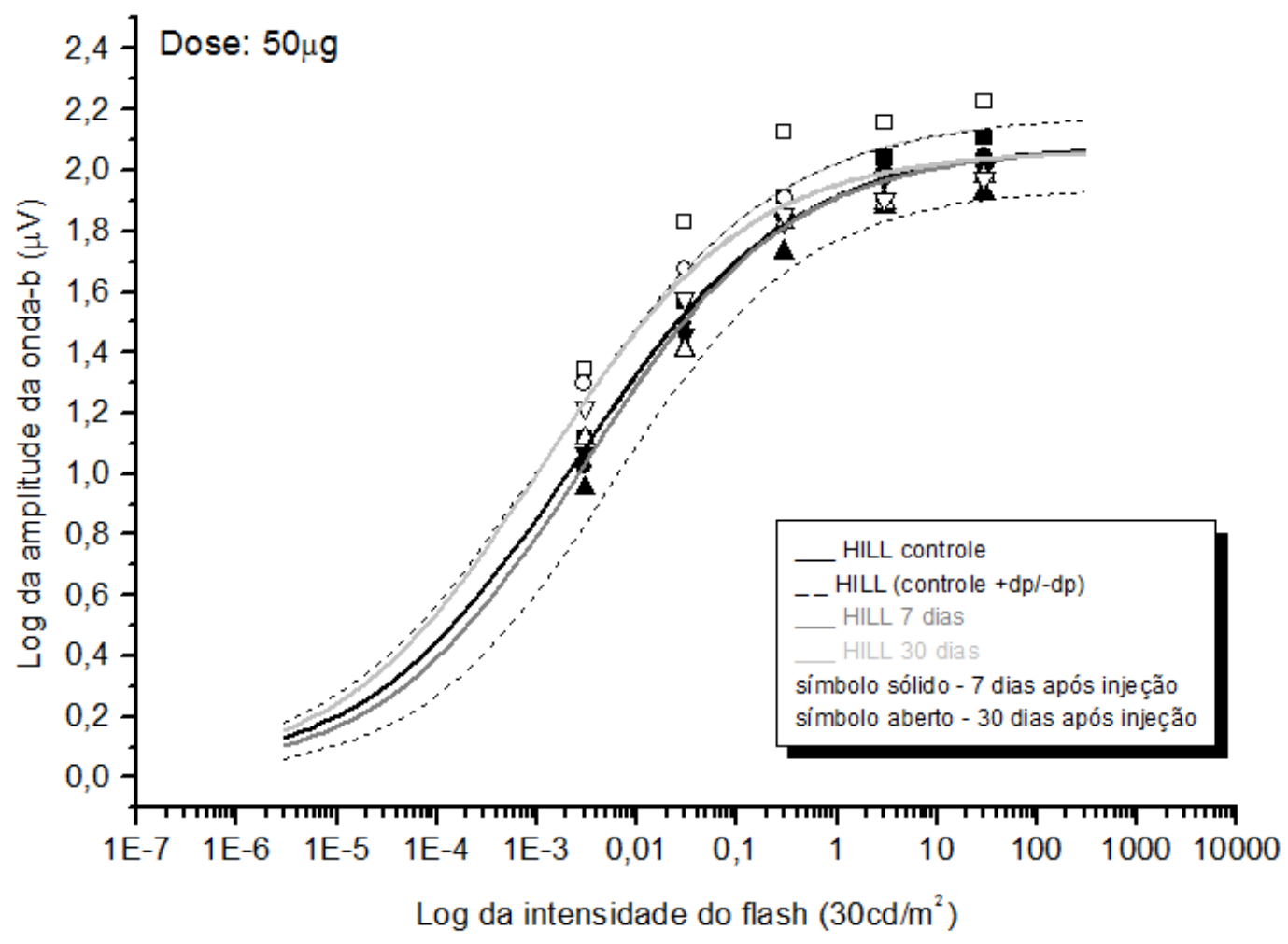

Figura 29: Relação intensidade-resposta da onda b escotópica de animais/olhos injetados com $50 \mu \mathrm{g}$ de MPA (símbolos, $n=4$ ), ajustada pela função de Hill (linha cinza escuro, 7 dias após injeção e cinza claro, 30 dias após injeção). A função/curva da população controle/não injetada ( $n=9$, linha preta contínua) é mostrada +/- dp (linhas pretas tracejadas) para fins de comparação. 


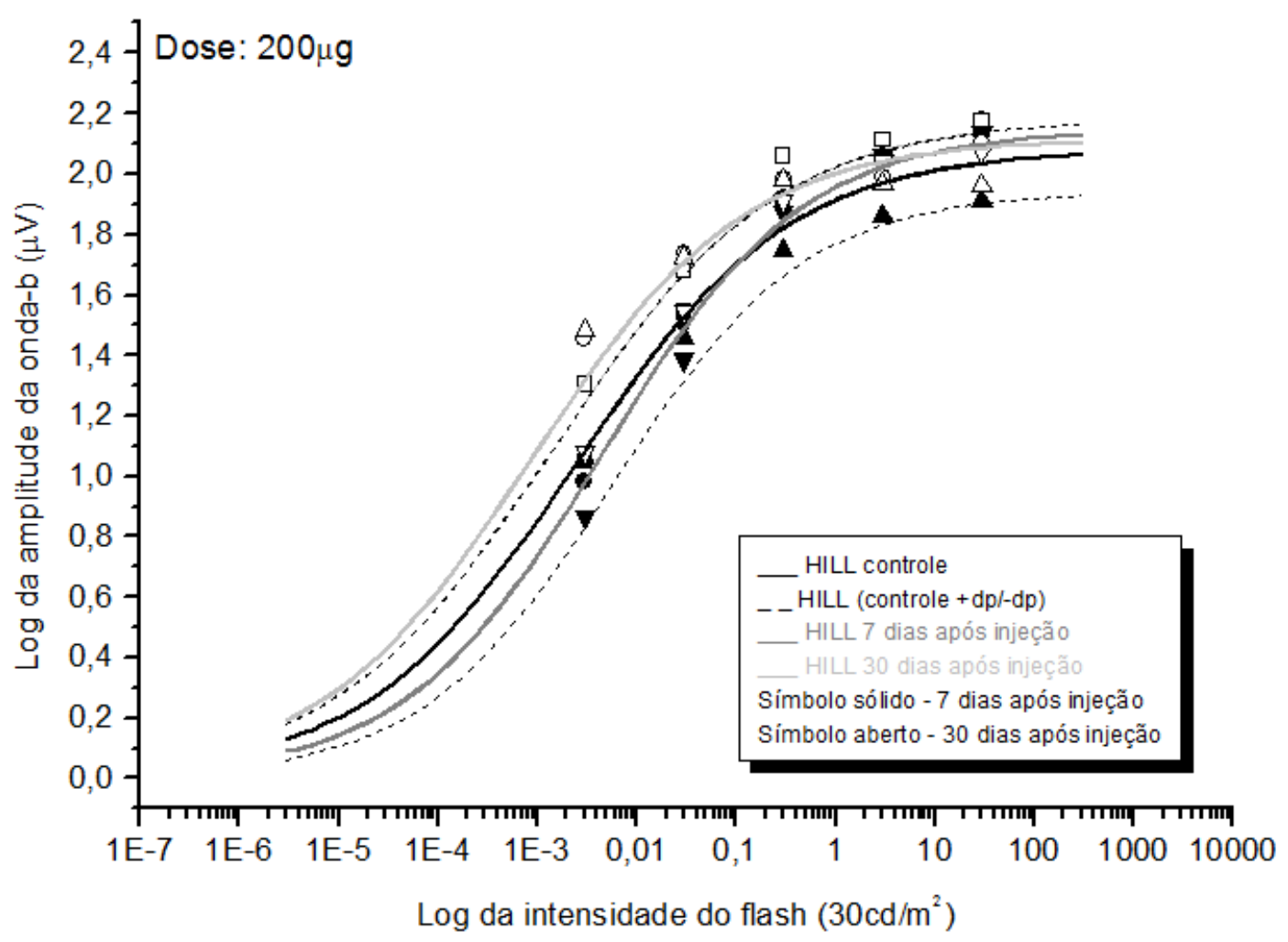

Figura 30: Relação intensidade-resposta da onda b escotópica de animais/olhos injetados com $200 \mu \mathrm{g}$ de MPA (símbolos, $n=4$ ), ajustada pela função de Hill (linha cinza escuro, 7 dias após injeção e cinza claro, 30 dias após injeção). A função/curva da população controle/não injetada (n=9, linha preta contínua) é mostrada +/- dp (linhas pretas tracejadas) para fins de comparação.

Nas figuras 31 a 34, de relação onda b/onda a é possível notar que, da mesma forma que a dose de $5 \mu \mathrm{g}$, a maioria dos dados concorda com os estabelecidos no grupo controle. Essa observação vale tanto para a condição escotópica máxima quanto para a relação fotópica. Pode-se verificar também que para a resposta ao flicker, a média dos resultados, em sua maioria, encontra-se adequada (Figs. 35 e 36). 


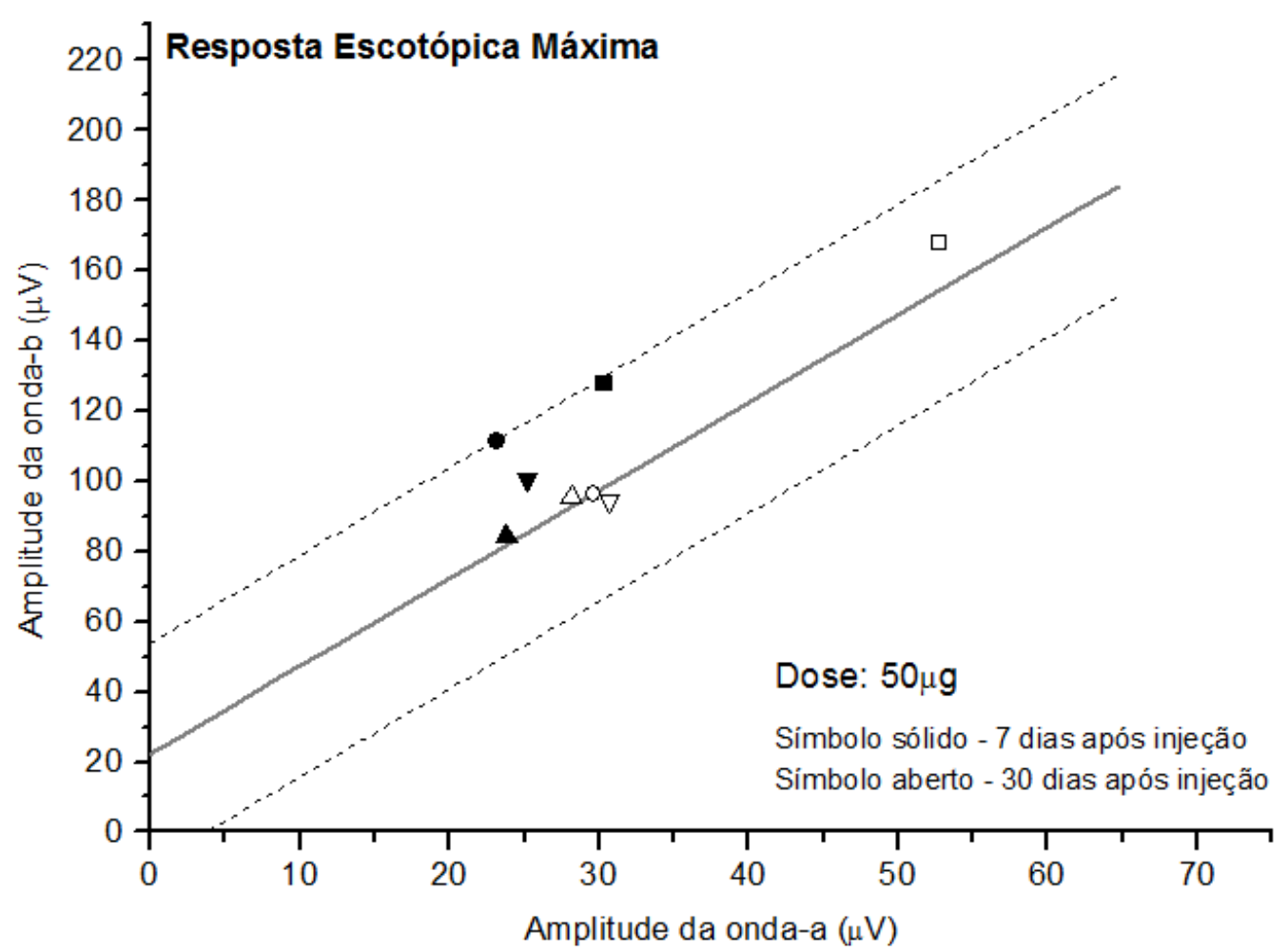

Figura 31: Relação de amplitude de onda b/onda a na condição escotópica máxima. Cada símbolo representa o registro obtido em um olho. A linha cinza representa a curva de regressão linear e a linha tracejada representa a curva $\pm \mathrm{dp}$.

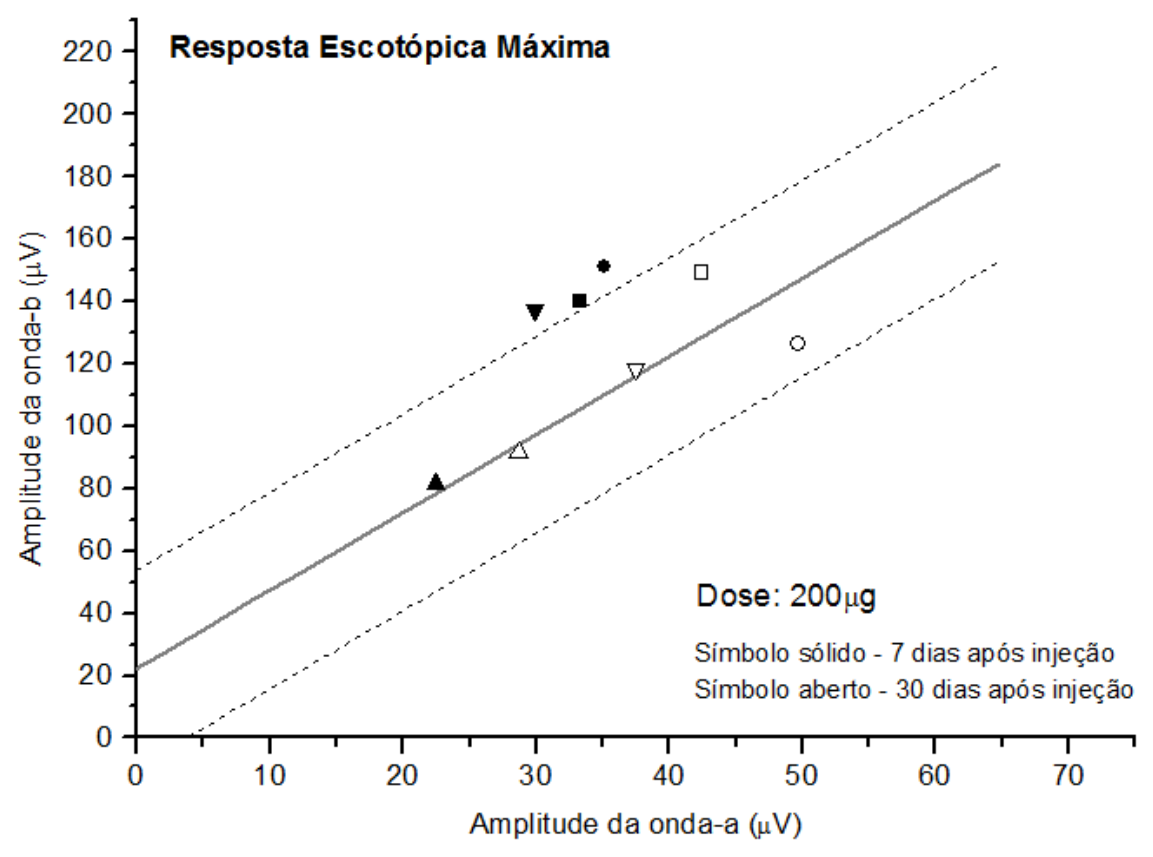

Figura 32: Relação de amplitude de onda b/onda a na condição escotópica máxima. Cada símbolo representa o registro obtido em um olho. A linha cinza representa a curva de regressão linear e a linha tracejada representa a curva \pm dp. 


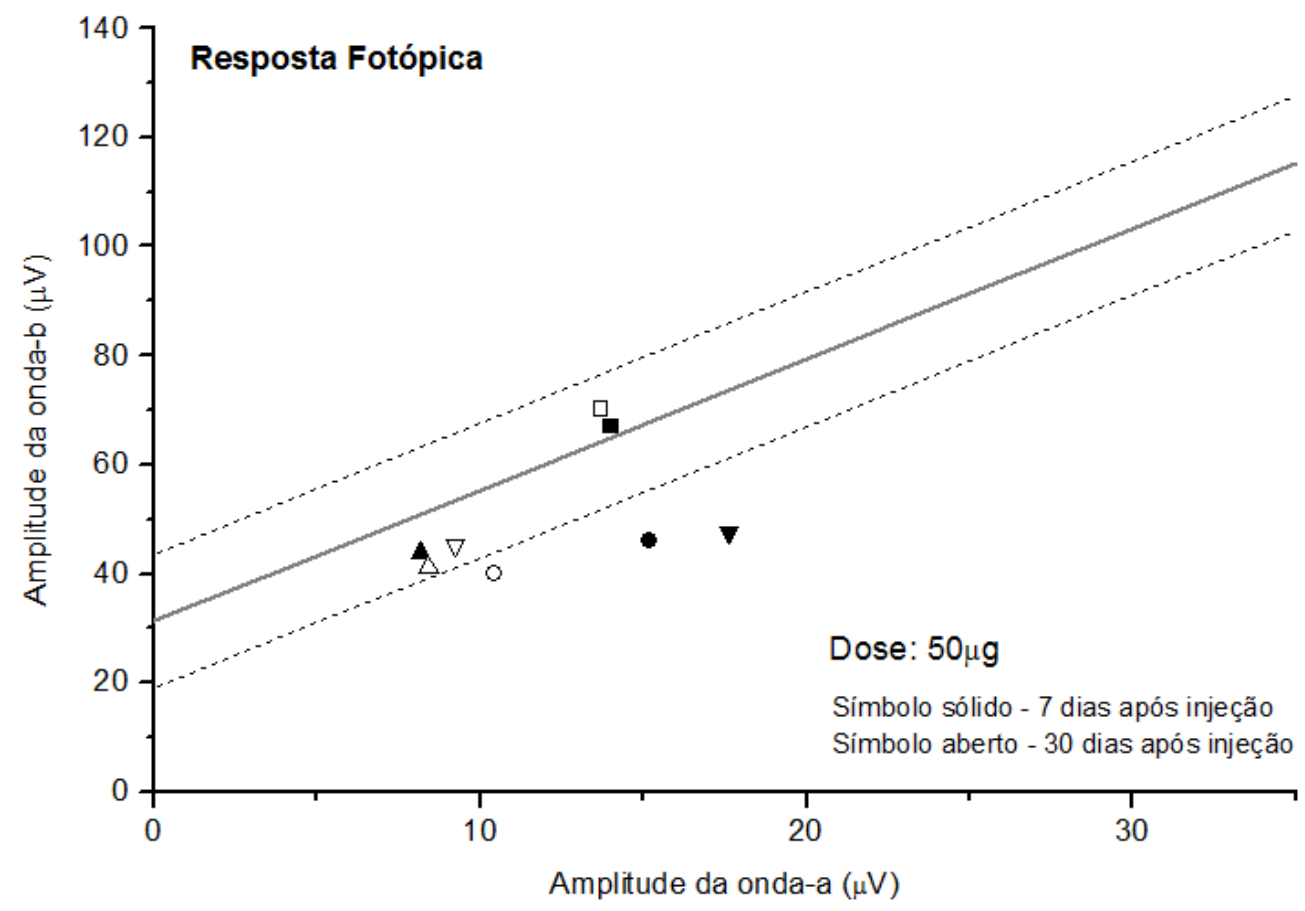

Figura 33: Relação de amplitude de onda b/onda a na condição fotópica. Cada símbolo representa o registro obtido em um olho. A linha cinza representa a curva de regressão linear e a linha tracejada representa a curva \pm dp.

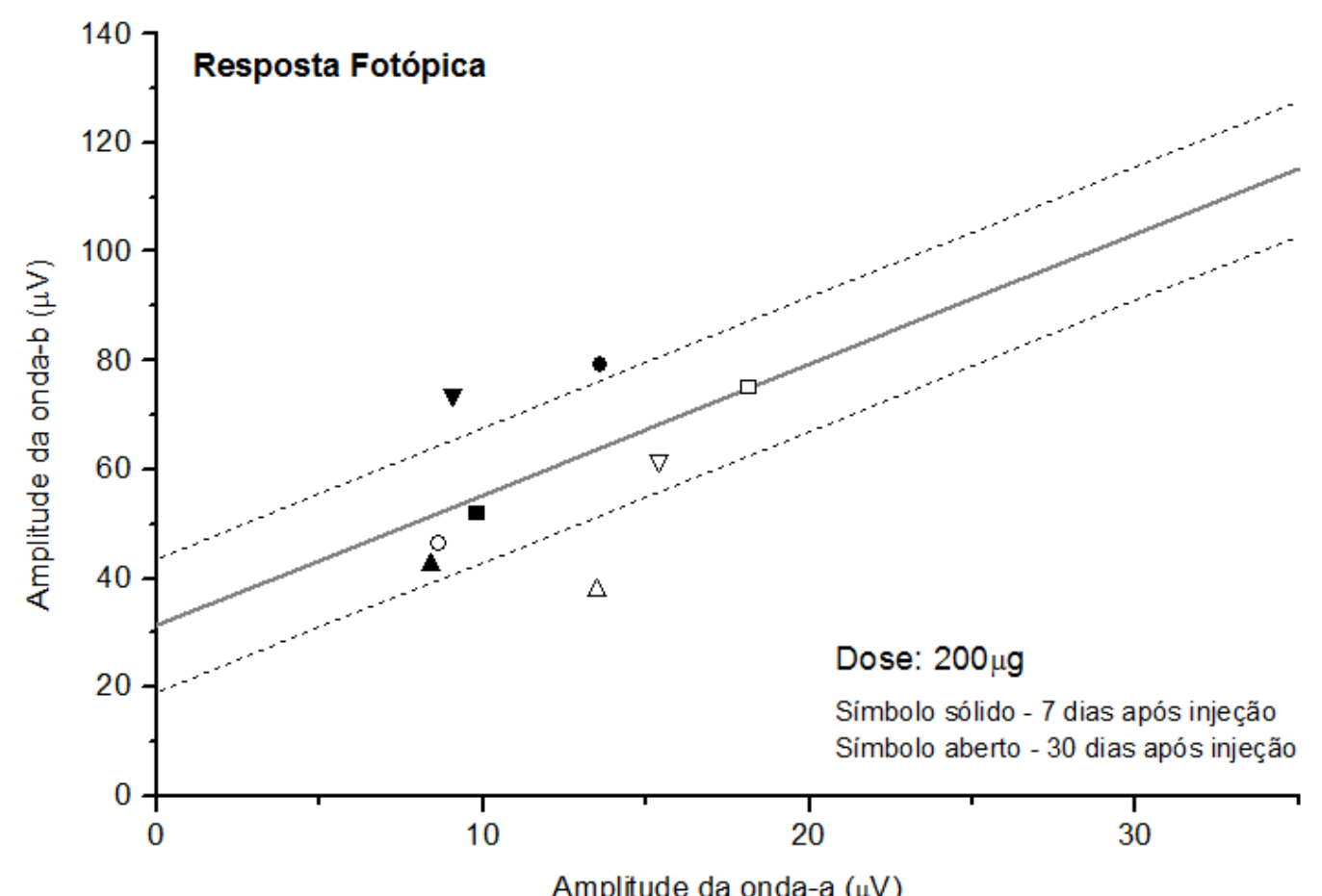

Figura 34: Relação de amplitude de onda b/onda a na condição fotópica. Cada símbolo representa o registro obtido em um olho. A linha cinza representa a curva de regressão linear e a linha tracejada representa a curva \pm dp. 


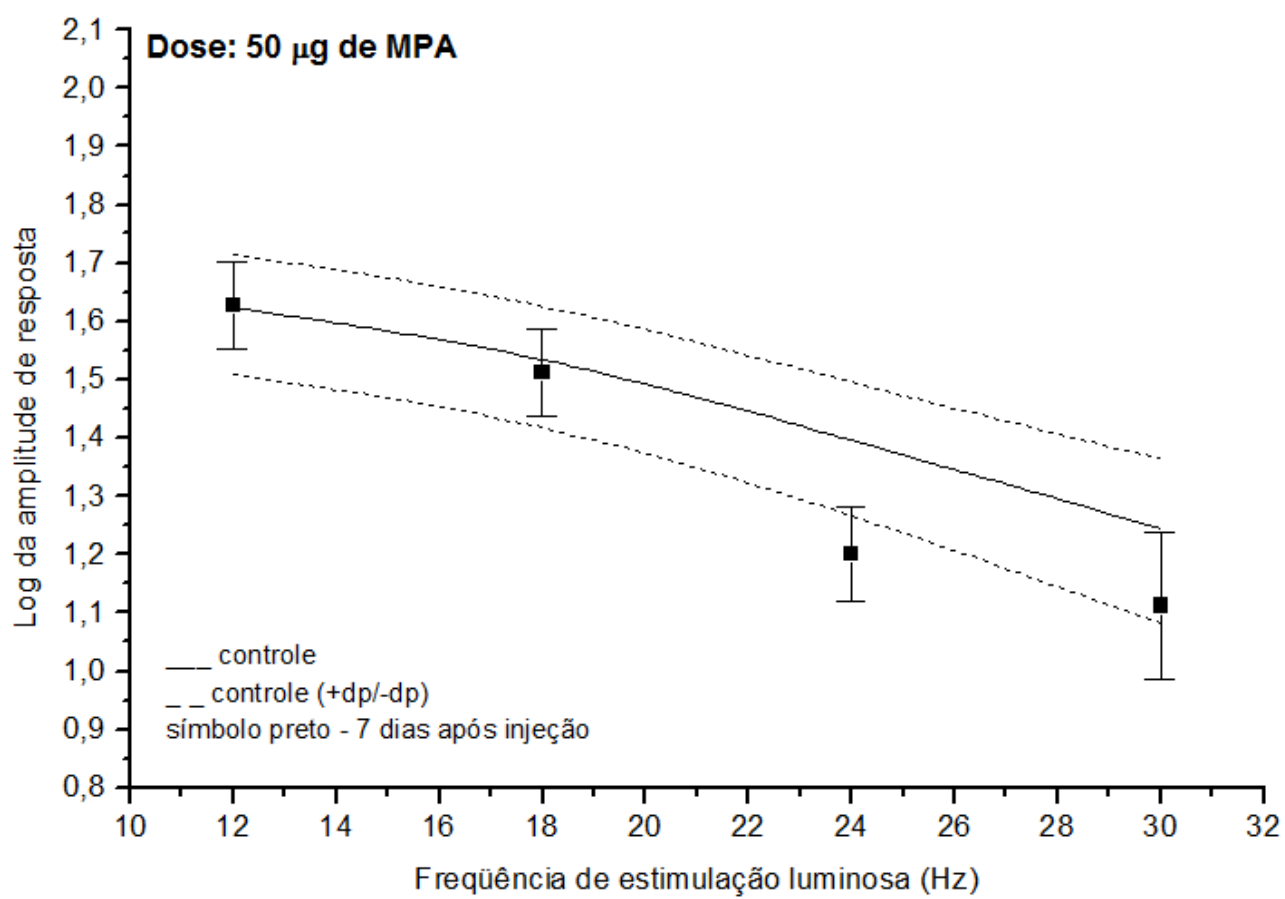

Figura 35: Relação frequência de estimulação luminosa e amplitude de resposta. Cada símbolo representa o registro obtido em um olho. A linha cinza representa a média e a linha tracejada representa a média \pm dp.

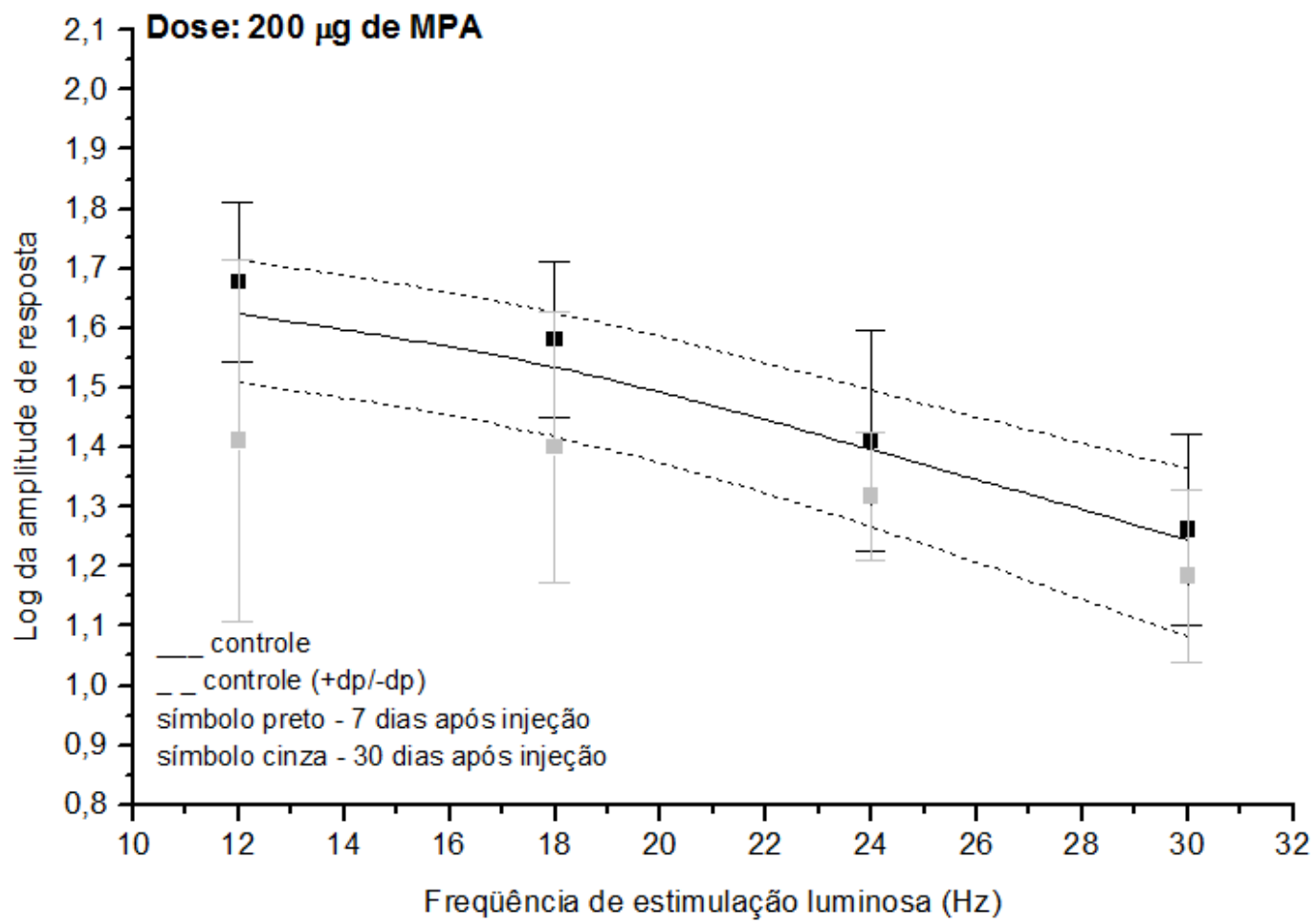

Figura 36: Relação frequência de estimulação luminosa e amplitude de resposta. Cada símbolo representa o registro obtido em um olho. A linha cinza representa a média e a linha tracejada representa a média $\pm d p$. 
Tabela 6: Comparação das latências das respostas das ondas a e b do grupo controle com o grupo pósinjeção de MPA $(50 \mu \mathrm{g})$. Os valores máximos e mínimos do grupo controle são as médias $+\mathrm{dp}$ e $-\mathrm{dp}$. Valores em vermelho e verde representam latências abaixo do mínimo e do máximo, respectivamente.

\begin{tabular}{|c|c|c|c|c|c|c|c|}
\hline \multirow{2}{*}{\multicolumn{2}{|c|}{ LATÊNCIA(ms) }} & \multicolumn{3}{|c|}{ onda-a } & \multicolumn{3}{|c|}{ onda-b } \\
\hline & & MíNINO & MÁXIMO & MÉDIA & MÍNINO & MÁXIMO & MÉDIA \\
\hline \multirow{4}{*}{$\begin{array}{l}\text { PRÉ-INJEÇÃO } \\
\text { (CONTROLE) }\end{array}$} & $\begin{array}{l}\text { Resposta Escotópica } \\
l=3 \mathrm{~cd} / \mathrm{m}^{2}\end{array}$ & & & & 42,23 & 58,41 & $50,32( \pm 8,09)$ \\
\hline & $\begin{array}{l}\text { Resposta Esc. Máxima } \\
=30 \mathrm{~cd} / \mathrm{m}^{2}\end{array}$ & 14,99 & 18,17 & $16,58( \pm 1,59)$ & 45,49 & 61,77 & $53,63( \pm 8,14)$ \\
\hline & $\begin{array}{l}\text { Resposta Fotópica } \\
=78 \mathrm{~cd} / \mathrm{m} 2(B G=15 \mathrm{~cd} / \mathrm{m} 2)\end{array}$ & 9,98 & 14,94 & $12,46( \pm 2,48)$ & 31,12 & 34,48 & $32,80( \pm 1,68)$ \\
\hline & & \multicolumn{3}{|c|}{ MÉDIA } & \multicolumn{3}{|c|}{ MÉDIA } \\
\hline \multirow{3}{*}{$\begin{array}{c}\text { OD (MPA) } \\
(\text { Dose }=50 \mu \mathrm{g})\end{array}$} & $\begin{array}{l}\text { Resposta Es cotópica } \\
=3 \mathrm{~cd} / \mathrm{m}^{2}\end{array}$ & & & & \multicolumn{3}{|c|}{$48,62( \pm 2,12)$} \\
\hline & $\begin{array}{l}\text { Resposta Esc. Máxima } \\
=30 \mathrm{~cd} / \mathrm{m}^{2}\end{array}$ & \multicolumn{3}{|c|}{$15,83( \pm 0,73)$} & \multicolumn{3}{|c|}{$42,42( \pm 7,24)$} \\
\hline & \begin{tabular}{|l} 
Resposta Fotópica \\
$=78 \mathrm{~cd} / \mathrm{m} 2(\mathrm{BG}=15 \mathrm{~cd} / \mathrm{m} 2)$
\end{tabular} & \multicolumn{3}{|c|}{$13,13( \pm 2,37)$} & \multicolumn{3}{|c|}{$33,32( \pm 3,59)$} \\
\hline
\end{tabular}

Tabela 7: Comparação das latências das respostas das ondas a e b do grupo controle com o grupo pósinjeção de MPA $(200 \mu \mathrm{g})$. Os valores máximos e mínimos do grupo controle são as médias $+\mathrm{dp}$ e -dp. Valores em vermelho e verde representam latências abaixo do mínimo respectivamente.

\begin{tabular}{|c|c|c|c|c|c|c|c|}
\hline \multirow{2}{*}{\multicolumn{2}{|c|}{ LATÊNCIA (ms) }} & \multicolumn{3}{|c|}{ onda-a } & \multicolumn{3}{|c|}{ onda-b } \\
\hline & & MÍNINO & MÁXIMO & MÉDIA & MíNINO & MÁXIMO & MÉDIA \\
\hline \multirow{4}{*}{$\begin{array}{l}\text { PRÉ-INJEÇÃO } \\
\text { (CONTROLE) }\end{array}$} & $\begin{array}{l}\text { Resposta Escotópica } \\
l=3 \mathrm{~cd} / \mathrm{m}^{2}\end{array}$ & & & & 42,23 & 58,41 & $50,32( \pm 8,09)$ \\
\hline & $\begin{array}{l}\text { Resposta Esc. Máxima } \\
=30 \mathrm{~cd} / \mathrm{m}^{2}\end{array}$ & 14,99 & 18,17 & $16,58( \pm 1,59)$ & 45,49 & 61,77 & $53,63( \pm 8,14)$ \\
\hline & $\begin{array}{l}\text { Resposta Fotópica } \\
=78 \mathrm{~cd} / \mathrm{m} 2(\mathrm{BG}=15 \mathrm{~cd} / \mathrm{m} 2)\end{array}$ & 9,98 & 14,94 & $12,46( \pm 2,48)$ & 31,12 & 34,48 & $32,80( \pm 1,68)$ \\
\hline & & \multicolumn{3}{|c|}{ MÉDIA } & \multicolumn{3}{|c|}{ MÉDIA } \\
\hline \multirow{3}{*}{$\begin{array}{c}\text { OD (MPA) } \\
(\text { Dose }=200 \mu \mathrm{g})\end{array}$} & $\begin{array}{l}\text { Resposta Escotópica } \\
=3 \mathrm{~cd} / \mathrm{m}^{2}\end{array}$ & & & & \multicolumn{3}{|c|}{$46,93( \pm 2,9)$} \\
\hline & $\begin{array}{l}\text { Resposta Esc. Máxima } \\
=30 \mathrm{~cd} / \mathrm{m}^{2}\end{array}$ & \multicolumn{3}{|c|}{$16,15( \pm 1,2)$} & \multicolumn{3}{|c|}{$43,66( \pm 6,8)$} \\
\hline & $\begin{array}{l}\text { Resposta Fotópica } \\
=78 \mathrm{~cd} / \mathrm{m} 2(\mathrm{BG}=15 \mathrm{~cd} / \mathrm{m} 2)\end{array}$ & \multicolumn{3}{|c|}{$15,09( \pm 5,6)$} & \multicolumn{3}{|c|}{$37,15( \pm 5,8)$} \\
\hline
\end{tabular}

Para valores de latência (Tabelas 6 e 7), as médias que mostraram discreto aumento de tempo de resposta foram as de onda a e onda b de resposta fotópica (10 e $7 \%)$. 


\subsubsection{Doses que apresentaram alterações eletrorretinográficas}

Os parâmetros da equação de Hill mostram que houve diminuição de sensibilidade ao estímulo luminoso na dose de $1.000 \mu \mathrm{g}, 7$ dias após injeção $(\mathrm{k}=0,01455$ e $\mathrm{n}=0,48863)$ (Figura 37). Na dose de $10.000 \mu \mathrm{g}$ ocorreu a mesma tendência, $7(\mathrm{k}=0,00998$ e $\mathrm{n}=0,67741)$ e 30 dias $(\mathrm{k}=0,01$ e $\mathrm{n}=0,60246)$ após administração de MPA. Parece ter ocorrido recuperação da sensibilidade na dose de $1.000 \mu \mathrm{g}, 30$ dias após injeção ( $\mathrm{k}=0,00143$ e $\mathrm{n}=0,44361)$ (Figura 38).

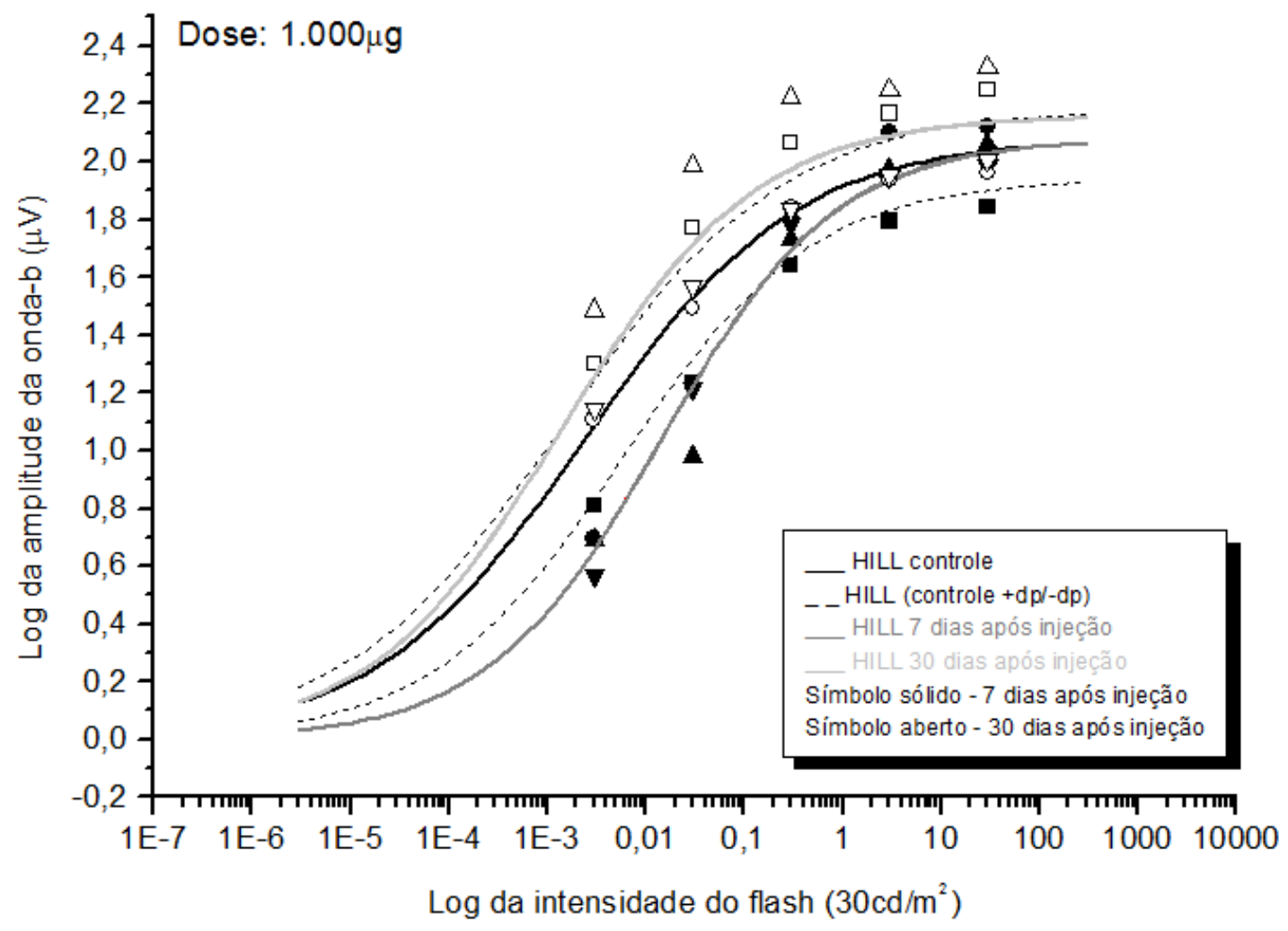

Figura 37: Relação intensidade-resposta da onda b escotópica de animais/olhos injetados com $1.000 \mu \mathrm{g}$ de MPA (símbolos, n=4), ajustada pela função de Hill (linha cinza escuro, 7 dias após injeção e cinza claro, 30 dias após injeção). A função/curva da população controle/não injetada (n=9, linha preta contínua) é mostrada $+/$ - dp (linhas pretas tracejadas) para fins de comparação. 


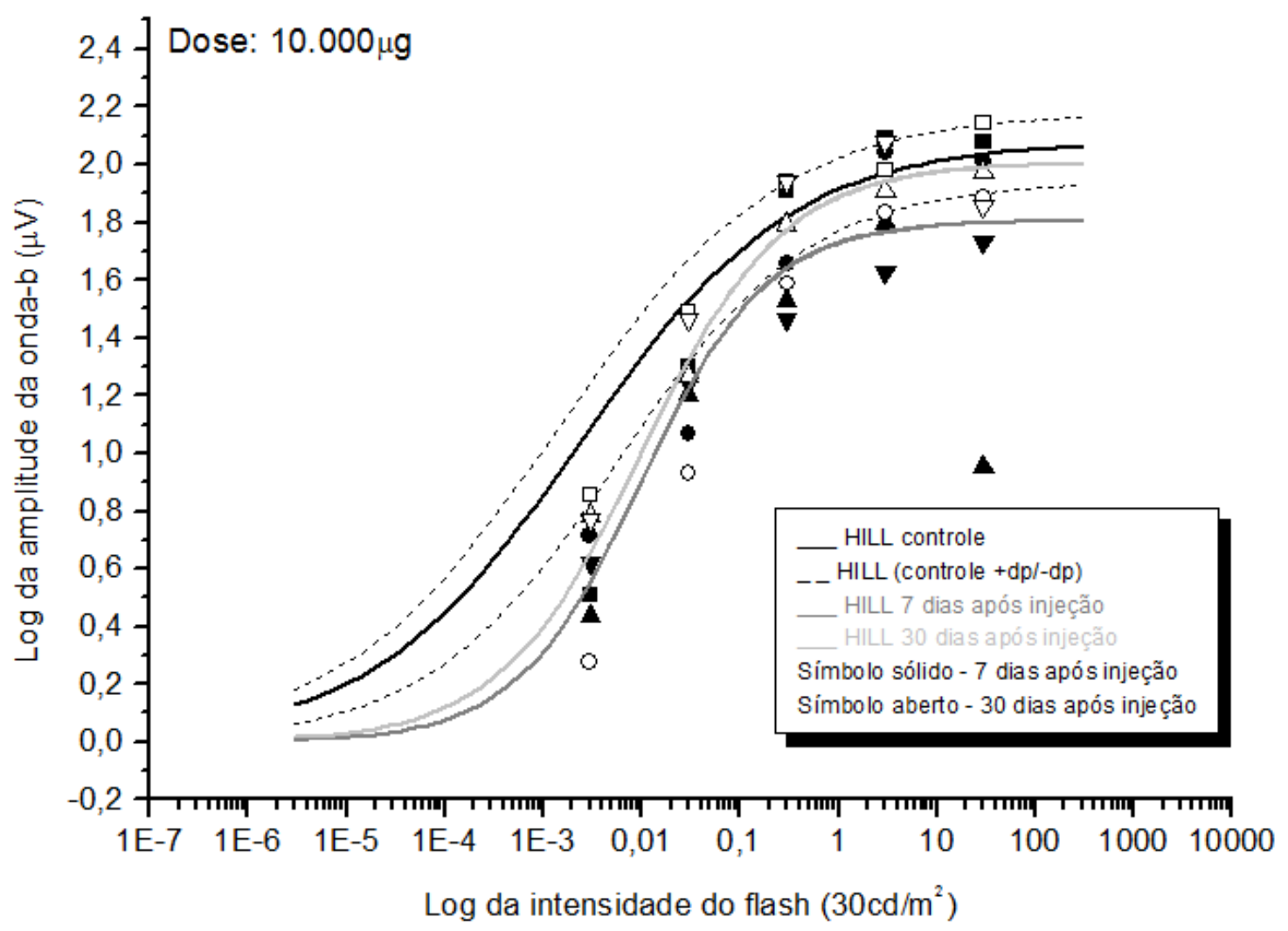

Figura 38: Relação intensidade-resposta da onda b escotópica de animais/olhos injetados com $10.000 \mu \mathrm{g}$ de MPA (símbolos, n=4), ajustada pela função de Hill (linha cinza escuro, 7 dias após injeção e cinza claro, 30 dias após injeção). A função/curva da população controle/não injetada (n=9, linha preta contínua) é mostrada +/- dp (linhas pretas tracejadas) para fins de comparação.

Nos gráficos de relação onda b/onda a da resposta escotópica máxima e fotópica não houve nenhuma dose que apresentasse a maioria dos indivíduo distante da curva de regressão linear (Figs. 39 a 43). Na dose de $10.000 \mu$ g ocorreu erro em alguns registros fotópicos e, por esse motivo, não foi incluída a relação onda b/onda a na análise. 


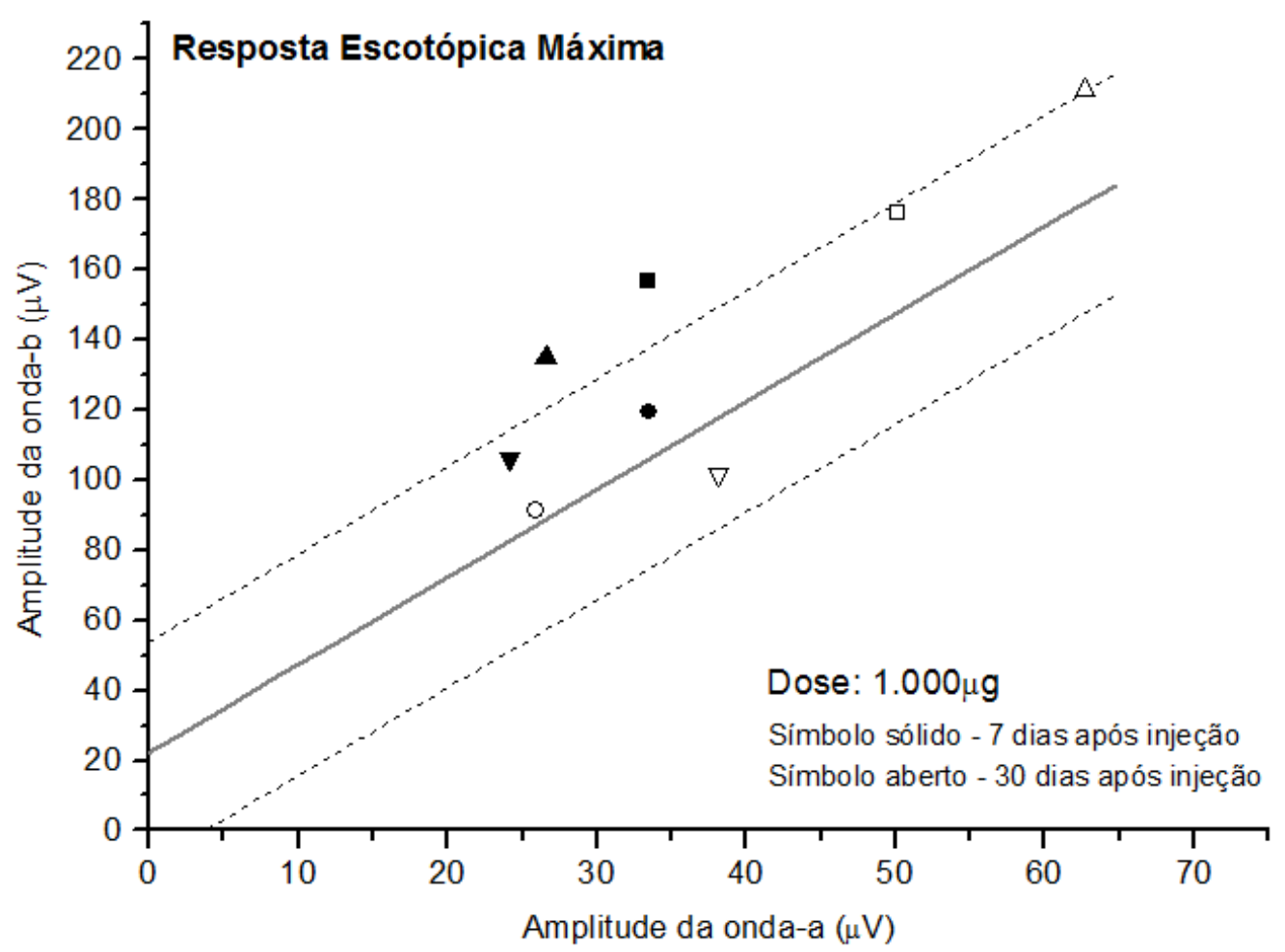

Figura 39: Relação de amplitude de onda b/onda a na condição escotópica máxima. Cada símbolo representa o registro obtido em um olho. A linha cinza representa a curva de regressão linear e a linha tracejada representa a curva $\pm d p$.

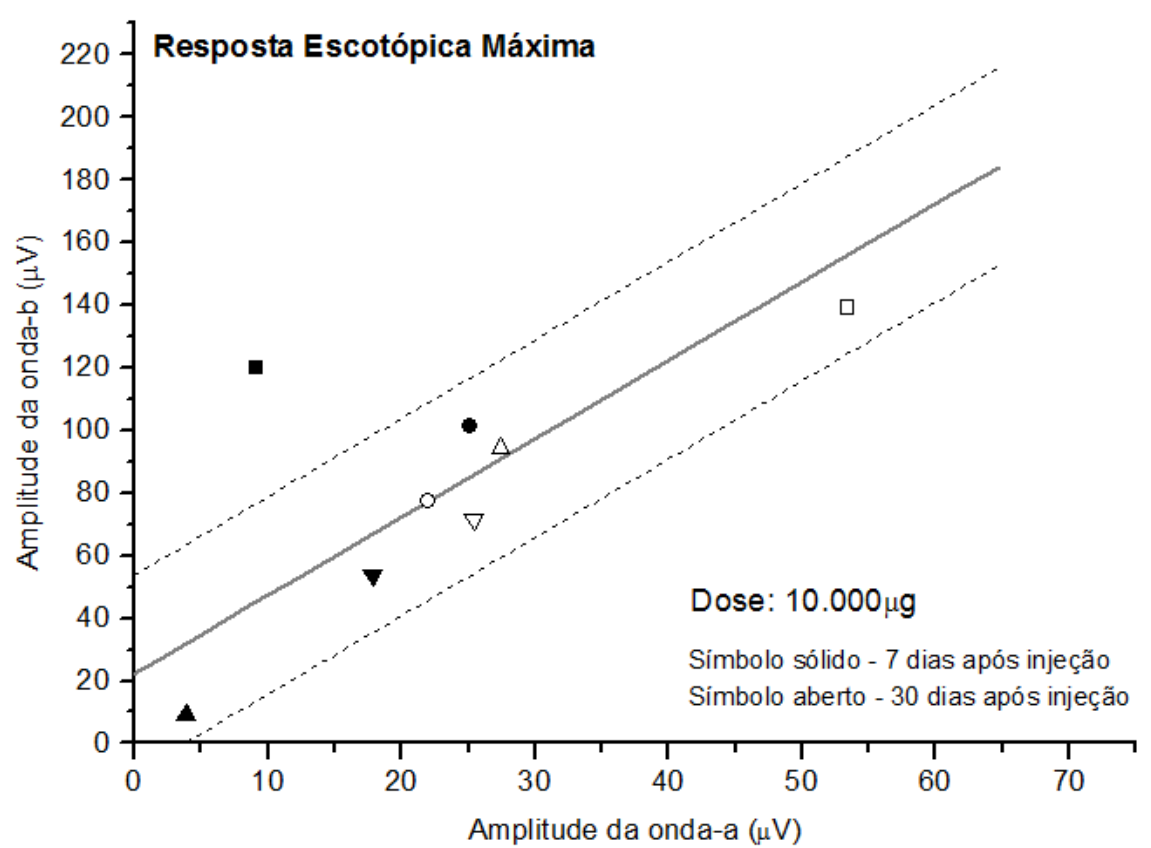

Figura 40: Relação de amplitude de onda b/onda a na condição escotópica máxima. Cada símbolo representa o registro obtido em um olho. A linha cinza representa a curva de regressão linear e a linha tracejada representa a curva $\pm d p$. 


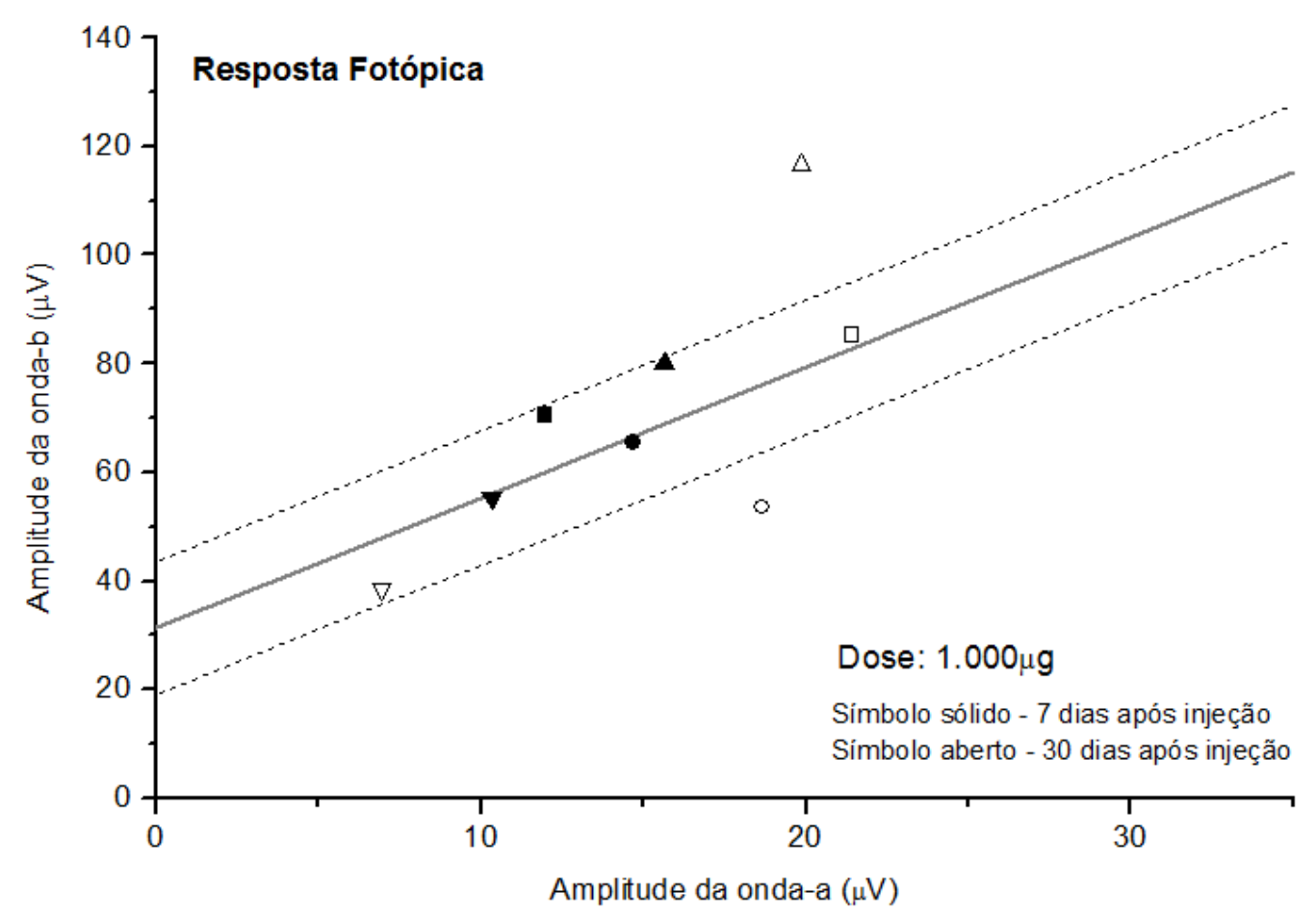

Figura 41: Relação de amplitude de onda b/onda a na condição fotópica. Cada símbolo representa o registro obtido em um olho. A linha cinza representa a curva de regressão linear e a linha tracejada representa a curva $\pm \mathrm{dp}$.

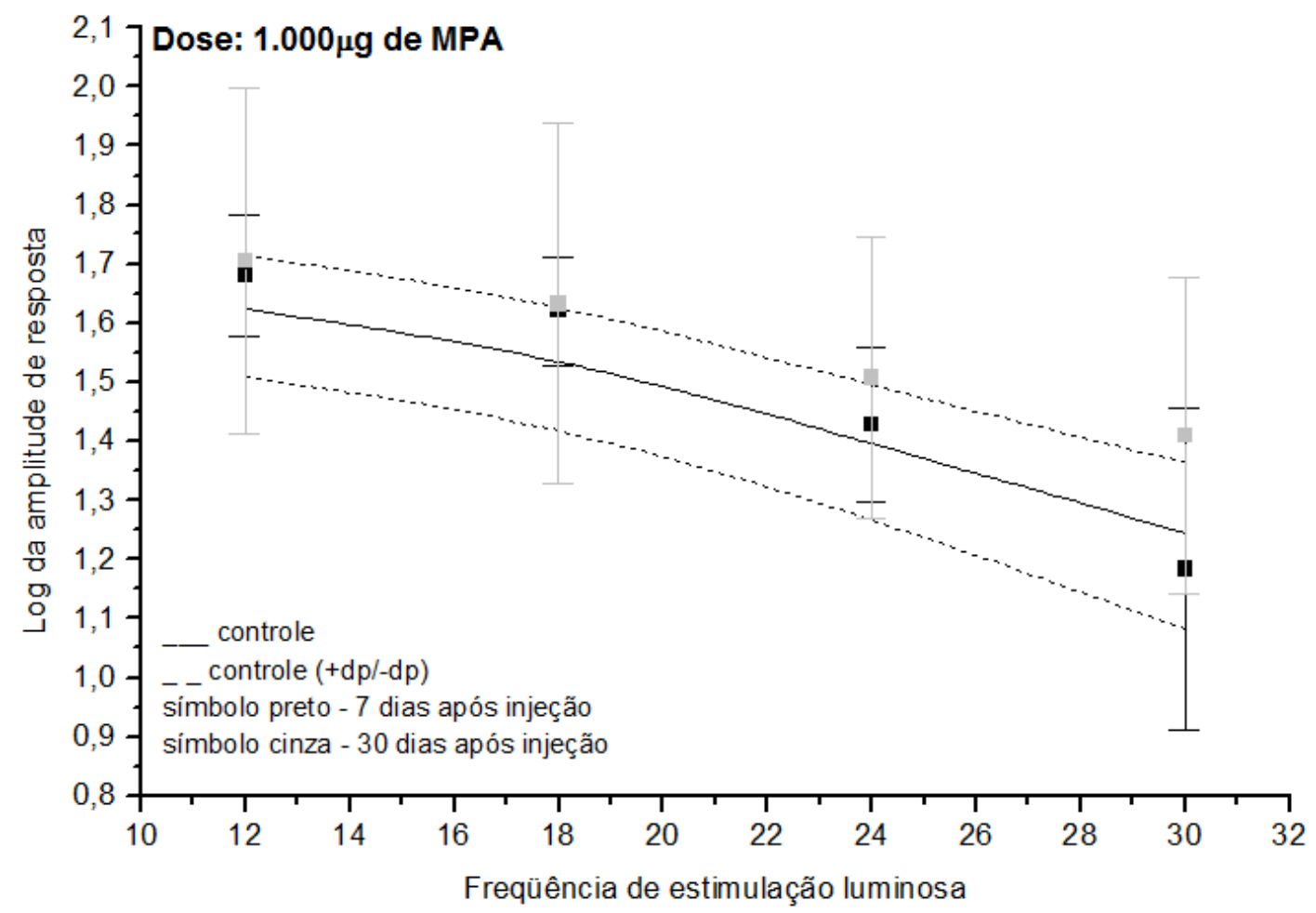

Figura 42: Relação frequência de estimulação luminosa e amplitude de resposta. Cada símbolo representa o registro obtido em um olho. A linha cinza representa a média e a linha tracejada representa a média \pm dp. 


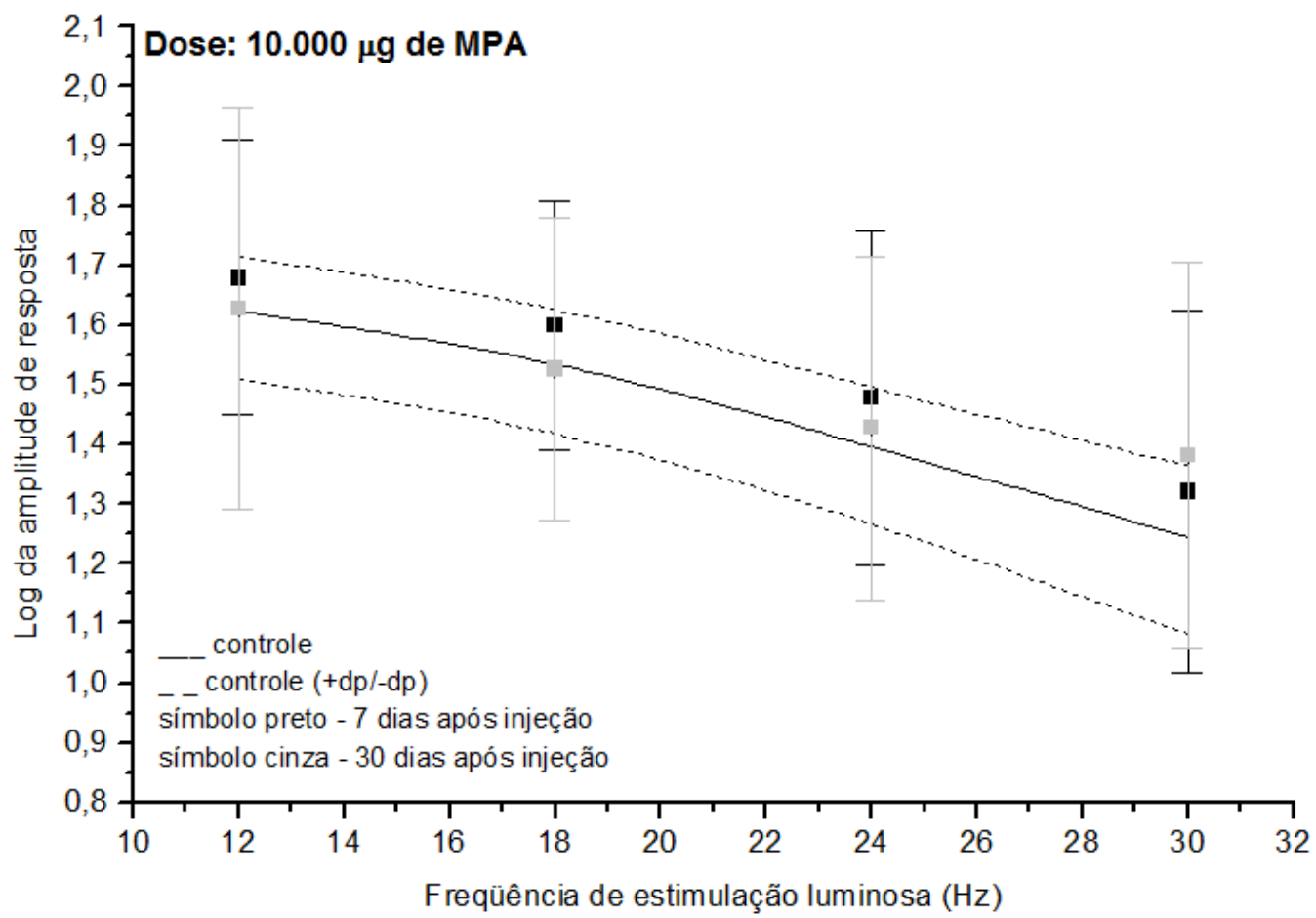

Figura 43: Relação frequência de estimulação luminosa e amplitude de resposta. Cada símbolo representa o registro obtido em um olho. A linha cinza representa a média e a linha tracejada representa a média \pm dp.

As tabelas 8 e 9 mostram as médias das latências dos olhos administrados com as duas maiores doses da droga. Houve aumento de $1 \%$ no tempo de respostas de onda $b$ fotópica na dose de $1.000 \mu \mathrm{g}$. As latências de onda b escotópica máxima apresentaram redução em todas as doses. Porém, foram discretas e a maior redução foi de $13 \%$ (dose de $1.000 \mu \mathrm{g}$ ). A dose de $10.000 \mu \mathrm{g}$ apresentou redução de $8 \%$ no tempo implícito da onda b escotópica máxima. 
Tabela 8: Comparação das latências das respostas das ondas a e b do grupo controle com o grupo pósinjeção de MPA $(1.000 \mu \mathrm{g})$. Os valores máximos e mínimos do grupo controle são as médias + dp e -dp. Valores em vermelho e verde representam latências abaixo do mínimo e do máximo, respectivamente.

\begin{tabular}{|c|c|c|c|c|c|c|c|}
\hline \multirow{2}{*}{\multicolumn{2}{|c|}{ LATÊNCIA (ms) }} & \multicolumn{3}{|c|}{ onda-a } & \multicolumn{3}{|c|}{ onda- $b$} \\
\hline & & M IÍNINO & MÁXIMO & MÉDIA & MÍNINO & MÁXIMO & MÉDIA \\
\hline \multirow{4}{*}{$\begin{array}{l}\text { PRÉ-INJEÇÃO } \\
\text { (CONTROLE) }\end{array}$} & $\begin{array}{l}\text { Resposta Escotópica } \\
=3 \mathrm{~cd} / \mathrm{m}^{2}\end{array}$ & & & & 42,23 & 58,41 & $50,32( \pm 8,09)$ \\
\hline & $\begin{array}{l}\text { Res posta Esc. Máxima } \\
=30 \mathrm{~cd} / \mathrm{m}^{2}\end{array}$ & 14,99 & 18,17 & $16,58( \pm 1,59)$ & 45,49 & 61,77 & $53,63( \pm 8,14)$ \\
\hline & \begin{tabular}{l|l} 
Res posta Fotópica \\
$=78 \mathrm{~cd} / \mathrm{m} 2(\mathrm{BG}=15 \mathrm{~cd} / \mathrm{m} 2)$
\end{tabular} & 9,98 & 14,94 & $12,46( \pm 2,48)$ & 31,12 & 34,48 & $32,80( \pm 1,68)$ \\
\hline & & \multicolumn{3}{|c|}{ MÉDIA } & \multicolumn{3}{|c|}{ MÉDIA } \\
\hline \multirow{3}{*}{$\begin{array}{c}\text { OD (MPA) } \\
\text { (Dose }=1.000 \mu \mathrm{g})\end{array}$} & $\begin{array}{l}\text { Res posta Es cotópica } \\
=3 \mathrm{~cd} / \mathrm{m}^{2}\end{array}$ & & & & \multicolumn{3}{|c|}{$43,09( \pm 4,3)$} \\
\hline & $\begin{array}{l}\text { Resposta Esc. Máxima } \\
=30 \mathrm{~cd} / \mathrm{m}^{2}\end{array}$ & \multicolumn{3}{|c|}{$15,60( \pm 1,2)$} & \multicolumn{3}{|c|}{$39,21( \pm 4,3)$} \\
\hline & \begin{tabular}{l|l} 
Res posta Fotópica \\
$=78 \mathrm{~cd} / \mathrm{m} 2(\mathrm{BG}=15 \mathrm{~cd} / \mathrm{m} 2)$
\end{tabular} & \multicolumn{3}{|c|}{$10,84( \pm 4,8)$} & \multicolumn{3}{|c|}{$35,10( \pm 3,3)$} \\
\hline
\end{tabular}

Tabela 9: Comparação das latências das respostas das ondas a e b do grupo controle com o grupo pósinjeção de MPA $(10.000 \mu \mathrm{g})$. Os valores máximos e mínimos do grupo controle são as médias +dp e -dp. Valores em vermelho e verde representam latências abaixo do mínimo e do máximo, respectivamente.

\begin{tabular}{|c|c|c|c|c|c|c|c|}
\hline \multirow{2}{*}{\multicolumn{2}{|c|}{ LATÊNCIA (ms) }} & \multicolumn{3}{|c|}{ onda-a } & \multicolumn{3}{|c|}{ onda- $b$} \\
\hline & & MÍNINO & MÁXIMO & MÉDIA & MÍNINO & MÁXIMO & MÉDIA \\
\hline \multirow{4}{*}{$\begin{array}{l}\text { PRÉ-INJEÇÃO } \\
\text { (CONTROLE) }\end{array}$} & $\begin{array}{l}\text { Resposta Es cotópica } \\
=3 \mathrm{~cd} / \mathrm{m}^{2}\end{array}$ & & & & 42,23 & 58,41 & $50,32( \pm 8,09)$ \\
\hline & $\begin{array}{l}\text { Resposta Esc. Máxima } \\
=30 \mathrm{~cd} / \mathrm{m}^{2}\end{array}$ & 14,99 & 18,17 & $16,58( \pm 1,59)$ & 45,49 & 61,77 & $53,63( \pm 8,14)$ \\
\hline & \begin{tabular}{l||l} 
Resposta Fotópica \\
$=78 \mathrm{~cd} / \mathrm{m} 2(\mathrm{BG}=15 \mathrm{~cd} / \mathrm{m} 2)$
\end{tabular} & 9,98 & 14,94 & $12,46( \pm 2,48)$ & 31,12 & 34,48 & $32,80( \pm 1,68)$ \\
\hline & & \multicolumn{3}{|c|}{ MÉDIA } & \multicolumn{3}{|c|}{ MÉDIA } \\
\hline \multirow{3}{*}{$\begin{array}{c}\text { OD (MPA) } \\
(\text { Dose }=10.000 \mu \mathrm{g})\end{array}$} & \begin{tabular}{||l} 
Resposta Es cotópica \\
$=3 \mathrm{~cd} / \mathrm{m}^{2}$
\end{tabular} & & & & \multicolumn{3}{|c|}{$40,3( \pm 1,5)$} \\
\hline & \begin{tabular}{l||l} 
Resposta Esc. Máxima \\
$=30 \mathrm{~cd} / \mathrm{m}^{2}$
\end{tabular} & \multicolumn{3}{|c|}{$15,8( \pm 1,7)$} & \multicolumn{3}{|c|}{$41,8( \pm 7,2)$} \\
\hline & \begin{tabular}{l||l} 
Resposta Fotópica \\
$=78 \mathrm{~cd} / \mathrm{m} 2(\mathrm{BG}=15 \mathrm{~cd} / \mathrm{m} 2)$
\end{tabular} & \multicolumn{3}{|c|}{$11,8( \pm 6,9)$} & \multicolumn{3}{|c|}{$34,5( \pm 3,1)$} \\
\hline
\end{tabular}




\section{Discussão}

Os resultados deste estudo sugerem que o veículo Polissorbato não apresenta toxicidade para o tecido retiniano. As doses até $200 \mu \mathrm{g}$ podem ser considerada seguras para administração intravítrea de MPA em coelhos. Olhos injetados com doses de 1.000 e $10.000 \mu \mathrm{g}$ apresentaram diminuição de sensibilidade à luz, o que pode ser um indicativo de toxicidade para as células da retina.

A principal variabilidade encontrada neste estudo ocorreu em condições de flash com baixa intensidade, nas quais a onda a é indetectável no ERG. Talvez esse tenha sido o motivo para a variabilidade encontrada, uma vez que, com flashes de intensidade maiores, os resultados foram muito consistentes e reprodutíveis.

$\mathrm{Na}$ análise do veículo, no presente estudo, foi constatado apenas um valor de média de latência fora dos padrões, a de onda b (escotópica máxima Tabela 4), e as curvas $\log$ da amplitude da onda $\mathrm{b}$ x $\log$ da intensidade do flash apresentaram-se dentro dos parâmetros. Portanto, nesse estudo, a administração do veículo não apresentou toxicidade para os tecidos retinianos.

O eletrorretinograma é uma resposta de massa da retina, que resulta em uma onda complexa. Apesar de refletir a atividade somada de diferentes componentes retinianos, é possível separar suas contribuições. Uma abordagem para analisar a função da retina in vivo, é verificar a relação entre as amplitudes da onda b e da onda a ou razão b/a. Como a maior contribuição para a onda a é de fotorreceptores e para a onda $\mathrm{b}$ é de células bipolares centro-ON, a dependência da onda b em relação à onda a reflete a integridade funcional dos fotorreceptores, das células bipolares centro-ON e a transmissão do sinal entre esses dois tipos celulares (Perlman, 2009).

A figura 45 ilustra esse tipo de análise, mostrando as respostas de ratos albinos 
expostos durante $24 \mathrm{~h}$ seguidas a luz branca intensa (direita) e coelhos albinos tratados com doses intravítreas de corticosteróide (Kenalog) (esquerda). Para os ratos expostos à luz intensa, as amplitudes da resposta escotópica estavam severamente reduzidas 30 dias após a exposição. Entretanto, a relação da onda b com a onda a aparece próxima ao normal, sugerindo que o maior dano ocorreu nos fotorreceptores.

Em contraste, o Kenalog intravítreo causou maior diminuição da onda b. Para uma dada amplitude de onda a, no grupo experimental, pode ser observada uma onda $b$ reduzida em relação ao controle, sugerindo que houve ação tóxica nas células bipolares centro-ON e/ou na transmissão sináptica entre os fotorreceptores e a células bipolares (Perlman, 2009) (Figura 44).

Não houve nenhuma dose do presente trabalho em que a as respostas dos gráficos onda b/onda a aparecessem deslocadas com relação aos controles. Portanto, não é possível dizer que, nesse tipo de análise, tenha ocorrido algum sinal de toxicidade para os fotorreceptores ou células bipolares centro-ON.
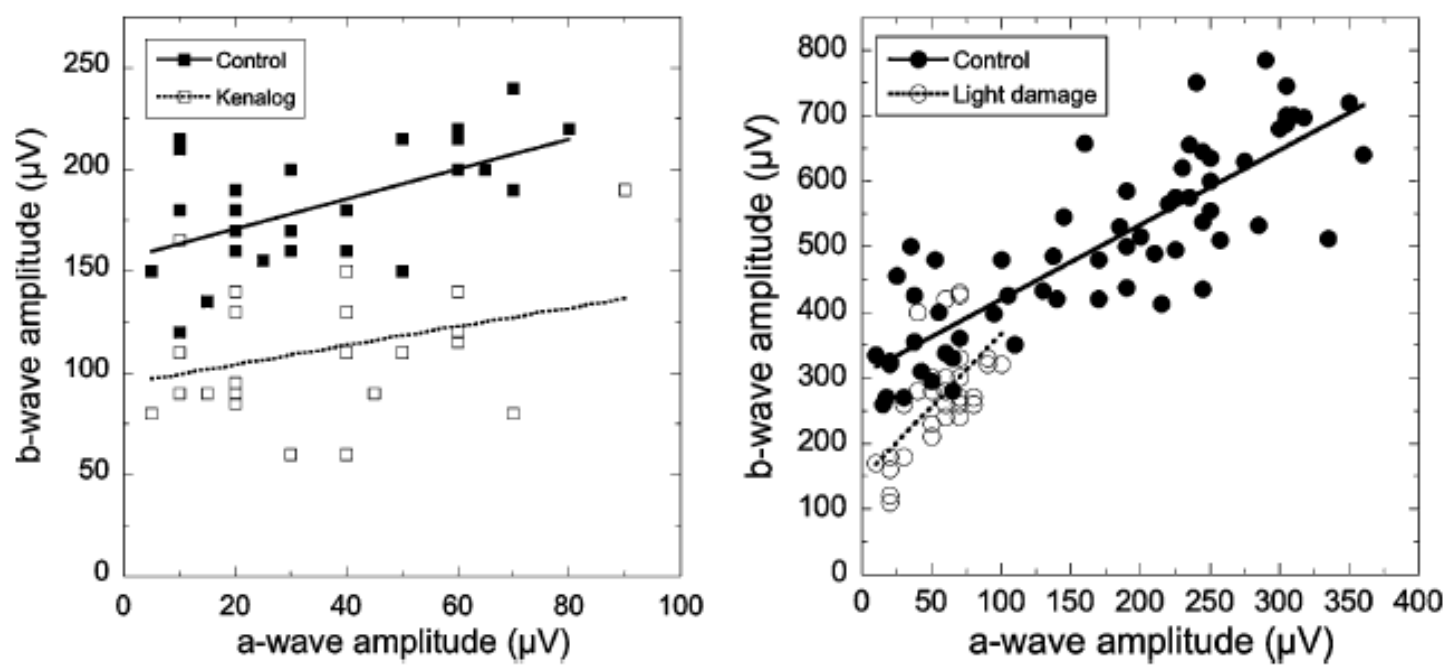

Figura 44: Relação amplitude de onda b/onda a dos controles comparados a dois grupos: um tratado com Kenalog e o outro exposto a luz intensa. (Perlman, 2009) 
Para os valores de latência, ocorreu redução de valores de onda b escotópica máxima em todas as medições de olhos administrados com a droga. Segundo GUARINO et. al., 2004, os resultados mostram que a escopolamina pode alterar não só a amplitude, mas também e especificamente a latência de respostas elétricas, então é sugerido pelos autores que drogas antimuscarínicas como Mydriacyl@ (Tropicamida $1 \%$ ) durante experimentos neurofisiológicos podem induzir variações nas respostas da retina (Fig.45).

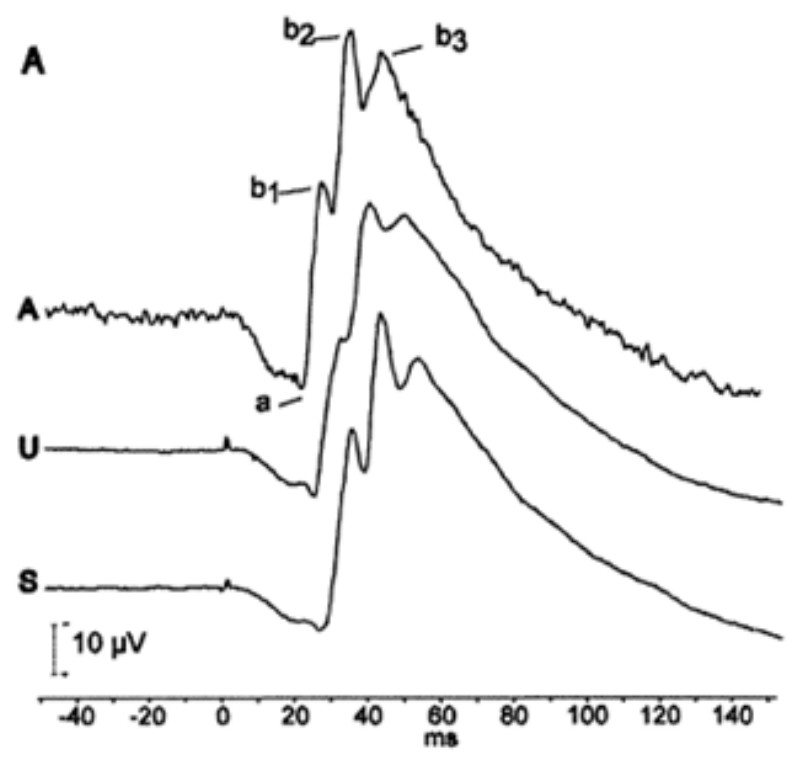

Figura 45: Exemplo de registro de ERG em ratos em três diferentes condições: acordado (A), anestesiado (U) e tratado com escopolamina (S). (GUARINO et. al., 2004).

A grande diversidade de métodos existentes na literatura afeta a comparação dos resultados de ERG em coelhos. A gama de combinações entre diferentes tipos de eletrodos, protocolos anestésicos, intensidades luminosas e tempo para adaptação ao escuro torna difícil a comparação dos estudos (Gjörloff et. al., 2004). Por isso, a primeira etapa, que tinha o objetivo de validar os métodos e obter resultados para 
comparações entre os grupos, aparece detalhada neste estudo.

A necessidade de utilização de anestésicos para realização do exame eletrorretinográfico em animais pode gerar alguns equívocos na análise dos dados, pois como as substâncias anestésicas podem afetar a neurotransmissão, também podem afetar os resultados do ERG. (Chaudhary et. al., 2003; Tremblay et. al., 2003). Não é possível descartar a hipótese de que as pequenas alterações encontradas nos dados desse trabalho possam ser causadas por efeitos de anestésicos.

No entanto, neste estudo todos os animais receberam doses muito parecidas de anestésico e as variações do ERG nos olhos sem manipulação foram insignificantes estatisticamente, sugerindo que esse não tenha sido um fator importante de interferência nos resultados.

Neste estudo ocorreram algumas variações em registros de ERG e isso é um achado comum na literatura (Mackiewicz et. al., 2007), como mostra a Figura 46. Podese notar os altos valores de desvio padrão em situação pré-operatória e é possível notar uma grande variação de amplitude nas respostas de diferentes olhos, o que corrobora os dados obtidos no presente estudo.

Esse fato demonstra que diferenças nos valores de registro podem ocorrer entre os coelhos e também com o mesmo olho em diferentes situações, tanto para olhos tratados com Polissorbato 80 quanto para olhos que receberam administração de Ácido Micofenólico (MPA). 


\begin{tabular}{|c|c|c|c|c|c|c|}
\hline & \multicolumn{4}{|c|}{ ISCEV Standard Light Stimulus } & \multicolumn{2}{|c|}{ Scotopic Stimulus $(-24 \mathrm{~dB})$} \\
\hline & $\begin{array}{c}\text { a-Wave } \\
\text { Amplitude }(\mu v)\end{array}$ & $\begin{array}{c}\text { a-Wave } \\
\text { Latency (ms) }\end{array}$ & $\begin{array}{c}\text { b-Wave } \\
\text { Amplitude }(\mu v)\end{array}$ & $\begin{array}{c}\text { b-Wave } \\
\text { Latency (ms) }\end{array}$ & $\begin{array}{c}\text { b-Wave } \\
\text { Amplitude }(\mu v)\end{array}$ & $\begin{array}{c}\text { b-Wave } \\
\text { Latency (ms) }\end{array}$ \\
\hline \multicolumn{7}{|l|}{ Silicone oil 1000} \\
\hline Preoperative & $108.60 \pm 44.70$ & $29.00 \pm 2.54$ & $304.60 \pm 83.25$ & $52.20 \pm 3.56$ & $142.20 \pm 36.56$ & $59.00 \pm 8.54$ \\
\hline $1 \mathrm{mo}$ & $156.80 \pm 77.18$ & $28.00 \pm 1.87$ & $456.20 \pm 113.16$ & $51.00 \pm 2.24$ & $154.80 \pm 35.97$ & $63.40 \pm 1.52$ \\
\hline $3 \mathrm{mo}$ & $137.80 \pm 59.33$ & $29.00 \pm 1.41$ & $391.40 \pm 144.08$ & $50.60 \pm 1.34$ & $175.00 \pm 49.45$ & $69.60 \pm 6.43$ \\
\hline \multicolumn{7}{|l|}{ Densiron 68} \\
\hline Preoperative & $116.00 \pm 74.21$ & $27.60 \pm 4.33$ & $336.00 \pm 109.05$ & $51.00 \pm 4.24$ & $177.20 \pm 75.33$ & $58.80 \pm 7.98$ \\
\hline $1 \mathrm{mo}$ & $145.00 \pm 83.79$ & $27.80 \pm 1.64$ & $473.00 \pm 156.31$ & $50.20 \pm 1.79$ & $208.00 \pm 112.08$ & $63.80 \pm 5.36$ \\
\hline $3 \mathrm{mo}$ & $94.80 \pm 22.57$ & $29.80 \pm 0.45$ & $384.00 \pm 42.57$ & $51.60 \pm 4.82$ & $225.00 \pm 58.09$ & $68.40 \pm 5.03$ \\
\hline \multicolumn{7}{|l|}{ Silicone oil 3000} \\
\hline Preoperative & $239.00 \pm 197.64$ & $32.40 \pm 2.96$ & $423.60 \pm 247.31$ & $52.20 \pm 7.29$ & $166.60 \pm 43.09$ & $56.20 \pm 8.41$ \\
\hline $1 \mathrm{mo}$ & $124.60 \pm 57.64$ & $28.20 \pm 2.17$ & $403.60 \pm 139.16$ & $50.80 \pm 2.49$ & $202.80 \pm 87.07$ & $68.00 \pm 5.15$ \\
\hline $3 \mathrm{mo}$ & $145.00 \pm 88.88$ & $27.80 \pm 2.39$ & $394.00 \pm 130.40$ & $48.60 \pm 3.36$ & $174.00 \pm 30.22$ & $67.20 \pm 3.96$ \\
\hline
\end{tabular}

Figura 46: Resultados e desvio padrão de amplitudes e latências sob diferentes estímulos. (MACKIEWICZ et. al., 2007).

Não é possível afirmar que as células da retina não foram danificadas pela injeção intravítrea de MPA, pois o ERG de campo total não detecta lesões pontuais. No trabalho de Zemel et. al. (1995) foi constatado que a lidocaína, injetada intravitrealmente, não afeta as resposta de ERG escotópico ou fotópico do coelho albino, quando os registros foram feitos uma semana após a injeção. No entanto, quando a estrutura da retina foi examinada no microscópio de luz, foi evidente um dano estrutural severo no olho experimental, perto do local da injeção. A lidocaína é tóxica para a retina de coelhos, mas seus efeitos são localizados e por isso não são evidenciados no ERG de campo total.

Algumas limitações deste estudo devem ser consideradas, como as diferenças entre o olho humano e o olho de coelhos. Os olhos de coelhos têm aproximadamente um terço do volume do olho humano e, portanto, as concentrações seguras de MPA para injeção intravítrea em humanos precisam ser estabelecidas baseadas nos achados do presente estudo. Outra limitação deste estudo é o pequeno numero de animais em cada grupo.

Outro ponto que deve ser especulado é o pequeno número de olhos analisados, que pode levar a interpretações equivocadas dos resultados, devido ao número limitado 
de dados. Como este é um estudo inédito, não era possível prever o grau de toxicidade de cada dose de MPA e, por esse motivo, foi necessário estudar várias concentrações da droga para aumentar a chance de determinar as doses seguras e as tóxicas. Isso limitou o número de indivíduos por grupo.

Além desse fato, é necessário citar a limitação do equipamento em si, que permitia apenas registro monocular. Normalmente, os registros de ERG são feitos nos dois olhos ao mesmo tempo (Loewenstein A., et al., 1993) para estabelecer, com menor risco de alterações, o controle de cada animal. As medições, neste trabalho, foram realizadas primeiramente nos olhos direitos dos indivíduos, e em um diferente momento, nos olhos esquerdos.

No entanto, as análises dos resultados de amplitude e tempo implícito das ondas a e b do ERG foram muito consistentes e apresentaram variações aceitáveis, o que valoriza os resultados encontrados. 


\section{Conclusão}

- O veículo utilizado na preparação da solução de MPA (polissorbato 80) não apresenta toxicidade para as células da retina de coelhos New Zealand na concentração usada na diluição da droga.

- Doses de até $200 \mu \mathrm{g}$ de MPA podem ser utilizadas em olhos de coelhos New Zealand sem produzir alterações eletrorretinográficas.

- Análises adicionais deverão ser realizadas para estabelecer se as doses acima de $200 \mu \mathrm{g}$ são seguras para administração intravítrea. 


\section{Referências Bibliográficas}

Adams, E., Todd, G., Gibson, W. (1975). Long-term Toxicity Study of Mycophenolic Acid in Rabbits. Toxicol. Appl. Pharmacol., 34:509-512;

Aiello LP, Brucker AJ, Chang S, Cunningham ET Jr, D'Amico DJ, Flynn HW Jr, (2004). Evolving guidelines for intravitreous injections. Retina.; 24(Suppl 5):S3-19. Review;

Allison A. C. and Eugui E. M. (2000) Mycophenolate mofetil and its mechanisms of action. Immunopharmacology, 47:85-118;

Allison AC, Kowalski WJ, Muller CJ, Waters RV, Eugui EM. (1993) Mycophenolic acid and brequinar, inhibitors of purine and pyrimidine synthesis, block the glycosylation of adhesion molecules. Transplant Proc.;25(3 Suppl 2):67-70;

Allison AC, Eugui EM. (1990) Immunosuppressive and other effects of mycophenolic acid and an ester prodrug, mycophenolate mofetil. Immunol Rev.;136:528 ;

Allison, A.C. (1996). Purine metabolism and immunossuppressive effects of MMF, Clin Transplant., 10:77-84).

Ames, A. and Nesbett, F. B (1981). In Vitro Retina as an Experimental Model of the Central Nervous System. Journal of Neurochemistry 37(4):867-877;

Armstrong VW, Tenderich G, Shipkova M, Parsa A, Koerfer R, Schroder H, Oellerich M (2005). Pharmacokinetics and bioavailability of mycophenolic acid after intravenous administration and oral administration of mycophenolate mofetil to heart transplant recipients. Ther Drug Monit.;27:315-21 
Asi, H. \& Perlman, I. (1992). The relationships between the ERG a-wave, bwave and oscillatory potentials and their application to clinical diagnosis. Documenta Ophthalmologica 79:125-139;

Baltatzis S., Tufail F., Yu E. N., Vredeveld C. M., Foster C.S. (2003). Mycophenolate mofetil as an immunomodulatory agent in the treatment of chronic ocular inflammatory disorders. Ophthalmology, 110:1061-1065;

Bekchanov, A.N. (1970), Histological investigation of the rabbit retina, Bulletin of experimental biology and medicine, vol., 69(3): 343-344;

Bill A, Stjernschantz J. (1980). Cholinergic vasoconstrictor effects in the rabbit eye: vasomotor effects of pentobarbital anesthesia. Acta Physiol Scand. 108(4):419-24;

Bill A. Proceedings: Physiology and pharmacology of ocular circulation (1973). Exp Eye Res. 5;17(4):387;

Bloch -Michel E, Nussenblatt RB. (1987) International Uveitis Study Group recommendations for the evaluation of intraocular inflammatory disease. Am $\mathbf{J}$ Ophthalmol;103:234-235;

Brindley, G.S. (1956) The passive electrical properties of the frog's retina, choroid and sclera for radial fields and currents. Journal of Physiology , 134:339-352;

Brindley, G.S. and Hamasaki, D.I. (1963) The properties and nature of the R membrane of the frog's eye. Journal of Physiology , 167:599-60;

Brown, K. T. \& Murakami, M. (1964a). A new receptor potential of the monkey retina with no detectable latency. Nature 201, 626;

Brown, K. T. \& Wiesel, T. N. (1961a). Analysis of the intraretinal electroretinogram in the intact cat eye. Journal of Physiology , 158:229-256; 
Brown, K. T. \& Wiesel, T. N. (1961b). Localization of origins of electroretinogram components by intraretinal recording in the intact cat eye. Journal of Physiology , 158: 257-280;

Brown, K. T. (1968). The electroretinogram: its components and their origin. Vision Research 8, 633;

Byzov, A.L. (1968) Localization of the R-membrane in the frog eye by means of an electrode marking method. Vision Research, 8:697-700;

Chalupa, L. M. \& Werner J. S. (2004)Visual Neuroscience (vol.1).The MIT press Cambridge, Massachusetts.

Chaudhary V, Hansen R, Lindgren H, Fulton A (2003). Effects of telazol and nembutal on retinal responses. Doc Ophthalmol. 107(1):45-51;

Chen J., Fujino Y. and Takahash T. (1999) Experimental Uveitis Induced by Intravitreal or Intravenous Lipoteichoic Acid in Rabbits. Jpn J Ophthalmol, 43:368374 ;

Chiu K, Chang RC, So KF (2007). Intravitreous injection for establishing ocular diseases model.. J. Vis. Exp. 313(8);

Colotto A, Falsini B, Salgarello T, Iarossi G, Galan ME, Scullica L. (2000) Photopic negative response of the human ERG: losses associated with glaucomatous damage.Invest Ophthalmol Vis Sci.;41:2205-11. 21;

Conner J. D. and Macleod D. I. A.(1977) Rod photoreceptors detect rapid flicker. Scince, N.Y. 195: 698-699;

Creel, D. (2010). The Electroretinogram: Clinical Applications In: Webvision: The organization of the retina and visual sistem;

Darrell RW, Wagener HP, Kurland LT. (1962) Epidemiology of uveitis. Incidence and prevalence in a small urban community. Arch Ophthalmol.;68:502-14; 
Deschenes J, Murray PI, Rao NA, Nussenblatt RB. (2008) International Uveitis Study Group. International Uveitis Study Group (IUSG): clinical classification of uveitis. Ocul Immunol Inflamm;16:1-2;

Díaz-Llopis M, Gallego-Pinazo R, García-Delpech S, Salom-Alonso D (2009). General principles for the treatment of non-infectious uveitis.Inflamm Allergy Drug Targets. 8(4):260-5;

Doycheva, D., Deuter, C., Stuebiger, N., Biester, S., Zierhut, M. (2007) Mycophenolate mofetil in the treatment of uveitis in children Br J. Ophthalmol;91:180184.

Fagundes D. J. and Taha M. O. (2004). Animal disease model: choice’s criteria and current animals specimens. Acta Cir. Bras., 19 (no.1);

Gjörloff K., Andreásson S., Ehinger B. (2004). Standardized full-field electroretinography in rabbits. Documenta Ophthalmologica, 109:163-168;

Gouras P. (1970). Electroretinography: Some basic principles. Investigative Ophthalmology, 9(8):557-569;

Gouras P. (1970). Electroretinography: Some basic principles. Investigative Ophthalmology, 9(8):557-569;

Gouveia EB, Abdalla M, Yamamoto JH, Hirata CE, Kubo P, Olivalves E. (2004) Causas das uveítes em serviço terciário em Säo Paulo, Brasil. Arq Bras Oftalmol;67:139-45;

Granit R. (1933). The Components of the Retinal Action Potential in Mammals and Their Relation to the Discharge in the Optic Nerve.

Gualtieri, M (2009). Avaliação funcional da visão de pacientes diabéticos em estados pré e pós retinopatia diabética, Tese de Doutorado, USP/NEUROCIÊNCIAS E COMPORTAMENTO, São Paulo; 
Gurevich, L. \& Slaughter, M. M. (1993). Comparison of the waveforms of the ON bipolar neuron and the b-wave of the electroretinogram. Vision Research 33, 24312435

Harazny J, Scholz M, Buder T, Lausen B, Kremers J (2009). Electrophysiological deficits in the retina of the DBA/2J mouse. Doc Ophthalmol. 119(3):181-97;

Helga Kolb, webvision, http://webvision.med.utah.edu/book The Organization of the Retina and Visual System, Simple Anatomy of the Retina)

Helm C. J , Holland G. N. (1993). Ocular tuberculosis. Surv Ophthalmol., 38:229-56;

Heynen, H., Wachtmeister, L. \& van Norren, D. (1985). Origin of the oscillatory potentials in the primate retina. Vision Research 25:1365-1373;

Hoeve, JNV., Kim, CB., Nork, TM., Christian, BJ., Murphy, CJ. (2011), Interocular And Inter-subject Variability In The Full-field Electroretinograms Of Rabbits And Monkeys, ARVO.

Holland GH, Stiehm ER. (2003) Special considerations in the evaluation and management of uveitis in children. Am J Ophthalmol;135:867-78.

Inada E T, (Watanabe K P, Tanaka S G, Sakakisbara L A. (2005) Ocular toxicity caused by chloroquine: case report. Arq Bras Oftalmol. 68(3):407-9;

International Uveitis Study Group (IUSG);

Jabs DA, Rosenbaum JT, Foster CS, et al. (2000). Guidelines for the use of immunosuppressive drugs in patients with intraocular inflammatory disorders: recommendations of an expert panel. Am J Ophthalmol;130:492-513 
Jager RD, Aiello LP, Patel SC, Cunningham ET (2004). Risks of intravitreous injection: a comprehensive review. Retina; 24:676-98;

Jabs DA, Nussenblatt RB, Rosenbaum JT. (2005) Standardization of Uveitis Nomenclature (SUN) Working Group. Standardization of uveitis nomenclature for reporting clinical data. Results of the First International Workshop. Am J Ophthalmol;140:509-516;

Jaissle GB, Szurman P, Bartz-Schmidt KU (2005). [Recommendation for the implementation of intravitreal injections - statement of the German Retina Society, the German Society of Ophthalmology (DOG) and the German Professional Association of Ophthalmologists (BVA)]. Klin Monatsbl Augenheilkd.;222(5):390-5;

Imai K, Loewenstein A, Koroma B, Grebe R, de Juan Jr. E (2000) Herbimycin A in the treatment of experimental proliferative vitreoretinopathy: toxicity an efficacy study. Graefe's Arch Clin Exp Ophthalmol, 238:440-447;

Kilmartin D. J., Forrester J. V., Dick A. D. (1998). Rescue therapy with mycophenolate mofetil in refractory uveitis. Lancet., 352:35-6;

Krishna VA, Alexander KR, Peachey NS. Temporal properties of the mouse cone electroretinogram. Journal of Neurophysiology. 2002;87:42-48;

Kwok A. K. H., Lai T. Y. Y., Yeung C. K., Yeung Y. S., Li W. W. Y. and Chiang S. W. (2005). The effects of indocyanine green and endoillumination on rabbit retina: an electroretinographic and histological study. Br J Ophthalmol, 89:897-900;

Larkin G., Lightman S. (1999) Mycophenolate Mofetil A Useful Immunosuppressive in Inflammatory Eye Disease Ophthalmology. 106(2): 370-374;

Lent, R. (coord.) 2008. Neurociência da mente e do comportamento, cap. 7, pag 139, Rio de Janeiro: Guanabara-Koogan; 
Machida S, Gotoh Y, Tanaka M, Tazawa Y. (2004) Predominant loss of the photopic negative response in central retinal artery occlusion.Am $\mathbf{J}$ Ophthalmol.;137:938-40;

Mackiewicz J, Muhling B, Hiebl W, Meinert H, Maaijwee K, Kociok N, Luke C, Zagorski Z, Kirchhof B, Joussen AM (2007) In vivo retinal tolerance of various heavy silicone oils. Invest Ophthalmol Vis Sci. 48(4):1873-83;

Malmivuo J. and Plonsey R. (1995). Bioelectromagnetism: Principles and Applications of Bioelectric and Biomagnetic, Chapter 28- OXFORD UNIVERSITY PRESS, Eye New York;

Marmor MF, Fulton AB, Holder GE, Miyake Y, Brigell M, Bach M. Standard for clinical electroretinography (2008 update). Doc Ophthalmol 2009;118:69-77;

Mo J. S., Matsukawa A., Ohkawara S. and Yoshinaga M. (1998) Involvement of TNF $\alpha$ IL-1 $\beta$ and IL-1 receptor antagonist in LPS-induced rabbit uveitis. Exp. Eye Res., $66: 547-557$

Morris RE, Hoyt EG, Murphy MP, Eugui EM, Allison AC. (1990) Mycophenolic acid morpholinoethylester (RS-61443) is a new immunosuppressant that prevents and halts heart allograft rejection by selective inhibition of $\mathrm{T}$ - and $\mathrm{B}$-cell purine synthesis. Transplant Proc.; 22:1659-62;

Murakami, M. \& Kaneko, A. (1966). Subcomponents of P3 in cold-blooded vertebrate retinae. Nature 210:103-104;

Nussenblat, RB. (1990). The natural history of uveitis. Int Ophthalmol.;14:3038

Suttorp-Schulten MS, Rothova A. (1996) The possible impact of uveitis in blindness: a literature survey. Br J Ophthalmol.;80:844-8; 
Ogden, T.E. and Ito, H. (1971) Avian retina. II. An evaluation of retinal electrical anisotropy. Journal of Neurophysiology, 34:367-373;

Ogden, T. E. (1973). The oscillatory waves of the primate electroretinogram. Vision Research 13:1059-1074;

Perlman, I. (1983). Relationship between the amplitudes of the b wave and the a wave as a useful index for evaluating the electroretinogram. British Journal of Ophthalmology, 67: 443-448;

Perlman, I. (2009). Testing retinal toxicity of drugs in animal models using electrophysiological and morphological techniques. Doc. Ophthalmol, 118:3-28;

Perlman, I. (2010). The Electroretinogram: ERG. In: Webvision: The organization of the retina and visual system;

Peyman, G.A., Lad, E. M., Moshfeghi, D. M. (2009). Intravitreal Injection of Therapeutic Agents, Retina 29:875-912;

Prow, T. W. (2010). Toxicity of nanomaterials to the eye. Nanomed Nanobiotechnol, 2:317-333;

Rodrigues, E.B., Maia, M., Penha, F.M., Dib, E., Bordon. A.F., Magalhães , O. Jr., Farah, M. E. (2008). Técnica para injeção intravítrea de drogas no tratamento de doenças vítreorretinianas. Arq. Bras. Oftalmol. 71 (6);

Schechner R, Gdalon M, Cohen F, Meyer E, Zonis and I. Perlmani . (1987) Recovery of the Elecfroretinogrom in Rabbits After Argon Laser Photocoagulation Invest Ophthalmol Vis Sci, 28:1605-1613;

Scott, I.U., Flynn, Jr H.W . Intravitreal Injections: Guidelines to Minimize the Risk of Endophthalmitis,., General Concepts in the Diagnosis and Treatment of Retinal Vascular Disease; 
Siepmann K., Huber M., Stubiger N., Deuter C., Zierhut M. (2006). Mycophenolate mofetil is a highly effective and safe immunosuppressive agent for the treatment of uveitis A retrospective analysis of 106 patients. Graefe's Archive for Clinical and Experimental Ophthalmology, 244: 788 - 794;

Sillman, A. J., Ito, H. \& Tomita, T. (1969a). Studies on the mass receptor potential of the isolated frog retina. I. General properties of the response. Vision Research 9:1435-1442;

Sollinger H. W. (2004)Mycophenolates in transplantation. Clin Transplant., 18: 485-492;

SILV, A. M. (1997). Changing trends in the etiologic diagnosis of uveitis, Documenta Ophthalmologica, 94: 25-37,).

Tano Y, Sugita G, Abrams G, Machemer R. (1980). Inhibition of intraocular proliferations with intravitreal corticosteroids. Am J Ophthalmol. Jan;89(1):131-6;

Terumi, E I, Watanabe, K P, Tanaka, S G, Sakakisbara, L A. (2005). Ocular toxicity caused by chloroquine: case report. Arq Bras Oftalmol., 68(3):407-9;

Thorne J. E., Jabs D. A.,Qazi F. A., Nguyen Q. D., Kempen J. H., Dunn J. P. (2005). Mycophenolate Mofetil Therapy for Inflammatory Eye Disease. American Academy of Ophthalmology, 112:1472-1477;

Tomita, T. (1950). Studies on the intraretinal action potential. I. Relation between the localization of micropipette in the retina and the shape of the intraretinal action potential. Japanese Journal of Physiology 1:110-117;

Tremblay F, Parkinson JE. (2003). Nov Alteration of electroretinographic recordings when performed under sedation or halogenate anesthesia in a pediatric population. Doc Ophthalmol.;107(3):271-9; 
Ubeyt U, Avci B, Kusbeci T, Kaderli B, Avci R, Temel S G. (2007) Preclinical Safety Evaluation of Intravitreal Injection of Full-Length Humanized Vascular Endothelial Growth Factor Antibody in Rabbit Eyes, Investigative Ophthalmology \& Visual Science, 48(4): 1773-81;

Vavvas D, Foster CS. Immunomodulatory medications in uveitis (2004). Int Ophthalmol Clin., 44(3):187-203;

Wachtmeister, L. \& Dowling, J. E. (1978). The oscillatory potentials of the mudpuppy retina. Investigative Ophthalmology \& Visual Science 17:1176-1188;

Wallentén K. G., Malmsjö M., Andréasson S., Wackenfors A., Johansson K., Ghosh F. (2007). Retinal function and PKC alpha expression after focal laser photocoagulation. Graefes Arch Clin Exp Ophthalmol , 245:1815

Yonemura, D. \& Kawasaki, K. (1979). New approaches to ophthalmic electrodiagnosis by retinal oscillatory potential, drug-induced responses from retinal pigment epithelium and cone potential. Documenta Ophthalmologica 48:163-222. 
